\title{
Imaging Constructs: The Rise of Iron Oxide Nanoparticles
}

\author{
Bianca Elena-Beatrice Crețu ${ }^{1}$, Gianina Dodi ${ }^{1, *} \mathbb{C}$, Amin Shavandi ${ }^{2}{ }^{\mathbb{D}}$, Ioannis Gardikiotis ${ }^{1}$, \\ Ionela Lăcrămioara Serban ${ }^{3}$ and Vera Balan ${ }^{4}$ (i)
}

1 Advanced Centre for Research-Development in Experimental Medicine, Grigore T. Popa University of Medicine and Pharmacy of Iasi, 700115 Iasi, Romania; bianca.cretu@umfiasi.ro (B.E.-B.C.); dr.gardikiotis@yahoo.com (I.G.)

2 BioMatter-Biomass Transformation Lab, École Polytechnique de Bruxelles, Université Libre de Bruxelles, 1050 Brussels, Belgium; amin.shavandi@ulb.be

3 Physiology Department, Grigore T. Popa University of Medicine and Pharmacy of Iasi, 700115 Iasi, Romania; ionela.serban@umfiasi.ro

4 Faculty of Medical Bioengineering, Grigore T. Popa University of Medicine and Pharmacy of Iasi, 700115 Iasi, Romania; balan.vera@umfiasi.ro

* Correspondence: gianina.dodi@umfiasi.ro; Tel.: +40-232-267-801

Citation: Crețu, B.E.-B.; Dodi, G.;

Shavandi, A.; Gardikiotis, I.;

Șerban, I.L.; Balan, V. Imaging

Constructs: The Rise of Iron Oxide

Nanoparticles. Molecules 2021, 26,

3437. https://doi.org/10.3390/

molecules26113437

Academic Editor: Jianjun Wei

Received: 24 April 2021

Accepted: 1 June 2021

Published: 5 June 2021

Publisher's Note: MDPI stays neutral with regard to jurisdictional claims in published maps and institutional affiliations.

\begin{abstract}
Over the last decade, an important challenge in nanomedicine imaging has been the work to design multifunctional agents that can be detected by single and/or multimodal techniques. Among the broad spectrum of nanoscale materials being investigated for imaging use, iron oxide nanoparticles have gained significant attention due to their intrinsic magnetic properties, low toxicity, large magnetic moments, superparamagnetic behaviour and large surface area-the latter being a particular advantage in its conjunction with specific moieties, dye molecules, and imaging probes. Tracers-based nanoparticles are promising candidates, since they combine synergistic advantages for non-invasive, highly sensitive, high-resolution, and quantitative imaging on different modalities. This study represents an overview of current advancements in magnetic materials with clinical potential that will hopefully provide an effective system for diagnosis in the near future. Further exploration is still needed to reveal their potential as promising candidates from simple functionalization of metal oxide nanomaterials up to medical imaging.
\end{abstract}

Keywords: iron oxide core; biopolymer shell; bio-inspired polymers; imaging techniques; in vivo; clinical trials

\section{Introduction}

Over the past century, the field of molecular imaging in living systems has expanded tremendously [1]. In general, molecular imaging modalities include, for example, magnetic resonance imaging (MRI), optical bioluminescence, optical fluorescence, targeted ultrasound (US), single-photon emission computed tomography (SPECT), and positron emission tomography (PET) [2]. Although all these molecular imaging modalities are available in clinics today, there is no single modality that is perfectly sufficient to obtain all necessary information for a particular question [3]. Hong et al. [1] established in their review that it is difficult to accurately quantify fluorescence signals in living subjects, particularly in deep tissues. MRI has high resolution, but it suffers from low sensitivity. Radionuclide-based imaging techniques have very high sensitivity but relatively poor resolution. Examples such as these could continue.

There are numerous review papers in the literature that describe imaging modalities and their available agents in detail. Therefore, we chose not to reiterate all these aspects in this paper. Instead, we focused on the essential feasibility and practicality of different imaging vehicles. Briefly: MRI is a non-invasive tool, and is generally used in clinics for high spatial resolution diagnostic imaging with the aid of conventional gadolinium compounds (such as $\mathrm{T}_{1}$-positive contrast agents and magnetic iron oxide nanoparticles 
as $\mathrm{T}_{2}$-specific agents that generate a bright or negative image where the compounds are accumulated. The main task of MRI contrast agents is to express short relaxation times- $\mathrm{T}_{1}$ and $\mathrm{T}_{2}-$ which characterize the two independent processes of proton relaxation. These are longitudinal relaxation, which is responsible for bright images, and transverse relaxation, which is accountable for dark images [4]. The main drawbacks of gadolinium chelates are their non-specific distribution, fast elimination in tissue, accumulation in kidneys-which can impair function — and their limited ability to improve MRI imaging sensitivity. More details on MRI theory can be found in the review of Ellis et al. [5].

Functional imaging modalities such as SPECT and PET are situated at opposite corners of the electromagnetic spectrum, being based on $\gamma$-ray emissions. They provide 3D images of the administered radiopharmaceutical distribution and are dependent on the properties of radionuclides [6]. SPECT is more widely available than PET, but it is approximately ten times less sensitive. It is valuable because it enables concurrent imaging of multiple radionuclides. It is important to mention, as seen above, that SPECT radionuclides are simple to prepare and usually have a longer half-life than PET radionuclides; thus, they are available in a variety of chemical structures. Nonetheless, even if both techniques have quantitative advantages over MRI and optical imaging, the poor resolution of PET led to the design of hybrid imaging to track molecular events [7]. The most commonly used radionuclides in nuclear medicine include ${ }^{99 \mathrm{~m}} \mathrm{Tc}$ (metastable, short life of $6 \mathrm{~h}$ ) and ${ }^{111} \mathrm{In}$ (half-life of 2.8 days) for SPECT imaging, and ${ }^{64} \mathrm{Cu}\left(\mathrm{t}_{1 / 2}=12.7 \mathrm{~h}\right),{ }^{18} \mathrm{~F}\left(\mathrm{t}_{1 / 2}=109.8 \mathrm{~min}\right)$ and ${ }^{68} \mathrm{Ga}\left(\mathrm{t}_{1 / 2}=68.1 \mathrm{~min}\right)$ for PET [8].

To help physicians to look inside the human body and detect diseased tissue without the need for surgery, research in imaging is conducted in: (1) developing new tracers and (2) creating new technologies for accurate diagnosis. This review focused on the first objective, concerning the development of new tracers.

In this context, an important challenge in nanomedicine imaging is to design multifunctional agents that can be detected by single or multimodal techniques. An ideal nanoparticle imaging probe for next-generation, multifunctional tracers should have the following features: easy administration, excellent in vivo and radiolabelling stability [9], biocompatibility [10], selectivity, sensitivity [11], ability to observe accumulation in realtime and monitor disease progression [12], biodegradability or rapid excretion after imaging is complete, minimal-to-no side effects and cost-effectiveness-all while producing a strong imaging signal [13]. In recent years, various contrast/radiolabelled and/or fluorescent nanoparticles were developed as promising diagnostic and cancer evaluation tools [14]; however, multifunctional imaging agents simultaneously exhibiting all these features are extremely rare.

In the past 30 years, magnetic nanoparticles comprising an iron oxide core (usually magnetite- $\mathrm{Fe}_{3} \mathrm{O}_{4}$, maghemite- $\gamma-\mathrm{Fe}_{2} \mathrm{O}_{3}$ or hematite- $\alpha-\mathrm{Fe}_{2} \mathrm{O}_{3}$ ) have attracted growing attention for their unique properties, e.g., magnetic functionality, surface-to-volume ratio, greater surface area, favourable toxicity profile and potential applications in biomedicineespecially as contrast agents. Iron oxide nanoparticles are at the forefront of science in the 21 st century, boosted by the wide scope of their potential biomedical applications. This field is of tremendous importance, which can be confirmed by the scientific output of the last two decades and the more than 3000 scientific articles published each year, according to the Scopus platform.

The Molecular Imaging and Contrast Agent Database (MICAD) is an online source of molecular imaging and contrast agents that are under progress, in clinical trials or commercially available for medical applications. It was developed by the National Institutes of Health (NIH), sourced by the FDA (Food and Drug Administration) and published by the National Center for Biotechnology Information (US), (Bethesda, MD, USA) [15]. The database covers data published in peer-reviewed scientific journals from 2004 up to 2013, updated annually. It includes nearly 1444 agents developed for MRI, PET, SPECT, US, CT, optical, planar radiography, and planar gamma imaging. Briefly, this text presents-in MRI, SPECT and Multimodal sections-a chapter dedicated to iron oxide-based materi- 
als as contrast agents in various combinations. Tables $1-3$ provide an overview of iron oxide-based materials that were developed as contrast agents during this period of time.

Table 1. Iron oxide-based MRI contrast agents, as described in MICAD [15], with $\mathrm{Fe}_{3} \mathrm{O}_{4} / \mathrm{SPIONs} / \mathrm{USPIONs} /$ iron oxide nanoparticles as a source of signal.

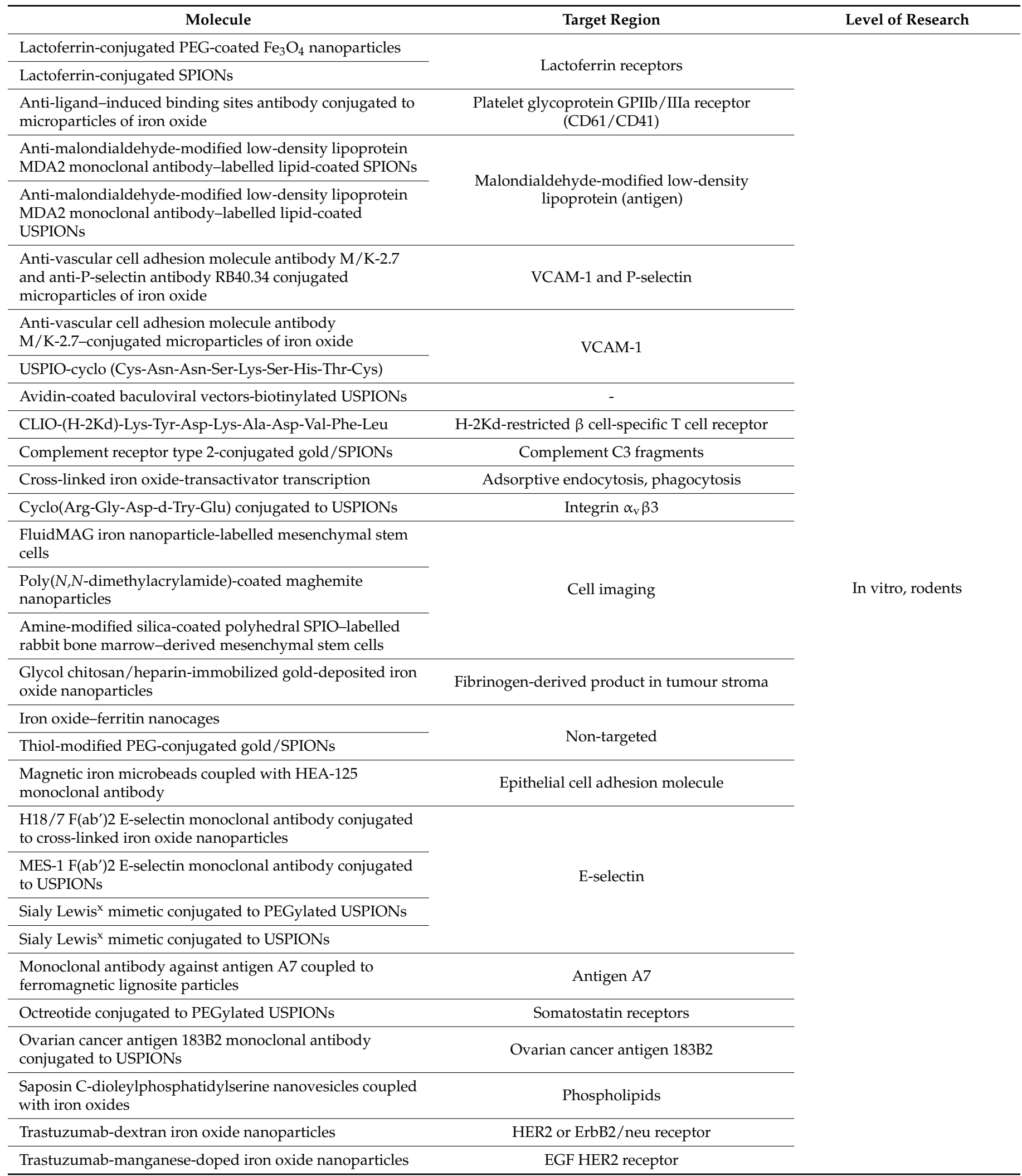


Table 1. Cont.

\begin{tabular}{|c|c|c|}
\hline Molecule & Target Region & Level of Research \\
\hline $\mathrm{Z}_{\mathrm{HER2}: 342}$ Affibody-PEG-SPIONs & \multirow[b]{2}{*}{ EGF } & \\
\hline $\begin{array}{l}\text { Single-chain anti-epidermal growth factor receptor } \\
\text { antibody fragment conjugated to magnetic iron oxide } \\
\text { nanoparticles }\end{array}$ & & \\
\hline USPIO-Leu-Ile-Lys-Lys-Pro-Phe & Phosphatidylserine & \\
\hline USPIONs conjugated with Ile-Pro-Leu-Pro-Phe-Tyr-Asn & B-amyloid $\left(A \beta_{42}\right)$ peptide & \\
\hline USPIO-anti-CD20 monoclonal antibody & CD20 antigen & \\
\hline PEG-coated and folic acid-conjugated SPONs & Folate receptor & \\
\hline N-Alkyl-polyethylenimine 2 kDa-stabilized SPIONs & Mesenchymal stem cell labelling & \\
\hline SPION stabilized by alginate & \multirow{2}{*}{ RES } & \\
\hline Ferumoxsil (Siloxane-coated SPIO) & & In vitro, rodents, humans \\
\hline Citrate-coated (184th variant) SPIONs & Phagocytosis & \multirow{3}{*}{$\begin{array}{l}\text { In vitro, rodents } \\
\text { non-primate non-rodent } \\
\text { mammals, humans }\end{array}$} \\
\hline Ferumoxides (Dextran-coated SPIO) & RES & \\
\hline Iron oxide nanoparticles-poly-L-lysine complex & - & \\
\hline Ferumoxtran (USPIONs) & RES & $\begin{array}{l}\text { In vitro, rodents, non-primate } \\
\text { non-rodent mammals, } \\
\text { non-human primates, humans }\end{array}$ \\
\hline
\end{tabular}

Table 2. Iron oxide-based SPECT contrast agents as described in Molecular Imaging and Contrast Agent Database [15].

\begin{tabular}{cccc}
\hline \multicolumn{1}{c}{ Molecule } & Source of Signal & Target Region & Level of Research \\
\hline $\begin{array}{l}{ }^{99 \mathrm{~m}} \text { Tc-Diethylenetriamine pentaacetic acid } \\
\text { SPIONs conjugated with lactobionic acid }\end{array}$ & Iron oxide, ${ }^{99 \mathrm{~m}} \mathrm{Tc}$ & Asialoglycoprotein receptors & In vitro, rodents \\
\hline
\end{tabular}

Table 3. Iron oxide based multimodal contrast agents as described in MICAD [15].

\begin{tabular}{|c|c|c|c|}
\hline Molecule & Source of Signal & Target & Level of Research \\
\hline \multicolumn{4}{|c|}{ MRI, SPECT Gamma Planar } \\
\hline $\begin{array}{l}{ }^{111} \text { In-Tetraazacyclododecane- } N, N^{\prime}, N^{\prime \prime}, N^{\prime \prime \prime} \text {-tetraacetic } \\
\text { acid-benzyl-ChL6-SPIONs }\end{array}$ & Iron oxide, ${ }^{111}$ In & Antibody-antigen binding & In vitro, rodents \\
\hline \multicolumn{4}{|c|}{ MRI and PET } \\
\hline $\begin{array}{l}{ }^{124} \text { I-Serum albumin-manganese-magnetism-engineered } \\
\text { iron oxide nanoparticles }\end{array}$ & Iron oxide, ${ }^{124} \mathrm{I}$ & Non-targeted & \multirow[b]{2}{*}{ In vitro, rodents } \\
\hline $\begin{array}{c}{ }^{64} \mathrm{Cu}-1,4,7,10-\text { Tetraazacyclododecane- } N, N^{\prime}, N^{\prime \prime}, N^{\prime \prime \prime}- \\
\text { tetraacetic acid-iron oxide-c(RGDyK) } \\
\text { nanoparticles }\end{array}$ & ${ }^{64} \mathrm{Cu}$ and iron oxide & Integrin $\alpha_{\mathrm{v}} \beta_{3}$ & \\
\hline \multicolumn{4}{|c|}{ MRI, optical, PET } \\
\hline${ }^{64} \mathrm{Cu}-\mathrm{DTPA}-\mathrm{CLIO}-\mathrm{VT} 680$ & Iron oxides, VT680, ${ }^{64} \mathrm{Cu}$ & Macrophages & In vitro, rodents \\
\hline \multicolumn{4}{|c|}{ MRI, optical NIR fluorescence } \\
\hline Annexin V-cross-linked iron oxide-Cy5.5 & \multirow{5}{*}{ Iron oxide, Cy5.5 } & Phosphatidylserine & \multirow{6}{*}{ In vitro, rodents } \\
\hline $\begin{array}{l}\text { Anti-vascular cell adhesion molecule monoclonal M/K-2.7 } \\
\text { conjugated cross-linked iron oxide-Cy5.5 nanoparticles }\end{array}$ & & $\begin{array}{l}\text { Vascular cell adhesion } \\
\text { molecule-1 }\end{array}$ & \\
\hline Cross-linked iron oxide-Cy5.5 & & Phagocyte and tumour cell & \\
\hline $\begin{array}{l}\text { Lys-Thr-Leu-Leu-Pro-Thr-Pro-cross-linked iron } \\
\text { oxide-Cy5.5 }\end{array}$ & & Plectin-1 & \\
\hline VCAM-1 internalizing peptide-28 nanoparticles & & $\begin{array}{l}\text { Vascular cell adhesion } \\
\text { molecule- } 1\end{array}$ & \\
\hline Cys-Arg-Glu-Lys-Ala-SPIO-Cy7 nanoparticles & Iron oxide, $\mathrm{Cy} 7$ & Clotted plasma proteins & \\
\hline
\end{tabular}


Table 3. Cont.

\begin{tabular}{|c|c|c|c|}
\hline Molecule & Source of Signal & Target & Level of Research \\
\hline \multicolumn{4}{|c|}{ Optical, NIR fluorescence imaging and MRI } \\
\hline $\begin{array}{c}\text { Cy5.5-Amino-terminal fragment of urokinase-type } \\
\text { plasminogen activator conjugated to magnetic iron oxide } \\
\text { nanoparticles }\end{array}$ & \multirow{2}{*}{ Iron oxide, Cy5.5 } & $\begin{array}{l}\text { Urokinase-type plasminogen } \\
\text { activator receptor }\end{array}$ & \multirow{2}{*}{ In vitro, rodents } \\
\hline $\begin{array}{l}\text { Cy5.5-Arg-Arg-Arg-Arg-crosslinked iron oxide } \\
\text { nanoparticle }\end{array}$ & & Proteases & \\
\hline \multicolumn{4}{|c|}{ MRI, fluorescence molecular tomography (FMT), fluorescence reflectance imaging (FRI) } \\
\hline $\begin{array}{l}\text { Gly-Ser-Ser-Lys-(FITC)-Gly-Gly-Gly-Cys-Arg-Gly-Asp- } \\
\text { Cys-CLIO-Cy5.5 }\end{array}$ & Iron oxides, Cy5.5 & $\alpha_{v} \beta_{3}$ integrin & In vitro, rodents \\
\hline \multicolumn{4}{|c|}{ MRI, NIFR optical imaging } \\
\hline $\begin{array}{l}\text { Green fluorescent protein specified small interfering } \\
\text { RNA-crosslinked iron oxide nanoparticles-Cy5.5 }\end{array}$ & \multirow[t]{2}{*}{ Iron oxides, Cy5.5 } & \multirow{2}{*}{ RNAse III } & \multirow{3}{*}{ In vitro, rodents } \\
\hline Survivin specified small interfering RNA-CLIO-Cy5.5 & & & \\
\hline $\begin{array}{l}\text { Bombesin peptide conjugated-cross-linked iron } \\
\text { oxide-Cy5.5 }\end{array}$ & Iron oxide, Cy5.5, FITC & $\begin{array}{l}\text { Gastrin-releasing peptide } \\
\text { receptor }\end{array}$ & \\
\hline \multicolumn{4}{|c|}{ Optical, near-infrared fluorescence } \\
\hline IPLVVPLGGSC (Cy5.5-Cross-linked iron oxide) K(FITC) & Cy5.5, iron oxide & Hepsin & In vitro, rodents \\
\hline \multicolumn{4}{|c|}{ MRI and optical imaging } \\
\hline $\begin{array}{l}\text { Rhodamine B isothiocyanate-incorporated, silica-coated } \\
\text { magnetic nanoparticle-labelled human cord blood-derived } \\
\text { mesenchymal stem cells }\end{array}$ & SPIO, RITC & Cell imaging & In vitro, rodents \\
\hline
\end{tabular}

Taking into account all of the available presented data, the main objective of this review paper was to outline multifunctional magnetic tracers as single/multi-modality imaging probes. Specifically, we reviewed both the key technical principles of magneticbased materials and the ongoing advancement toward an ideal contrast agent. First, this review examined iron oxide nanoparticle preparation approaches that are in current use in diagnostics as the core material. Second, this work reviewed multifunctional polymeric chain designs employed as the shell, followed by in vivo imaging evaluations on experimental animals using different imaging techniques and the current success of magnetic materials as contrast agents in clinical trials.

\section{Techniques for Synthesis of Iron Oxide Core for Imaging Purposes}

Iron oxide magnetic nanoparticle synthesis methods have enhanced the significant advances in magnetic materials applications, meaning that fabrication processes are significant pillars of the field. According to Ali et al. (2016) [16], more than $90 \%$ of magnetic nanoparticles are prepared using chemical methods. Nearly $8 \%$ are prepared using physical methods, and only $2 \%$ through biological processes. Each method has its own advantages and disadvantages; therefore, the physical and chemical properties of the obtained nanoparticles are dependent upon the conditions of fabrication.

Physical processes-such as aerosol/gas phase deposition, electron beam lithography, pulsed laser ablation, laser-induced pyrolysis and power ball milling - have the advantage of being easy to perform, but it is not possible to control the particles' size in the nanometer region, resulting in irregular spheres. In the case of chemical techniques, the obtained nanoparticles may have irregular shapes, may be porous or nonporous, spheres, platelets, rod-like spheres, crystals, nanotubes, nanorods, bipyramids, facets, or other shapes. This is primarily dependent on the synthesis parameters, e.g., reagents, $\mathrm{pH}$, temperature, and ionic strength. Chemical methods are simple, efficient, and manageable in size, shape and composition. Biological procedures, such as microbial incubation, are characterized by good reproducibility and scalability, and are low-cost, high yield for obtaining platelets and spheres. However, they are also laborious and time-consuming. Synthesis routes have 
been reviewed in many publications over the years in great detail; thus, just a few are briefly discussed here.

Many review papers have described different techniques for synthesis of iron oxide cores in general, or as comparative studies, pointing out the main properties, advantages and disadvantages for each method. As such, this review presents only magnetic particles reportedly in use as contrast agents [17-22].

A review worth mentioning is that of Niculescu et al. [23], which offered a general presentation of magnetite synthesis methods divided into conventional and unconventional procedures and correlated them with process outcomes, in terms of particle size, shape, magnetization properties and potential applications. Special attention was given to unconventional methods, i.e., microfluidic and recycled iron-based methods, from an alternative perspective. These methods are still under development but have already shown promising results in nanomedicine.

Another significant review paper is that of Caspani et al. [21], published in 2020. In addition to the principles associated with the use of contrast agents in MRI, their review discussed iron oxide nanoparticle synthesis methods, associated with their shape, properties, and their $\mathrm{T}_{1}$ and/or $\mathrm{T}_{2}$ capability.

Additionally, in the Fatima \& Kim review, the summary of the frequently used preparation methods for iron-based nanoparticle synthesis displayed the advantages and disadvantages as they related to the shape and reaction temperature. They concluded that, although solvo \& hydrothermal synthesis showed better control over shape and size, co-precipitation is still the predominately studied method [24].

Among these methods, the most frequently reported processes for the fabrication of iron oxide nanoparticles as diagnostic platforms were: co-precipitation, thermal decomposition, hydrothermal, sol-gel, and microemulsion, as presented in Figure 1. These were followed by polyol, magnetotactic bacteria, aerosol, microwave, electrochemical, and microfluidic methods, briefly described below.

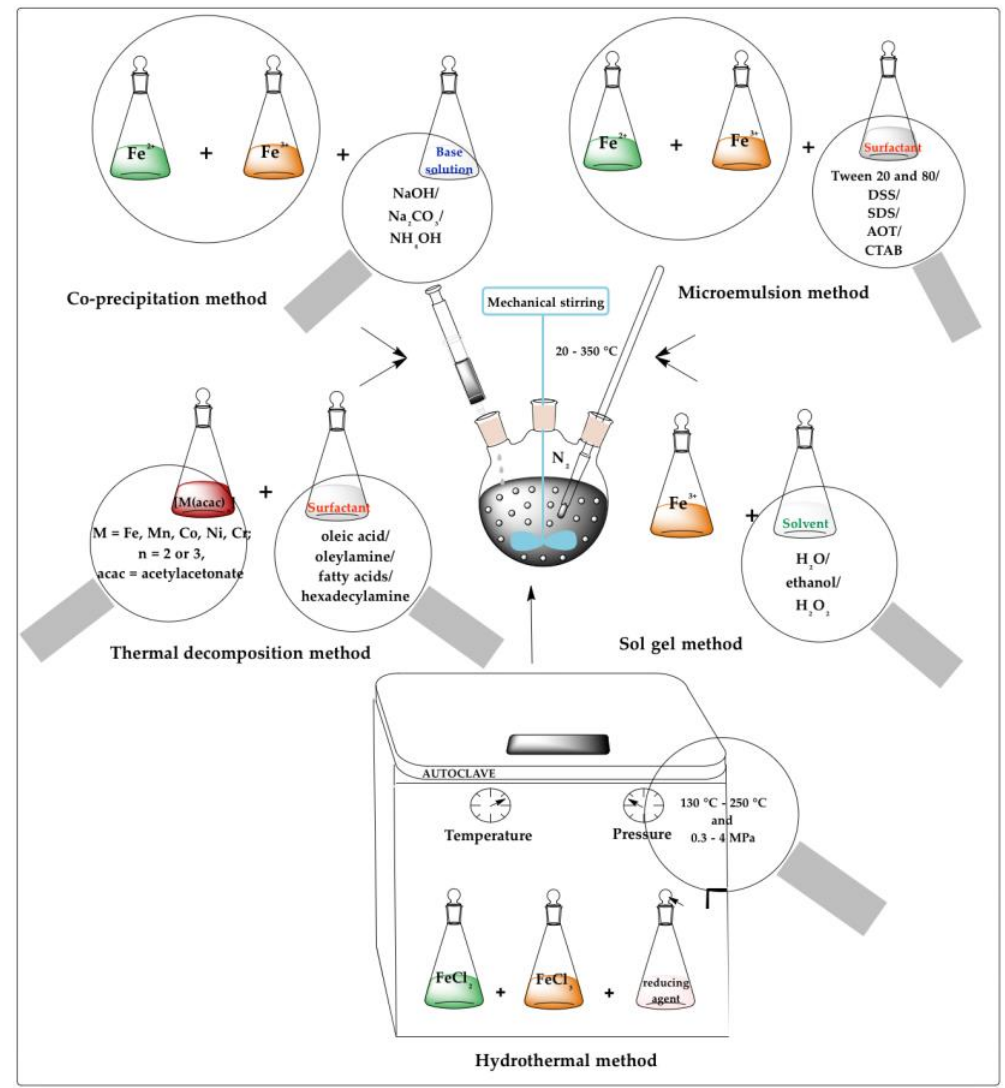

Figure 1. Techniques for synthesis of iron oxide core for imaging purposes. 


\subsection{Co-Precipitation}

The co-precipitation method is the most implemented, simple, efficient, and (partially) eco-friendly chemical route used to synthesize iron oxides (either $\mathrm{Fe}_{3} \mathrm{O}_{4}$ or $\gamma-\mathrm{Fe}_{2} \mathrm{O}_{3}$ ) from aqueous $\mathrm{Fe}^{2+} / \mathrm{Fe}^{3+}$ salt solutions and a weak or strong base, at high temperature (from 20 to $150{ }^{\circ} \mathrm{C}$ ) and under inert atmosphere. The chemical reaction for co-precipitation is depicted below:

$$
\mathrm{Fe}^{2+}+2 \mathrm{Fe}^{3+}+8 \mathrm{OH}^{-} \rightarrow \mathrm{Fe}\left(\mathrm{OH}_{2}\right)+2 \mathrm{Fe}(\mathrm{OH})_{3} \rightarrow \mathrm{Fe}_{3} \mathrm{O}_{4}+4 \mathrm{H}_{2} \mathrm{O}
$$

Khalafalla et al. [25] proposed a co-precipitation method for the synthesis of aqueous magnetic fluid for the first time in 1980, followed by Massart [26] in 1981, who reported roughly spherical magnetite $\left(\mathrm{Fe}_{3} \mathrm{O}_{4}\right)$ particles with a diameter of $8 \mathrm{~nm}$ as measured by $\mathrm{X}$-ray diffraction analysis. Further studies, developed in this area over the years, indicated that the size, shape and iron oxide nanoparticle composition depended on several parameters, including: the $\mathrm{Fe}^{2+} / \mathrm{Fe}^{3+}$ ratio, the type of salts used in the reaction (e.g., chlorides, sulphates, nitrates, perchlorates), temperature reaction, $\mathrm{pH}$ value, ionic strength, base type $\left(\mathrm{NaOH}, \mathrm{Na}_{2} \mathrm{CO}_{3}, \mathrm{NH}_{4} \mathrm{OH}\right)$, stirring rate, inlet of nitrogen/argon gas, and flow rate of the basic solution [27]. The most important steps to achieve a complete precipitation are: to maintain the $\mathrm{pH}$ range between 8 and 14 , a stoichiometric ratio of $\mathrm{Fe}^{3+} / \mathrm{Fe}^{2+}$ at $2: 1$ and a non-oxidizing (oxygen-free) environment [28]. However, the obtained bare nanoparticles usually have the tendency to aggregate, mainly due to high surface-area-to-volume ratio, strong magnetic attraction among particles, van der Waals forces and high surface energy [29]. The addition of anionic surfactants as dispersing agents and surface coatings with polymers, proteins, starches, non-ionic detergents or polyelectrolytes can control the size of the nanoparticles and stabilize them. If all these parameters are properly adjusted, it is possible to tailor the characteristics of iron oxide nanoparticles and to obtain uniform magnetic particles with a size ranging from 17 to $2 \mathrm{~nm}$, magnetic functionality, high surface area and a non-toxic profile.

To obtain magnetic colloidal ferrofluids with suitable properties for imaging aims, bare magnetic nanoparticles are coated with different biocompatible agents, represented by inorganic materials (e.g., silica, gold, or gadolinium), or polymer stabilizers (e.g., dextran, carboxydextran, carboxymethylated dextran, PEG, PVA, chitosan), which provide high colloidal stability against aggregation in biological media and/or allow tailoring the surface properties and coating. This is discussed further in the next section.

\subsection{Thermal Decomposition}

This method involves the decomposition of organometallic precursors, such as metal acetylacetonates $\left[\mathrm{M}(\mathrm{acac})_{\mathrm{n}}\right],(\mathrm{M}=\mathrm{Fe}, \mathrm{Mn}, \mathrm{Co}, \mathrm{Ni}, \mathrm{Cr} ; \mathrm{n}=2$ or $3, \mathrm{acac}=$ acetylacetonate $)$, metal cupferronates $\left[\mathrm{M}(\mathrm{Cup})_{\mathrm{x}}\right]$ (Cup $=N$-nitrosophenyl hydroxylamine) or metal carbonyls, in high-boiling organic solvents (diphenyl ether, diethylene glycol diethyl ether, dimethyl formamide, benzyl ether, octadecene, chloroform), in the presence of stabilizing surfactants such as fatty acids, oleic acid and hexadecylamine [30]. The thermal decomposition method implies high temperatures, around $280-350^{\circ} \mathrm{C}$, and an inert atmosphere (nitrogen/argon). The parameters that can tune the size, morphology, and chemical stability of the produced nanoparticles are: the type and ratio of the precursors, surfactants, and solvents, temperature, time, and aging phase [31]. Magnetic iron oxide particles synthesized by this technique are characterized by a better control over size and shape, high level of monodispersity and good crystallinity compared to the co-precipitation method. The synthesis process time is approximately an hour and magnetic nanoparticles are collected by centrifugation, but the high temperatures, expensive toxic reagents, and the laborious purification steps of the final product all hamper its implementation in biomedical applications. 


\subsection{Hydrothermal}

The hydrothermal method yields magnetic nanoparticles with very good size and shape control and relatively broad size distribution from aqueous solutions of metal salt precursors (ferric nitrate, ferric chloride, ferrous oxalate, potassium ferrocyanide) dissolved along with surfactants/capping agents (sodium dodecylsulfonate (SDS), sodium dodecylbenzene sulphonate (DBS), cetyltrimethyl ammonium bromide (CTAB), hexadecylpyridinium chloride (HPC), polyvinylpyrrolidone (PVP)) in a reactor or autoclave at high temperatures (from $130^{\circ} \mathrm{C}$ to $250^{\circ} \mathrm{C}$ ) and high pressures (from 0.3 to $4 \mathrm{MPa}$ ) under inert atmosphere (nitrogen/argon flow) [32]. The reaction parameters [33]—e.g., temperature, pressure, $\mathrm{pH}$, solution concentration, precursor type and concentration, and residence time- define the morphology and particle size, as well as the possibility of growing crystals of varied shapes [30]. This adaptable method has the advantage of simplicity without requiring special reagents, but its need for high pressures and temperatures reduces the scalability and potential biomedical applications.

\subsection{Sol-Gel}

The sol-gel technique is a relatively simple and cost-effective route to synthesize nanostructured monodispersed metal oxides that are precisely controlled in size, shape and internal structure, with a pure amorphous phase and homogeneity. This method is based on the formation of colloidal sol using hydrolysis and condensation of the precursors, metal alkoxides (ferric nitrate, ferric chloride, ferrous chloride, ferrous sulphate), in ethanol/water solution. Using additional condensation and inorganic polymerization, the sol is then gelled in order to obtain three-dimensional metal oxide networks [34]. As these reactions are conducted at ambient conditions, the formed gels need extra heat treatments to obtain the final crystalline state. The parameters that influence the properties and the structure of the iron oxide nanoparticles are: the precursor concentration, solvent nature, temperature, $\mathrm{pH}$, kinetics, properties of the gel and mechanical stirring rate. The associated disadvantages include high permeability, weak bonding and low wear resistance [17].

\subsection{Microemulsion}

This method involves dispersion of two immiscible liquids (oil-in-water $(\mathrm{o} / \mathrm{w})$ or water-in-oil (w/o)) separated by an interfacial film of surfactant molecules. The reaction mixture is composed of an aqueous $\mathrm{Fe}^{2+} / \mathrm{Fe}^{3+}$ solution phase subjected to sonication and heat at a particular temperature (in the range of 20 to $80^{\circ} \mathrm{C}$ ) and the other, containing organic solvents (propyl alcohol, heptane, cyclohexane) and stabilizing surfactants (e.g., Tween 20 and Tween 80, DSS, SDS, AOT and CTAB) [27]. The surfactant is an amphiphilic molecule that lowers the interfacial tension between oil and water phases. Magnetic iron oxide particles synthesized through this method are characterized by good control over the particle shape, relatively narrow size distribution and crystalline structure. The type and structure of the surfactant, along with physiological conditions (near ambient conditions of temperature and pressure) modulate the magnetic nanoparticles. The main advantage of this two-phase-method is the narrow particle size distribution, but the low yields of nanoparticles, the large amount of solvent required for their synthesis and the presence of residual surfactants create barriers in scale-up procedures and specific functions [35].

\subsection{Other Used Methods}

Polyol synthesis turned out to be a versatile wet-chemistry method for the synthesis of magnetic nanoparticles with variable shapes, sizes and compositions, using a liquid organic compound (polyols, such as ethylene/diethylene/tetraethylene glycol, 1,2 propylene glycol, PVA or 2-pyrrolidone) acting both as a solvent and a reducing agent. The basic principle of the polyol method was explained by Caruntu et al. [36], as a two-step procedure; first, the formation of the hydroxides, followed by metal centres chelation. Through simple optimization of the operating synthesis conditions-namely, the nature of the magnetic precursors and precipitator, the solvents' nature, the addition of an extra stabilizer, 
and the temperature, pressure and duration of the reaction-the metal nanoparticles features can be tailored for the targeted application [37,38]. Compared with thermal decomposition or co-precipitation methods, the polyol process yields nanoparticles with a narrow particle size distribution in a simple, environmentally friendly, reproducible and cost-effective way, without the need for an inert atmosphere [39]. This method, considered an iteration of the solvothermal approach, is not without drawbacks; the formed particles lack homogeneity [20].

Another eco-friendly method used to produce magnetic nanoparticles for use as imaging contrast agents is magnetotactic bacteria, a group of Gram-negative bacteria called magnetosomes [40]. Magnetotactic bacteria are defined as intracellular nanocrystals of the magnetic minerals (magnetite or greigite) surrounded by a phospholipid bilayer membrane [41]. During biosynthesis, the magnetosomes are aligned in a linear sequence by connecting them to a cytoskeletal filament, which permits the bacteria to navigate along the geomagnetic field. The magnetosomes' features are controlled by a specific set of parameters, e.g., genes (different species) that encode proteins and maintain the structural integrity or transport iron, magnetotactic bacteria isolation (sonication, treatment with sodium hydroxide, press, pressure homogenizer), purification (magnetic separation, proteinase $\mathrm{K}$ treatment), sterilization, heating, and so on. Compared with chemically synthesized magnetite nanoparticles, magnetosomes are of high chemical purity, display a narrow size range, are highly uniform and are permanently magnetic at ambient temperatures as stable single-magnetic domain crystals. Because of these physical/chemical properties, magnetosomes are used in many biomedical applications, but the main concerns of researchers are linked with the safety index-since the introduction of magnetosomes or the magnetosome reporter gene into cells can have adverse effects on cells over the $200 \mu \mathrm{mol} / \mathrm{kg}$ dose [42].

Since the first synthesis of $\gamma-\mathrm{Fe}_{2} \mathrm{O}_{3}$ by aerosol spray pyrolysis in 1993 , the method grew into a promising, cost-effective, and scalable procedure that led to high particle production levels [43]. This approach involves the spraying of precursor salts into a hot reactor, where they are condensed as small droplets in vapor form, a parameter that determines the size. Other important factors that control the size of the particles are precursor composition, solvent nature, rate of evaporation, time spent in the reactor, and temperature. The technique produces spherical nanoparticles with narrow size distribution, high homogeneity and monodispersity, and it has a high yield. However, it falls short due toto the particles' inner structure, pore size uniformity and extremely high temperatures [44].

Electrochemical synthesis of magnetic iron oxide nanoparticles like maghemite and magnetite involves passing electric current between electrodes (anode and cathode) located in an electrolyte. The anode is oxidized to metal ion species, reduced to metal by the cathode with the assistance of stabilizers, and then deposited in the form of a coating or thin film on the electrode [19]. The parameters that are used to obtain unique products (which are not possible to obtain using other methods) relate to the current passed through the cell, cell potential, oxidizing or/and reducing power, bath composition, $\mathrm{pH}$, electrolysis type, electrolyte concentration and composition. This method does not require high temperatures, and has the advantage of control over particle size, but it is complicated and lacks reproducibility. Additionally, it is prone to the presence of amorphous impurities due to poorly ordered products [45].

The microfluidic method first appeared as a proposed solution to the identified drawbacks of existing synthesis procedures, and as an alternative to traditional reactors [46]. The microfluidic synthesis strategy is based on the fluid movement within micro-scaled channels with unique geometries that allows for improved control over reaction conditions and real-time, in-line characterization [47]. The microfluidic systems used for the synthesis of magnetic cores are single-phase flow reactors, due to their homogeneity and versatility in controlling process parameters and droplet-based microreactors as well as their rapid production and analysis of reproducible and scalable particles with specific sizes, shapes, and morphologies. The obtained nanoparticles are known for their narrow size distribution, uniform shape, improved reproducibility, shorter reaction time, increased 
yield-formation of pure phase magnetite, and friendly reaction conditions with no extra additives or heating. However, since the field of microfluidics as applied to nanomedicine is still in its infancy, there are several drawbacks associated with this method, namely: surface roughness, limited production rate, possibility of clogging micro-channels, leaks-leading to experimental failure, capillary force and chemical interactions $[48,49]$.

\section{Surface Shell Engineering of Magnetic Materials for Imaging Purposes}

Many approaches have focused on the encapsulation of iron oxide nanoparticles with biocompatible materials forming a composite morphology often referred to as a core-shell structure [50]. Bare surface iron oxides agglomerate due to strong magnetic attraction between particles, van der Waals forces and high surface energy, as mentioned above. Additionally, they endure rapid elimination by the RES when exposed to biological media or can be toxic in high concentrations due to iron dissolution [51]. All these drawbacks are limited when magnetite nanoparticles are embedded in a non-magnetic matrix. The appropriate coatings can stabilize them in a physiological environment, provide chemical functionality for extra modifications and control the particle size and shape. Furthermore, the shell addition and geometric arrangement improve the biocompatibility of the material as well as the biokinetics and biodistribution in the body. The nature of the surface coating of magnetic nanoparticles depends on the application and required functionalities. Polysaccharides, synthetic polymers, proteins, enzymes or antibodies bind to hydrophobic surfaces with a large surface-area-to-volume ratio of the iron oxide cores in order to design core-shell materials with additional chemical and physical functions for specific applications [52].

Several review reports can be found in the literature that deal with the most important topic in the design of iron oxide nanoparticles as diagnostic agents: functionalization/shell coating/surface modification. This topic and its associated methods offer high stability in physiological media, stealth, biological ligand-binding ability, biocompatibility, non-toxicity, enhanced physiochemical and mechanical properties and improved dispersion [53-56].

In 2008, Laurent et al. [17] summarized different stabilization methods of magnetic iron oxide nanoparticles using monomeric stabilizers (carboxylates and phosphates), inorganic materials (silica and gold) and polymeric stabilizers (dextran, PEG, PVA, alginate, chitosan, PEI, PEI-PEO-block PGA, PLGA, PVP, PAA, poly( $\varepsilon$-caprolactone), sulphonated styrene-divinylbenzene, polymethacrylic acid, PEO- $b$-poly(methacrylic acid), polyalkylcyanoacrylate, or arabinogalactan) as their main strategies to obtain magnetic colloidal ferrofluids that were stable against aggregation in both biological media and magnetic fields. Another strategy mentioned by the authors to synthesize polymeric core/shell magnetic nanoparticles is to use preformed synthetic polymers as a matrix to control the formation of magnetic cores, e.g., $\mathrm{ABC}$ triblock polymer (polyisopropene-block-poly (2-cinnamoylethyl methacrylate)-block-poly(tert-butyl acrylate)), polystyrene-polyacrylate copolymer gel template, poly(methylmethacrylate)/polypyrrole bilayers and in situ polymerization of iron oxide nanoparticles in poly(styrene/acetoacetoxyethylmethacrylate) particles.

In 2016, Narayanaswamy et al. [57] published a review which described, in a chapter focused on nanoparticle-based imaging agents, different nanobiomaterials for image enhancement. Their review covered developments up to 2010, based on the coating type but not on the magnetic core. After a brief representation of these, the authors presented polysaccharides and proteins-such as albumin, alginate, apoferritin, beta-glucan, casein, cellulose, chitosan, chondroitin-sulfate, collagen, cyclodextrin, dextran, fibrinogen, fucoidan, gelatin, heparin, hyaluronic acid, lectin, mannan, mannose, pullulan, starch and zein-based nanoparticles-widely used as imaging agents.

More recently, in 2020, the review paper of Avasthi et al. [20] addressed key aspects in the development of IONPs only for MRI applications-namely, the synthesis of the magnetic core, functionalization processes and in vivo studies with emphasis on tumour models. Their chapter on the functionalization of IONPs was divided according 
to the methods used to functionalize IONPs for clinical purposes, e.g., in organic suprastructures, inorganic coverage and ligand exchange. The first class of highly branched macromolecules were defined by 3D architectures, and included nanomicelles, dendrimers, liposomes and nanogels, developed to create hybrid materials for imaging and therapy. In their review, the authors described the use of polymeric folate-conjugated N-palmitoyl chitosan and PEG-phosphatidylethanolamine micelles, poly (amidoamine) dendrimer, 1,2-distearoyl-snglycero-3-phosphoethanolamine phospholipids liposomes, copolymer [ $\mathrm{N}$-isopropylacrylamide, methacrylic acid and poly (ethylene glycol) methacrylate] and alginate-PEI nanogels for the encapsulation/conjugation of iron oxide nanoparticles. The inorganic materials for IONPs core coating described in this review paper were: mesoporous silica and its complexes with $N$-isopropylacrylamide, $N$-(hydroxymethyl) acrylamide, $N, N^{\prime}$-methylenebis(acrylamide) monomers, PVP and PEG molecules. The ligand exchange method, as expressed by the authors, required multiple interactions, potentials/forces, and the use of reactive binding molecules, making this coating strategy very complicated.

A list of commonly used SPION coating materials (as well as their sizes and properties) was presented by Nelson et al. [58] in their educational review paper, highlighting the associated challenges in the use of SPIONs in multiple imaging modalities. This review represented an important guide for young scientists, illustrating the basic concepts of MRI, the basic construct of SPIONs, in vitro challenges, shapes and sizes, various coatings with different materials, and application of SPIONs in diagnostics and therapy.

As presented above and in Figure 2, of the multitude of polymeric shells used to adjust the size and surface nature of iron oxide core nanoparticles-which are essential in the development of a successful diagnostic platform—only a few are summarized in Tables 4 and 5 and succinctly detailed in the next sections.

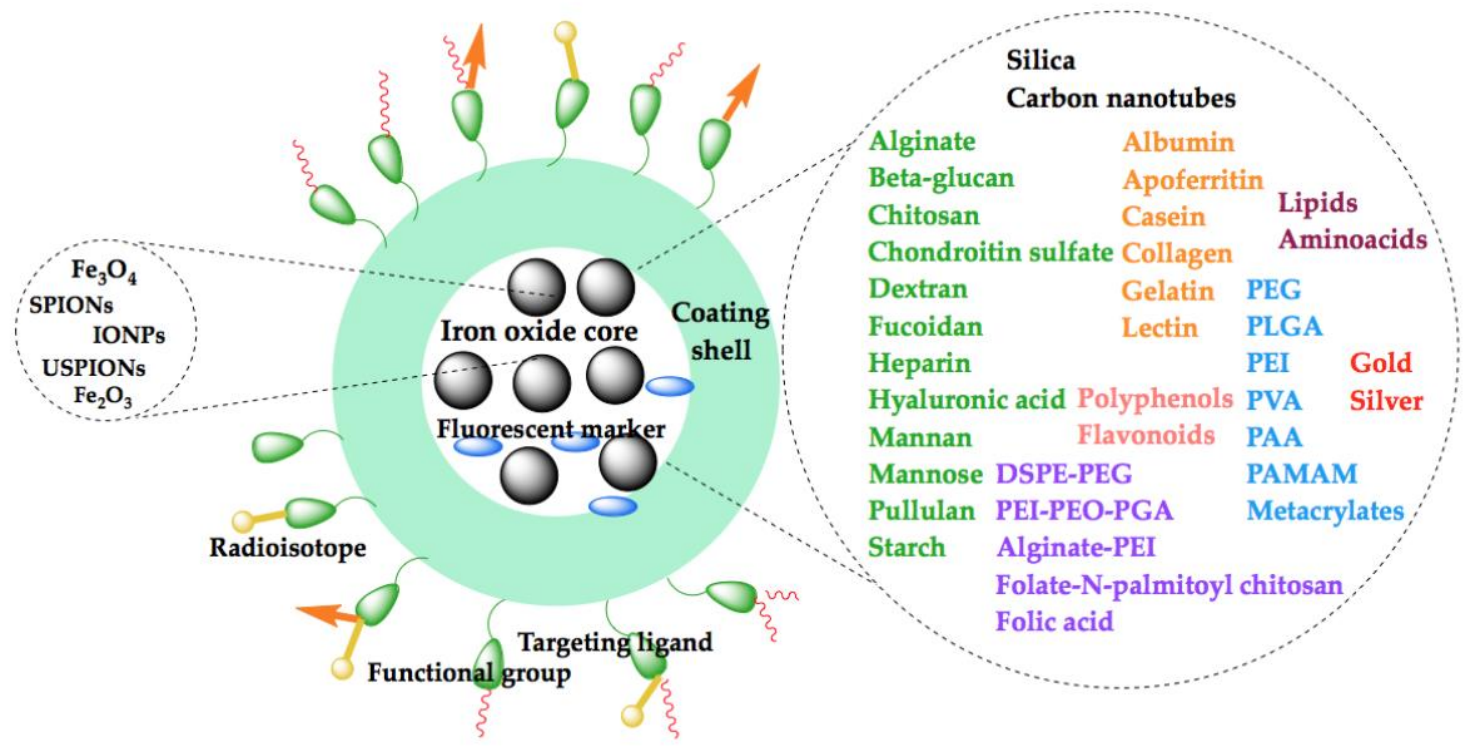

Figure 2. Schematic illustration of the coatings used for iron oxide nanoparticle functionalization for diagnostic purposes.

\subsection{Biopolymeric Shells}

Various natural polymers such as dextran [59,60], chitosan [61], hyaluronic acid [62], starch [63], albumin [64], alginate [65], gelatin [66] and polydopamine [67,68] (see Table 4) have been used as coating materials for superparamagnetic iron oxide nanoparticles, also known in the literature as SPIONs, to reduce aggregation, enhance their stability and biocompatibility [27], features also mentioned above. 
Table 4. A summary of biopolymer coating materials for iron oxide cores.

\begin{tabular}{|c|c|c|c|c|}
\hline $\begin{array}{l}\text { Magnetic } \\
\text { Material }\end{array}$ & $\begin{array}{c}\text { Synthesis } \\
\text { Method for Iron Oxide Core }\end{array}$ & Polymeric Coating & Applications & Reference \\
\hline \multirow{17}{*}{$\mathrm{Fe}_{3} \mathrm{O}_{4}$} & \multirow{12}{*}{ Co-precipitation } & Chitosan & \multirow{2}{*}{ MRI } & [69-72] \\
\hline & & Chitosan/Alginate & & [65] \\
\hline & & $\mathrm{N}, \mathrm{N}, \mathrm{N}$-trimethyl chitosan & MRI/PET $\left({ }^{68} \mathrm{Ga}\right)$ & [73] \\
\hline & & \multirow{4}{*}{ Dextran } & MRI & [74-77] \\
\hline & & & MRI/PET $\left({ }^{68} \mathrm{Ga}\right)$ & [59] \\
\hline & & & MRI/SPECT $\left({ }^{99 \mathrm{~m}} \mathrm{Tc}\right)$ & [78] \\
\hline & & & $\begin{array}{l}\text { MRI/SPECT }\left({ }^{99 \mathrm{~m}} \mathrm{Tc} \text {-dipicolylmie }\right. \\
\text { (DPA)-alendronate) }\end{array}$ & [78] \\
\hline & & Carboxymethyl dextran & \multirow{5}{*}{ MRI } & [79] \\
\hline & & BSA & & [80] \\
\hline & & $\mathrm{BSA} / \mathrm{HA}$ & & [64] \\
\hline & & Folic Acid-BSA & & [81] \\
\hline & & Alginate & & {$[82,83]$} \\
\hline & \multirow{2}{*}{ Thermal decomposition } & Dextran & MRI/PET $\left({ }^{64} \mathrm{Cu}\right)$ & [84] \\
\hline & & BSA & \multirow{4}{*}{ MRI } & [85] \\
\hline & Hydrothermal & Alginate/PEI & & [86] \\
\hline & Emulsion polymerization & HSA & & [87] \\
\hline & Emulsification & $\begin{array}{l}\text { PLGA/Chitosan/Dextran } \\
\text { sulfate }\end{array}$ & & [88] \\
\hline \multirow{6}{*}{$\gamma-\mathrm{Fe}_{2} \mathrm{O}_{3}$} & \multirow{4}{*}{ Co-precipitation } & Dextran & \multirow{2}{*}{ MRI } & [89] \\
\hline & & \multirow{2}{*}{ BSA } & & [90] \\
\hline & & & MRI/Fluorescent (FITC) & [91] \\
\hline & & rHSA & MRI & [92] \\
\hline & Nucleation & Gelatin & MRI/Fluorescence Imaging & [93] \\
\hline & $\begin{array}{l}\text { Co-precipitation/cross- } \\
\text { linking }\end{array}$ & Alginate & MRI & [94] \\
\hline \multirow{17}{*}{ IONPs } & \multirow{10}{*}{ Co-precipitation } & Glycol Chitosan/Heparin & \multirow{2}{*}{ MRI } & [95] \\
\hline & & \multirow{4}{*}{ Dextran } & & [96-99] \\
\hline & & & MRI/PET $\left({ }^{89} \mathrm{Zr}\right)$ & [100] \\
\hline & & & $\mathrm{MRI} / \mathrm{CT}$ & [101] \\
\hline & & & Mapping & [102] \\
\hline & & Dextran/Dextran sulfate & \multirow{2}{*}{ MRI } & [103] \\
\hline & & \multirow{2}{*}{ Dextran sulfate } & & [104] \\
\hline & & & MRI/PET $\left({ }^{64} \mathrm{Cu}\right)$ & [105] \\
\hline & & $\begin{array}{c}\text { Carboxymethyl- } \\
\text { diethylaminoethyl } \\
\text { dextran }\end{array}$ & \multirow[t]{2}{*}{ MRI } & [106] \\
\hline & & Gelatin & & [66] \\
\hline & \multirow{4}{*}{ Thermal decomposition } & Oleyl-Chitosan & \multirow{4}{*}{ MRI } & [107] \\
\hline & & Heparin & & [108] \\
\hline & & BSA & & [109] \\
\hline & & HSA & & {$[110,111]$} \\
\hline & \multirow{2}{*}{ Microemulsion } & \multirow{2}{*}{ Gelatin } & MRI & [66] \\
\hline & & & MRI/Optical & [112] \\
\hline & Microwave & Dextran & MRI/PET $\left({ }^{68} \mathrm{Ga}\right)$ & [113] \\
\hline
\end{tabular}


Table 4. Cont.

\begin{tabular}{|c|c|c|c|c|}
\hline $\begin{array}{l}\text { Magnetic } \\
\text { Material }\end{array}$ & $\begin{array}{c}\text { Synthesis } \\
\text { Method for Iron Oxide Core }\end{array}$ & Polymeric Coating & Applications & Reference \\
\hline & \multirow[t]{3}{*}{ Microwave-assisted } & $\begin{array}{l}\text { Different heparins of } \\
\text { distinct } \\
\text { anticoagulant/Anti- } \\
\text { heparanase }\end{array}$ & \multirow[t]{2}{*}{ MRI } & [114] \\
\hline & & \multirow{2}{*}{ Dextran } & & [115] \\
\hline & & & MRI/PET $\left({ }^{64} \mathrm{Cu}\right)$ & [116] \\
\hline & \multirow{2}{*}{ Nucleation } & \multirow{2}{*}{ HSA } & MRI & [117] \\
\hline & & & NIRF & [118] \\
\hline & \multirow{18}{*}{ Co-precipitation } & Chitosan & \multirow{6}{*}{ MRI } & [119] \\
\hline & & $\begin{array}{c}\text { Cationic/Anionic chitosan } \\
\text { derivatives }\end{array}$ & & [120] \\
\hline & & $\begin{array}{l}\text { Bioactive-conjugated } \\
N \text {-palmitoyl chitosan }\end{array}$ & & [121] \\
\hline & & Heparin & & [122] \\
\hline & & Unfractionated heparin & & [123] \\
\hline & & \multirow{2}{*}{ Dextran } & & {$[60,124-129]$} \\
\hline & & & MPI & {$[130,131]$} \\
\hline & & Dextran sulfate & \multirow{2}{*}{ MRI } & [132] \\
\hline & & \multirow{2}{*}{ Carboxydextran } & & [133] \\
\hline & & & PET $\left({ }^{89} \mathrm{Zr}\right) / \mathrm{SPECT}\left({ }^{99 \mathrm{~m}} \mathrm{Tc}\right)$ & [134] \\
\hline & & \multirow{5}{*}{ Carboxymethyl dextran } & MRI & {$[135,136]$} \\
\hline & & & MRI/SPECT ( ${ }^{111}$ In) & [137] \\
\hline & & & PET $\left({ }^{89} \mathrm{Zr}\right)$ & {$[138,139]$} \\
\hline & & & PET $\left({ }^{89} \mathrm{Zr}\right) /$ SPECT $\left({ }^{111} \mathrm{In}\right)$ & [140] \\
\hline & & & PET $\left({ }^{64} \mathrm{Cu}\right) /$ SPECT $\left({ }^{111} \mathrm{In}\right)$ & [140] \\
\hline \multirow[t]{11}{*}{ SPIONs } & & $\begin{array}{l}\text { Carboxymethyl } \\
\text { dextran/Fucoidan }\end{array}$ & \multirow{3}{*}{ MRI } & [141] \\
\hline & & HSA & & [142] \\
\hline & & Alginate & & [143] \\
\hline & \multirow{4}{*}{ Thermal decomposition } & $\begin{array}{l}N \text {-palmitoyl- } N- \\
\text { monomethyl- } N, N- \\
\text { dimethyl- } N, N, N- \\
\text { trimethyl-6-O- } \\
\text { glycolchitosan }\end{array}$ & \multirow[t]{3}{*}{ MRI } & [144] \\
\hline & & $\begin{array}{l}\text { Succinylated heparin } \\
\text { monolayer }\end{array}$ & & [145] \\
\hline & & $\begin{array}{l}\text { Amphiphilic starlike } \\
\text { dextran }\end{array}$ & & [146] \\
\hline & & PLGA/Glycol chitosan & MRI/SPECT ( $\left.{ }^{99 \mathrm{~m}} \mathrm{Tc}\right)$ & [147] \\
\hline & Sol gel & $\begin{array}{l}\text { Cationic derivative of } \\
\text { chitosan/Hyaluronic } \\
\text { acid-Curcumin conjugate }\end{array}$ & & [148] \\
\hline & Microemulsion & $\begin{array}{l}\text { Dextran-b-oligo } \\
\text { (amidoamine) }\end{array}$ & MRI & [149] \\
\hline & $\begin{array}{l}\text { Co-precipitation/Cold } \\
\text { gelation }\end{array}$ & Dextran & & [60] \\
\hline & $\begin{array}{l}\text { Alkaline co-precipitation in a } \\
\text { microfluidic droplet reactor }\end{array}$ & Dextran & MRI & [150] \\
\hline USPIOs & Thermal decomposition & Gelatin & MRI & [151] \\
\hline
\end{tabular}




\subsubsection{Chitosan and Its Derivatives}

Among polysaccharides, chitosan stands out as a biocompatible polymer, and one widely explored in biomedical applications due to its plentiful advantages. These include nontoxicity, controlled biodegradability, and antioxidant and antimicrobial activity $[152,153]$. Its functionality and ability to form nanoparticles and nanocapsules with iron oxides or other inorganics has extended its use for diagnostic, hyperthermic, cancer therapeutic or theranostic purposes [154-156]. Great interest has been devoted to the development of magnetic chitosan nanostructures with such remarkable features as MR imaging aids, especially as $\mathrm{T}_{2}$ contrast agents.

Studies on chitosan-iron oxide cores as nanobiomaterials for image enhancement from the 2000s were detailed in a chapter by Narayanaswamy et al. [57]. Therefore, we presented significant reports from 2010 up to the present below.

Several chitosan derivatives have been proposed as coating materials for SPIONs endowed with better contrast ability in MR imaging. For instance, glycol chitosan, a fully soluble derivate in neutral and acidic media, was employed to increase the steric stabilization and aqueous solubility [157]. In this regard, Lee et al. [147] prepared biodegradable magnetic nanoparticles composed of a hydrophobic core (PLGA and SPIO) and a hydrophilic shell (glycol chitosan) utilizing an emulsion-diffusion-evaporation technique. The nanoparticles were internalized in cells and accumulated in lysosomes. A high level of radioactivity was observed in the liver, shortly after intravenous administration of the ${ }^{99 \mathrm{~m}} \mathrm{Tc}-\mathrm{labeled}$ magnetic nanoparticles. Through in vitro and in vivo tests, the authors proved that magnetic nanoparticles could be useful as an efficient contrast agent for MRI, as they were able to be degraded after serving their imaging function.

Likewise, Xiao et al. [121] developed a tumour-targeted MRI nanosystem composed of iron oxide nanoparticles encapsulated in self-assembled micelles, based on folateconjugated $\mathrm{N}$-palmitoyl chitosan. They showed their tumour-targeting ability through in vitro and in vivo tests. Their results indicated that the signal intensities of $\mathrm{T}_{2}$-weighted images in established HeLa-derived tumours were significantly reduced, indicating that folate-functionalized micelles could serve as safe and effective MRI contrast agents for detecting folate receptor-positive tumours. Hobson et al. [144] prepared clustering SPIONs by encapsulation of hydrophobic iron oxide nanoparticles in an amphiphilic chitosan derivate, namely $N$-palmitoyl- $N$-monomethyl- $N$, $N$-dimethyl- $N, N, N$-trimethyl-6-O-glycolchitosan. Clustered SPIONS exhibited a high spin-spin $\left(r_{2}\right)$ to spin-lattice $\left(r_{1}\right)$ relaxation ratio $\left(r_{2} / r_{1}\right)$ that induced a superior contrast ability, accumulated only in the liver and spleen after intravenous administration and provided clear MRI images of the liver vascularization (when compared with Ferucarbotran, a commercially available contrast agent).

Biocompatible SPIONs coated with a layer of cationic derivative of chitosan and hyaluronic acid-curcumin conjugate with very high values of saturation magnetization $\left(43.4 \pm 0.2 \mathrm{~A} \cdot \mathrm{m}^{2} / \mathrm{kg} \mathrm{Fe}\right)$ and transverse relaxivity $\left(469.7 \pm 2.3 \mathrm{mM}^{-1} \cdot \mathrm{s}^{-1}\right)$ were developed by Lachowicz et al. [148] The coated SPIONs could be considered as bimodal agents for both MRI and fluorescence detection. In a further study, comprehensive results on uptake and bioreactivity of charged chitosan-coated SPIONs with high stability, designed as $T_{2}$ contrast agents, were reported by Kania et al. [120] in 2018. The authors explored the in vivo bioreactivity of SPIONs coated with either cationic (low molecular weight chitosan with quaternary ammonium groups, DS-57\%) or anionic chitosan derivatives (carboxymethyl chitosan substituted with sulfonate groups, degree of substitution of $66 \%$ ) using a BALB/c mouse model. The overall results proved that the kidneys and liver were the organs involved in SPIONs removal. It is noteworthy to mention that chitosan-coated SPIONs could be employed for long-term studies as they showed liver-enhancing MRI contrast even 7 days after administration.

Additionally, amphiphile chitosan derivatives were developed as suitable coating materials for SPIONs, planned for imaging purposes. For instance, oleyl chitosan-coated iron oxide nanoparticles were recommended as a dual probe for optical and magnetic resonance imaging of tumours [107]. In a recent report, Hemalatha et al. [158] showed that 
oleyl chitosan was a suitable platform for inorganic nanoparticle encapsulation (namely hybrid iron oxide/gold nanostructures) that guaranteed both high colloidal stability and better magnetic resonance imaging. At the same time, the magnetic nanocomposite exhibited good appropriate characteristics for computer tomography: biocompatibility, X-ray attenuation properties and hemocompatibility.

On the other hand, Khmara et al. [72] formulated chitosan-stabilized iron oxide nanoparticles in two steps: (i) co-precipitation method and (ii) consequent polymer coating, in the presence of urea (used to support a uniform distribution of iron oxide nanoparticles' size). The MRI tests showed a significant prevailing effect on $\mathrm{T}_{2}$ (the transversal relaxation time) with high transversal relaxivity values $\left(\mathrm{r}_{2}=238.16 \mathrm{mM}^{-1} \cdot \mathrm{s}^{-1}\right)$ that exceeded those of clinically-used iron-based contrast agents (namely Feridex $\mathrm{r}_{2}=120 \mathrm{mM}^{-1} \cdot \mathrm{s}^{-1}$, Resovist $\mathrm{r}_{2}=186 \mathrm{mM}^{-1} \cdot \mathrm{s}^{-1}$ and Combidex $\mathrm{r}_{2}=65 \mathrm{mM}^{-1} \cdot \mathrm{s}^{-1}$ [159]. In a recent report, Sun et al. [160] investigated the in vitro ability of chitosan iron oxide nanoparticles to be used for dual-mode US/MR imaging and concluded that they showed potential as efficient contrast agents.

In order to provide a more detailed in vivo diagnosis, Chung et al. [161] prepared an MRI and NIRF multimodal imaging system based on glycol chitosan-coated SPIONs and functionalized it with matrix metalloproteinase sensitive peptide conjugated with black hole quencher 3 and Cy5.5 dye at each end. NIRF-based optical techniques provided data regarding the biological events that occur at a molecular level through the degradation of activated linkers or molecular triggers, e.g., matrix metalloproteinase (MMP)-sensitive peptide. Magnetic nanosystems showed a maximum NIRF intensity at $48 \mathrm{~h}$ post-injection in tumour tissue (which was approximately 8 times higher than other organs) and a relative MRI contrast enhancement compared to normal muscles. Concurrently, magnetic nanosystems depicted the anatomic image of the tumour site and provided MMP-2-dependent biological data.

\subsubsection{Dextran and Derivatives}

Dextran is a polysaccharide consisting of linear chains of $\alpha-1,6$ linked glucopyranose residues with $\alpha-1,3$ or 1,4 side chains linked to the backbone units, in varying proportions and sequential arrangements with excellent water solubility, biocompatibility, biodegradability, improved transfection efficiency, low-cost and non-toxicity, suitable for use in biological systems.

Dextran has been used as a polymer coating material for iron oxide nanoparticles since the early 1980s. The first report of the formation of magnetite in the presence of dextran was by Molday and Mackenzie [162]. Five years later, Magin et al. [163] studied dextran magnetite as a liver tumour contrast agent for MRI, with both $\mathrm{T}_{1}$ and $\mathrm{T}_{2}$-weighted spin-echo images after intravenous injection on Fischer 344 rats. In 1996, the FDA approved Feridex I.V. (ferumoxides) Advanced Magnetics company as the first nanoparticle-based iron oxide imaging agent to detect liver lesions. Feridex ${ }^{\mathrm{TM}} \mathrm{I} . V .{ }^{\circledR}{ }^{(\text {ferumoxides injectable }}$ solution) is a sterile aqueous colloid of superparamagnetic iron oxide associated with dextran for intravenous administration as an MRI contrast media.

Dextran and its derivatives (e.g., carboxymethyl dextran, carboxydextran, aminodextran and dextran sulphate) were layered in iron oxide nanoparticle cores as early as 2000 and up to 2014, and were used as versatile platforms for MRI for tumour imaging (especially pancreatic and colon cancer cells), for in vitro labelling of cells and subsequent cell-tracking of phagocytic cells in vivo in liver fibrosis, atherosclerosis, lung cancer, head and neck cancer cells, etc., as described in Narayanaswamy et al. [57] and Table 4.

In the same period, a few of the SPIONs coated with dextran (e.g., Endorem, Resovist or Clariscan) were approved as clinical liver/lymph node MRI-based contrast agents. However, in 2009-2011, these products were withdrawn from the market due to insufficient clinical trial results and major safety concerns. These issues are discussed in the next section.

A contrast agent for both CT and MRI was proposed by Naha et al. [101] that synthesized dextran-coated bismuth-iron oxide nanoparticles and was used for in vivo imaging 
experiments in wild-type C57BL/6J inbred mice using a micro-CT and a 9.4 T MRI system. As shown in the experimental article, the composite nanoparticles were present in the heart, blood vessel and bladder, and were excreted via urination, with significant concentrations in the kidneys and urine. Substantial signal loss in $\mathrm{T}_{2}$-weighted MR images was also observed in the liver at $2 \mathrm{~h}$ post injection. Considering both positive in vivo $\mathrm{CT}$ and MR imaging results, the dextran-coated bismuth-iron oxide nanoparticles could be used as a dual modality contrast agent.

Valuable results were obtained by Wabler et al. [164] that established a relationship between MRI signal intensity and iron content for formulations, e.g., human prostate carcinoma DU-145 cells loaded with starch-coated, bionized nanoferrite, iron oxide (Nanomag ${ }^{\circledR}$ D-SPIO), Feridex ${ }^{\mathrm{TM}}$ and dextran-coated Johns Hopkins University particles (NanoMaterials Technology, Singapore). The MRI data showed a linear correlation between increased iron content-quantified using inductively-coupled plasma mass spectrometry—and decreased $\mathrm{T}_{2}$ times.

The surface charge in the range of surface $(-1.5 \mathrm{mV}$ to $+18.2 \mathrm{mV})$ of dextran-based SPIONs was tailored for increased uptake and MRI contrast of mesenchymal stem/stromal cells by Barrow et al. [126] using fluorescein isothiocyanate and diethylamino ethyl compounds. The in vitro MRI tests acknowledged that this functionalization strategy controlled the safe uptake into stem cells, which was a required condition before clinical evaluation.

Two types of materials - based on multicore superparamagnetic iron oxide nanoparticles stabilized with dextran and PEG-gallic acid polymer-were synthesized by Ziemian et al. [130] in 2015, in order to develop an optimized tracer for MPI, a new imaging modality, initiated by Gleich and Weizenecker [165] in 2005. The authors compared the capabilities of the two materials using Resovist agent, and demonstrated excellent MPI potential, superior to what was commercially available.

Bombesin peptide analogue (KGGCDFQWAV- $\beta$ Ala-HF-NIe), covalently attached to the dextran SPIONs, were used for the first time in 2015 as a new targeting MRI contrast agent for breast cancer detection [77]. The MRI study (on a $1.5 \mathrm{~T}$ MRI Scanner) indicated that this new contrast agent showed $\mathrm{T}_{2}{ }^{*}$ values at 13 and $30 \mathrm{~h}$ after the tail vein injection and demonstrated the ability to accumulate within a breast tumor.

The detection of lung cancer metastasis by MRI was enhanced using SPIONs coated with oleic acid and carboxymethyl dextran, conjugated to mouse anti-CD44v6 monoclonal antibody. After the determination of their physicochemical properties, the in vitro MRI studies detected human lung adenocarcinoma (A549) cells in $T_{2}$ relaxation time [135].

Commercially available dextran-coated SPIONs of nearly $215 \mathrm{~nm}$ and positive surface charge (FeraTrack Direct) were evaluated for direct labelling of stem cells and in vivo MRI tracking [166]. The nanoparticles were labelled with bone marrow-derived mesenchymal stromal cells and neural stem cells and injected to C6 glioma-bearing nude mice. The tracers were detected as hypointense regions within the tumour using $3 \mathrm{~T}$ clinical MRI up to 10 days post injection. These results were also confirmed by histological analysis.

Carboxymethyl-diethylaminoethyl dextran magnetite particles were synthesized as a blood-pooling, non-gadolinium-based contrast agent, since it is well known that gadolinium-based agents increase the risk for nephrogenic systemic fibrosis in severe renal insufficiency patients. Both positive $(+9.6 \mathrm{mV})$ and negative $(-10.4,-41.0 \mathrm{mV})$ surface charge particles were injected into Japanese white rabbits to evaluate if the degree of charge altered the blood-pooling time. The in vivo pooling time was prolonged for up to $300 \mathrm{~min}$ for all three differently charged particles, thus exhibiting prolonged vascular enhancing effects [167].

The following year, a positively charged dextran-coated SPION containing diethylaminoethyl and fluorescein isothiocyanate was used to efficiently label macrophages for MRI-based cell tracking in vivo up to 3 weeks post-transplantation. The labelling was more efficient than ferumoxytol, but the authors considered that further studies were required to determine if SPION-labelled bone marrow-derived macrophages had a therapeutic effect in liver disease [168]. 
Five different sizes, ranging from 30 to $130 \mathrm{~nm}$ of dextran-coated SPIONs were fabricated by cold gelation method [129] and tested for their imaging properties by $T_{2}, T_{2}{ }^{*}$ and $\mathrm{T}_{1}$ relaxation times with a $7 \mathrm{~T}$ MRI in vitro in agarose gels. Independent of their size, the nanoparticles displayed their safety and internalization by macrophages and the absence of hypersensitivity reactions - both properties suitable for future clinical development as MRI contrast agents [60].

A facile method to develop iron oxide nanoparticle-loaded magnetic dextran nanogels as an MRI guided nanoplatform was proposed by Su et al. in 2019 [74]. First, the iron oxide nanoparticles were pre-synthesized by co-precipitation method, followed by physical blending with aldehyde dextran solution and cross-linking with ethylenediamine in a w/o inverse microemulsion. In vitro MRI study using magnetic dextran nanogel and a clinical 1.5 T MRI scanner showed relatively higher $\mathrm{T}_{2}$ relaxivity $\left(277.2 \mathrm{mM}_{\mathrm{Fe}}{ }^{-1} \cdot \mathrm{s}^{-1}\right)$ than single $\mathrm{Fe}_{3} \mathrm{O}_{4}$ nanoparticles (5.6 fold), attributed, according to the authors, to the iron oxide cores trapping into the hydrogel network, leading to a lower water diffusion coefficient and increasing of the transverse relaxation rates.

A recent original article by Shin et al. [99] described the synthesis of a nanoparticle with a polysaccharide supramolecular core and a shell of amorphous ferric oxide. The article reported MRI evaluation of cerebral, coronary and peripheral microvessels in rodents and lower-extremity vessels in rabbits. The schematic of the nanoparticle production included the following steps: supramolecular dextran core (synthesized by cross-linking dextran with epichlorohydrin and ethylenediamine) and iron oxide surface coating under basic conditions, both at room temperature. After intravenous administration on BALB/c mice and Sprague-Dawley rats' tails and rabbit ears, the supramolecular iron oxide generated a strong $\mathrm{T}_{1}$ MRI contrast effect, with a relaxivity coefficient ratio of $\sim 1.2$. This was close to the ideal value and similar to the gadolinium, using a $3 \mathrm{~T}$ clinical MRI system. The authors compared the imaging capabilities with Dotarem (gadoterate meglumine), a clinically approved gadolinium-based MRI contrast agent. The high-resolution $\mathrm{T}_{1}$ feature was attributed to the hydrous ferric oxide shell interaction with water molecules. Another important feature of this compound was its excellent in vivo renal clearance, long blood circulation (attributed to $5 \mathrm{~nm}$ size and optimized charge) and the fact that it did not accumulate in the organs. All of these serve as favourable evidence of its potential to serve as a contrast agent for cerebral, peripheral and coronary vessels.

\subsubsection{Heparin}

Heparin is a natural glycosaminoglycan molecule containing sulphate and carboxylic groups, widely used as a clinical anticoagulant and in drug delivery and tissue engineering to improve the blood compatibility of biomaterials. Heparin consists of a complex combination of linear anionic polysaccharides, with an average molecular weight of $16 \mathrm{kDa}$ [169]. It is composed of disaccharide repeating units of D-glucosamine, D-glucoronic, and L-iduronic acid that carry $\mathrm{O}$-sulfo, $\mathrm{N}$-acetyl or $\mathrm{N}$-sulfo groups, resulting in a heterogenic mixture of sulfonated molecules. This high content of anionic groups in the heparin molecule warrants multiple point moieties to the iron oxide nanoparticles surface, mainly through electrostatic interactions.

In 2011, Yuk et al. [95] designed glycol chitosan/heparin-immobilized iron oxide nanoparticles as an MRI agent with a tumour-targeting feature. First, iron oxide nanoseeds were prepared by alkaline co-precipitation of ferrous $\left(\mathrm{Fe}^{2+}\right)$ and ferric $\left(\mathrm{Fe}^{3+}\right)$ chlorides followed by gold deposition through the reduction of $\mathrm{Au}^{3+}$ on the iron oxides surface. The next step involved the incorporation of gold-deposited iron oxide nanoparticles into the glycol chitosan/heparin network in the presence of Tween 80 to form composite nanoparticles. In vivo MR images of the composite nanoparticles containing iron oxide showed short spin-spin relaxation times $\left(\mathrm{T}_{2}^{*}\right)$ after dephasing the spin of neighbouring water protons, resulting in the darkening of $\mathrm{T}_{2}{ }^{*}$-weighted images, when compared with Resovist. The accumulation in the tumour site even $6 \mathrm{~h}$ post administration in $\mathrm{C}_{3} \mathrm{H} / \mathrm{HeN}$ 
mice, indicated that the obtained composites might be utilized as an MR imaging agent with enhanced targeting features.

Heparin-coated SPIONs were developed as a potential $\mathrm{T}_{2}$ contrast agent by Lee (2011) [122] and compared with dextran-coated SPIONs, commercially available as Feridex. In the relaxivity measurements, using a clinical 1.5 T MRI system in agarose phantom, heparin-coated SPIO $\left(r_{1}\right.$ and $r_{2}$ was 9.4 and $170.7 \mathrm{mM}^{-1} \cdot \mathrm{s}^{-1}$ ) demonstrated better signals than dextran-coated SPIO $\left(\mathrm{r}_{1}\right.$ and $\mathrm{r}_{2}$ was 2.2 and $72.4 \mathrm{mM}^{-1} \cdot \mathrm{s}^{-1}$ ), indicating that both could be useful for $\mathrm{T}_{2}$-weighted MR imaging due to their high $\mathrm{r}_{2} / \mathrm{r}_{1}$ ratio (above 10). Interestingly, the in vitro cellular labelling results confirmed that heparinized SPIO could visualize rat Ins-1 pancreatic $\beta$-cells after a short incubation time $(2 \mathrm{~h})$, because of its low $\mathrm{r}_{2} / \mathrm{r}_{1}$ ratio. Once more, from these findings, heparin-coated SPIO can be used as a good negative contrast agent in clinical MRI. The same group tested SPIO nanoparticles coated with unfractionated heparin as new negative contrast agents for in vivo MR imaging of human mesenchymal stem cells (hMSCs) in 2012 [123]. The in vitro $\mathrm{T}_{2}$-weighted MRI, performed using hMSCs suspended in low-melting agarose, showed a linear dependency of the signal from grey to dark black with the increasing of coated nanoparticle concentration. The authors also investigated the long-term in vivo tracking of heparin-SPIO labelled hMSCs, by transplanting the cells under the renal subcapsular membranes of the left kidneys of nude mice and monitoring the hypointensity signals with $\mathrm{T}_{2}$ - or $\mathrm{T}_{2}{ }^{*}$-weighted MRI on days 1,14 , and 28 . The in vivo results showed strong negative intensity with a detectable range of spatial resolution 28 days after transplantation-results consistent with the histological analysis of the ex vivo kidneys.

In 2017, iron oxide nanoparticles were coated with different heparins of distinct anticoagulant/anti-heparanase activity ratios, and investigated as positive contrast agents in MRI [114]. The authors used a one-step microwave-assisted method for the synthesis of heparin coated-iron oxide nanoparticles with hydrodynamic sizes between 30 and $60 \mathrm{~nm}$. The MRI performances of the obtained materials were assessed by investigating longitudinal $\left(\mathrm{r}_{1}\right)$ and transversal $\left(\mathrm{r}_{2}\right)$ relaxivities at $37^{\circ} \mathrm{C}$ and $1.5 \mathrm{~T}$, and the results displayed a $r_{2} / r_{1}$ ratio suitable for $T_{1}$-weighted MRI. The in vivo magnetic resonance angiography (7 T) showed a bright vascular architecture after injection in mice tail veins of heparincoated iron oxide nanoparticles, with excellent anatomical details of carotids, aorta, heart chambers, main veins, and even some smaller vessels, demonstrating that the nanoparticles could enhance $\mathrm{T}_{1}$ relaxation in the circulating system.

In 2019, Xie et al. [145] demonstrated that SPIONs coated with a monolayer of succinylated heparin exhibited over four-fold increased $\mathrm{T}_{2}$ relaxivity $\left(460 \mathrm{mM}^{-1} \cdot \mathrm{s}^{-1}\right)$ as compared to Feridex $\left(98.3 \mathrm{mM}^{-1} \cdot \mathrm{s}^{-1}\right)$ on in vitro MRI relaxivity measurements using a $3.0 \mathrm{~T}$ MR scanner. MRI imaging, performed using mice bearing human head and neck tumour (KB cell line) cells with a 7.0 T MRI scanner, confirmed the enhanced $\mathrm{T}_{2}$ imaging ability of succinylated heparin monolayer SPIONs (stable $14 \mathrm{~nm}$ nanoparticles) and the consequent accumulation in the tumour site-an ability imparted by the thinner coating. It is our belief that the aforementioned results demonstrate the potential of heparin-coated iron oxide nanoparticles as possible high-performance clinical $\mathrm{T}_{2}$ contrast agents.

Recently, the same group of authors reported a new magnetic iron oxide nanoparticle with a succinylated heparin monolayer coating. It exhibited the highest $\mathrm{T}_{1}$ relaxivity and the lowest $r_{2} / r_{1}$ ratio found to date [108]. Magnetic iron oxide nanoparticles with diameters of 2,3, and $5 \mathrm{~nm}$ were synthesized via the thermal decomposition of the ironoleate complex, then surface-functionalized with succinylated heparin by ligand exchange, obtaining nanoparticles with core sizes ranging from 2 to $18.5 \mathrm{~nm}$. After in vitro and in vivo MRI relaxivity measurements for all size particles, the authors demonstrated that the $2 \mathrm{~nm}$ succinylated heparin magnetic iron oxide nanoparticle had a high $\mathrm{T}_{1}$ relaxivity of $4.6 \mathrm{mM}^{-1} \cdot \mathrm{s}^{-1}$ and a low $\mathrm{r}_{2} / \mathrm{r}_{1}$ ratio of 4.0 at $7 \mathrm{~T}$ field strength. 


\subsubsection{Albumin}

Human serum albumin (HSA) is the most abundant protein found in the blood. It has excellent biocompatibility as a nanoparticle coating for biomedical applications. Commercially, albumins are obtained from egg white, bovine serum, human serum, milk, grains, and soybeans. Among these, bovine serum albumin (BSA) is the most commonly studied negatively-charged plasma protein, due to the similarity of sequence and structure between BSA and HSA, as well as its non-toxicity, good biocompatibility, and excellent biodegradability, serving often as a stabilizing agent for nanoparticles.

Since 1987, HSA-covered magnetite microspheres have been produced through a modified w/o emulsion polymerization method, as reported by Widder et al. [87], and tested as a contrast agent for MRI, with effects on both $\mathrm{T}_{1}$ and $\mathrm{T}_{2}$. In following years, multiple studies described different contrast agents based on iron oxide-albumin shells, with the potential to be introduced into clinical imaging (conclusions briefly detailed below).

Hybrid nanoclusters based on BSA/SPION were synthesized in a two-step procedure for liver-specific MRI by Zhang et al. [85]. First, the hydrophobic magnetic nanoparticles were obtained by thermo-chemical decomposition at $300^{\circ} \mathrm{C}$, followed by the formation of oil-in-water emulsion via ultrasonication in the presence of SPION/chloroform organic solution as the oil phase and BSA solution as the water phase. The as-prepared water-soluble BSA/SPION hybrid nanoclusters had a uniform size of $\sim 86 \mathrm{~nm}$, exhibited superparamagnetic behaviour and good colloidal stability and biocompatibility. The liver MRI acquired in vivo after the intravenous injections showed a high value of $r_{2} / r_{1}$ ratio (139.7), favourable for $T_{2}$ relaxation enhancement.

Copolymeric micelles-based on poly (2,2,3,4,4,4-hexafluorobutyl methacrylate-comethacryloxyethyl trimethyl ammonium chloride)-g-methoxy PEG- monomethacrylate functionalized with folate, conjugated with BSA and loaded with SPIONs-were prepared by self-assembling/electrostatic interactions and investigated as a specific contrast agent for tumour targeting and MRI in vitro and in vivo by Li et al. in 2015 [81]. The high $\mathrm{T}_{2}$ relaxivity was demonstrated using the obtained micelles for in vitro studies and sustained by in vivo tumour-specific MR imaging of hepatoma at $24 \mathrm{~h}$ post injection. The functionalized micelles were internalized by the tumour, as observed by the in vitro cellular uptake studies and prolonged circulation time, revealing their potential as a tumour-targeting contrast agent.

Superparamagnetic iron oxide, this time with $\gamma-\mathrm{Fe}_{2} \mathrm{O}_{3}$ nanoparticles, were synthesized from $\mathrm{Fe}_{3} \mathrm{O}_{4}$, then surface-coated with BSA, conjugated with tumour-specific ligand folic acid and decorated with FITC for dual-modal imaging (MRI and intracellular internalization and visualization) in human brain tumours [91]. In vitro MRI assessment on a $1.5 \mathrm{~T}$ scanner produced a significantly negative contrasted $\mathrm{T}_{2}$-weighted $\mathrm{MR}$ phantom imaging (signal darkening) of the in-human brain tumour U251 cells. The fluorescent capability was also demonstrated by intracellular internalization within the U251 cells treated with the obtained material.

Tzameret et al. [117] prepared core-shell near infrared fluorescent (NHS Cy7) iron oxide nanoparticles coated with BSA shell and tested in vivo tracking (by MRI) into the posterior segment of the eye in a rat model of retinal degeneration. The bioactive magnetic iron oxide/HSA nanoparticles were detected in the back part of the rats' eyes by MRI for up to 30 weeks following injection, with effects on $\mathrm{T}_{2}{ }^{*}$-and were detected for up to 6 weeks by histology, suggesting the nanoparticles' potential use for extended release drug delivery in the posterior segment.

A comparison of the $\mathrm{T}_{1}$-weight contrast performances of iron oxide nanoparticles modified with BSA and poly (acrylic acid)-poly(methacrylic acid macromolecule ligands with similar size and magnetization was reported by Tao et al. [80] in 2019. The obtained nanoparticles, coated with BSA, exhibited higher $\mathrm{r}_{2} / \mathrm{r}_{1}$ ratios in solution and darkening contrast enhancement for liver and kidney sites of mice under $\mathrm{T}_{1}$-weight imaging on a 0.5 T MRI scanner, when compared with the artificial macromolecule coated nanoparti- 
cles. Additionally, the $\mathrm{Fe}_{3} \mathrm{O}_{4}$-BSA displayed $\mathrm{T}_{2}$ contrast enhancement, demonstrating the dependence of MRI performance on the nanoparticle surface.

In a recent study, BSA nanocage protein was used as a biotemplate to synthesize $\sim 3.5 \mathrm{~nm}$ uniform monodispersed $\mathrm{Fe}_{2} \mathrm{O}_{3}$-BSA nanoparticles with good biocompatibility and a high $\mathrm{T}_{1}$ contrast effect [90]. The authors selected $\mathrm{Fe}_{2} \mathrm{O}_{3}$ instead of the more common $\mathrm{Fe}_{3} \mathrm{O}_{4}$ because it was reported that the first type of iron oxide increases the value of $\mathrm{r}_{1}$, maximizing the $\mathrm{T}_{1}$ contrast effect and weakening the $\mathrm{T}_{2}$ contrast effect [170]. The in vitro MRI relaxivity study, acquired on a $3 \mathrm{~T}$ scanner, showed a factor of 1.8 higher for $\mathrm{r}_{1}$ values when compared with the commercially available ferumoxytol and gadoliniumdiethylenetriamine pentaacetic acid (Gd-DTPA) values. In vivo MRI study was performed in healthy Sprague Dawley rats, and the same $3 \mathrm{~T}$ scanner demonstrated the clinical potential of the self-assembled BSA nanocages as $\mathrm{T}_{1}$-weighted contrast agents. The highest positive contrast appeared in the heart $15 \mathrm{~m}$ after injection.

\subsubsection{Gelatin}

Gelatin is a naturally-derived macromolecule with a high hydration degree, high biocompatibility and biodegradability, available at a low market price. It is obtained through the partial hydrolysis of native collagen, both acidic (for gelatin type A) and alkaline (for type B). Gelatin has been exploited in the biomedical field as a drug carrier and/or contrast agent, as well as a cell culture substrate in a variety of forms, owing to its unique chemical and physical nature. According to Narayanaswamy et al. [57], there have been very few studies focused on the design and manufacture of gelatin-based iron oxide nanoparticles as imaging agents (as of 2014, briefly mentioned in Table 4). Below, we indicate several recently reported findings that fit the purposes of this review, after an ample literature search performed using the PubMed, Web of Science and Scopus databases using the following terms: "gelatin" AND "iron oxide" AND "imaging-a search that returned 47 studies.

A multimodal probe capable of visualizing cells by optical and in vitro MRI modalities was prepared by emulsion method. It consisted of gelatin nanospheres incorporating quantum dots and iron oxide nanoparticles, cross-linked with glutaraldehyde and treated with octa-arginine (R8) of a cell-penetrating peptide [112]. The composite nanospheres (about $162 \mathrm{~nm}$ ) were efficiently internalized into the cells, as visualized by both confocal laser microscopy and $\mathrm{T}_{2}$-weighted MRI modalities.

In a more recent study, the current 3D printing method was employed for repairing and replacing diseased bile ducts using an artificial tubular composite scaffold based on polycaprolactone (PCL) as a matrix for the organoid cells of the bile duct [151]. In order to enhance the scaffold features, a layer of gelatin methacryloyl (GelMA) hydrogel was applied on the outer layer, followed by USPIO nanoparticle dispersion for contrast agent potential. The $\mathrm{T}_{2}$-weighted in vitro MRI images of the scaffolds using a clinical $3 \mathrm{~T}$ full body scanner illustrated a uniform signal area with clear continuous boundaries, which could clearly display position changes and degradation of the scaffold in real-time.

\subsubsection{Alginate}

Alginate is a linear anionic polysaccharide usually extracted from brown algae and formed by $\alpha$-L-guluronate $(\mathrm{G})$ and $\beta$-D-mannuronate $(\mathrm{M})$ copolymers arranged in a block structure as a homopolymer (consecutive poly-G/poly-M residues) or heteropolymer (an alternating $M$ and $G$ residues). Alginate has been extensively investigated and used for many biomedical applications due to its hydrophilicity, biocompatibility, biodegradability, lack of toxicity, mucoadhesiveness, relatively low cost, $\mathrm{pH}$ sensitivity, mild gelation with the addition of divalent cations, and lack of immunogenicity—having already received permission from the FDA for human use [171].

Bar-Shir et al. [143] used both in vitro and in vivo MRI studies for non-invasive determination of the $\mathrm{Ca}^{2+}$ level changes extracellular and in deep tissues, using selective SPIONs coated with monodispersed and purified alginate. The added $\mathrm{Ca}^{2+}$ sensors (obtained from 
ischemic astrocyte cell culture in DMEM) were detected by $\mathrm{T}_{2}$-weighted MRI—since the nanoparticles aggregated in the presence of $\mathrm{Ca}^{2+}$-and compared with images of the reference solutions. The alginate-coated magnetic nanoparticles were further tested in vivo in a quinolinic acid model of neurotoxicity in rat brains as proof of concept at 7 or 12 days post injection. The $\mathrm{T}_{2}$-weighted MR images clearly showed that the nanoparticles could be qualitatively used as a platform for the non-invasive MRI determination of extracellular $\mathrm{Ca}^{2+}$ levels.

Iron oxide nanoparticle-immobilized alginate nanogels were reported as novel contrast agents for enhanced MR imaging applications. Briefly, alginate carboxyl groups were activated by 1-ethyl-3-(3-dimethylaminopropyl) carbodiimide hydrochloride, followed by double water-in-oil emulsion formation using dichloromethane, dioctyl sodium sulfosuccinate and aqueous PVA solution to synthesize the nanogels, and in situ cross-linking with PEI-coated $\mathrm{Fe}_{3} \mathrm{O}_{4}$ nanoparticles obtained by the hydrothermal method [86]. The obtained alginate $/ \mathrm{PEI}-\mathrm{Fe}_{3} \mathrm{O}_{4}$ nanogels (with a size of $186.1 \mathrm{~nm}$ ) were water-dispersible, colloidal with high stability, and cytocompatible in the given concentration range. As suspected, the nanogels showed a negative contrast for $\mathrm{T}_{2}$-weighted MR imaging with a high $\mathrm{r}_{2}$ relaxivity $\left(170.87 \mathrm{mM}^{-1} \cdot \mathrm{s}^{-1}\right)$ as observed in vitro on cancer cells and in the xenografted tumour model in vivo after intravenous injection.

\subsection{Synthetic Biocompatible Polymers}

The unique identities and features of these polymers' architecture makes them suitable for use in the design of versatile, polymeric functionalities and demonstrates their potential use in specific and specialized applications. The term biocompatible has attracted significant attention in the biomedical field, wherein the introduction of specific polymeric moieties on a system defines extraordinary functions compatible with biological systems [172].

Over the years, developments in synthetic strategies for iron oxide nanoparticle coatings (e.g., PEG [173,174], PVA [175], PLGA [176], poly ( $N$-isopropylacrylamide) [177], etc.), as presented in Table 5, have defined multiple vehicles for diagnostic applications. Therefore, we described only silica and PEGylation strategies in this section, since our group has contributed to this field.

Table 5. Summarization of bio-inspired coating materials for iron oxide cores.

\begin{tabular}{|c|c|c|c|c|}
\hline $\begin{array}{l}\text { Magnetic } \\
\text { Material }\end{array}$ & $\begin{array}{l}\text { Synthesis Method for Iron } \\
\text { Oxide Core }\end{array}$ & Polymeric Coating & Applications & Reference \\
\hline \multirow{10}{*}{$\mathrm{Fe}_{3} \mathrm{O}_{4}$} & \multirow{11}{*}{ Co-precipitation } & \multirow[b]{2}{*}{ PEG } & MRI & {$[178,179]$} \\
\hline & & & SPECT ( ${ }^{111}$ In) & [180] \\
\hline & & PEG diacid (HOOC-PEG-COOH) & \multirow{2}{*}{ MRI } & [181] \\
\hline & & PLA/PEG/D-glucosamine & & [182] \\
\hline & & \multirow{4}{*}{ Silica } & MRI (Gd-DTPA) & [183] \\
\hline & & & MRI & [184] \\
\hline & & & MPI & [185] \\
\hline & & & $\mathrm{MRI} / \mathrm{PET}\left({ }^{11} \mathrm{C}\right)$ & [186] \\
\hline & & Mesoporous Silica & MRI & [187] \\
\hline & & APTES & Tumour imaging agent $\left({ }^{99 \mathrm{~m}} \mathrm{Tc}\right)$ & [188] \\
\hline \multirow[t]{8}{*}{$\mathrm{Fe}_{3} \mathrm{O}_{4} / \gamma-\mathrm{Fe}_{2} \mathrm{O}_{3}$} & & $\begin{array}{l}\text { Poly(2-acrylamido-2-methylpropane } \\
\text { sodium sulfonate) P(AMPS) }\end{array}$ & MRI & [189] \\
\hline & \multirow{7}{*}{ Thermal decomposition } & \multirow{7}{*}{ PEG } & MRI & [190-192] \\
\hline & & & MRI/SPECT $\left({ }^{99 \mathrm{~m}} \mathrm{Tc}\right)$ & [193] \\
\hline & & & MRI/SPECT $\left({ }^{125} \mathrm{I}\right)$ & {$[106,194]$} \\
\hline & & & MRI/PET $\left({ }^{68} \mathrm{Ga}\right)$ & [195] \\
\hline & & & MRI/PET $\left({ }^{64} \mathrm{Cu}\right)$ & [196] \\
\hline & & & MRI/PET ( $\left.{ }^{71} \mathrm{As}\right)$ & [197] \\
\hline & & & SPECT $\left({ }^{99 \mathrm{~m}} \mathrm{Tc}\right)$ & [174] \\
\hline
\end{tabular}


Table 5. Cont.

\begin{tabular}{|c|c|c|c|c|}
\hline $\begin{array}{c}\text { Magnetic } \\
\text { Material }\end{array}$ & $\begin{array}{l}\text { Synthesis Method for Iron } \\
\text { Oxide Core }\end{array}$ & Polymeric Coating & Applications & Reference \\
\hline & & PEG-phosphate & \multirow{2}{*}{ MRI } & [198] \\
\hline & & Hydroxyl-PEG-Phosphonic Acid & & [199] \\
\hline & & DSPE-mPEG $2000 /$ DSPE-mPEG 2000 amine & MRI/PET $\left({ }^{68} \mathrm{Ga}\right)$ & [200] \\
\hline & & \multirow{2}{*}{ Silica } & MRI & {$[201,202]$} \\
\hline & & & MRI/US & [203] \\
\hline & & \multirow{2}{*}{ Mesoporous Silica } & MRI & {$[202,204]$} \\
\hline & & & MRI/Fluorescence Imaging & [190] \\
\hline & & Silica & MRI/Optical (FITC) & [205] \\
\hline & \multirow{5}{*}{ Hydrothermal } & PEG & MRI/PET $\left({ }^{64} \mathrm{Cu}\right)$ & [206] \\
\hline & & DPPE-mPEG $_{2000} /$ DSPE-cPEG $_{2000}$ & SPECT $\left({ }^{67} \mathrm{Ga}\right)$ & [207] \\
\hline & & PEI & \multirow{2}{*}{ MRI } & [208] \\
\hline & & \multirow{2}{*}{ Silica } & & [209] \\
\hline & & & MPI & [210] \\
\hline & Solvothermal & Mesoporous Silica & & [211] \\
\hline & Sol gel & Silica & & [212] \\
\hline & Microemulsion & PEG & MRI & [213] \\
\hline & Reduction-precipitation & PEI & & [214] \\
\hline & & PEG bis(carboxymethyl) ether & & [215] \\
\hline & Polyol & PEG diacid (HOOC-PEG-COOH) & MRI (Gd) & [216] \\
\hline \multirow{3}{*}{$\gamma-\mathrm{Fe}_{2} \mathrm{O}_{3}$} & Co 0 - initi & PEG-based liposome & MRI/PET $\left({ }^{68} \mathrm{Ga}\right)$ & [217] \\
\hline & Co-precipitation & \multirow{2}{*}{ Silica } & \multirow{2}{*}{ MRI } & [218] \\
\hline & Sol gel & & & [219] \\
\hline \multirow{21}{*}{ IONPs } & \multirow{9}{*}{ Co-precipitation } & PEG & MRI & [213] \\
\hline & & PEG-Maleimide & MRI/PET $\left({ }^{64} \mathrm{Cu}\right)$ & [220] \\
\hline & & PEG/Terminated polystyrene/Linoleic acid & MRI & [221] \\
\hline & & Poly(4-vinylpyridine)/PEG acrylate & MRI/SPECT ( ${ }^{111}$ In) & [222] \\
\hline & & Silica/Silica-PEG & MRI & [223] \\
\hline & & \multirow{2}{*}{ Silica/PEG } & MRI/PET $\left({ }^{68} \mathrm{Ga}\right)$ & [224] \\
\hline & & & MRI/PET-CT $\left({ }^{68} \mathrm{Ga}\right)$ & [225] \\
\hline & & Poly(glycerol adipate) & MRI & [226] \\
\hline & & PLGA & SPECT $\left({ }^{111}\right.$ In) & [176] \\
\hline & \multirow{7}{*}{ Thermal decomposition } & & MRI & {$[227,228]$} \\
\hline & & PEG & $\begin{array}{c}\text { MRI/PET }\left({ }^{64} \mathrm{Cu}\right) / \text { Photoacoustic } \\
\text { Tomography (PAT) }\end{array}$ & [229] \\
\hline & & PEG diacrylate & MRI & [230] \\
\hline & & Amine-terminated PEG $\left(\mathrm{NH}_{2}\right.$-PEG- $\left.\mathrm{NH}_{2}\right)$ & MPI & [231] \\
\hline & & DSPE-PEG-2000 & MRI & [228] \\
\hline & & Mesoporous Silica/PEG & MRI/NIRF & [232] \\
\hline & & PVP & MRI & [233] \\
\hline & Hydrothermal & Mesoporous Silica & MRI & [234] \\
\hline & Solvothermal & PEG & MRI & [235] \\
\hline & Sol gel & PEI/Silica & MRI & [236] \\
\hline & \multirow{2}{*}{ Reverse microemulsion } & \multirow[b]{2}{*}{ Silica } & MRI/NIRF & [139] \\
\hline & & & MRI & {$[237,238]$} \\
\hline
\end{tabular}


Table 5. Cont.

\begin{tabular}{|c|c|c|c|c|}
\hline $\begin{array}{l}\text { Magnetic } \\
\text { Material }\end{array}$ & $\begin{array}{c}\text { Synthesis Method for Iron } \\
\text { Oxide Core }\end{array}$ & Polymeric Coating & Applications & Reference \\
\hline \multirow{19}{*}{ SPIOs } & \multirow{7}{*}{ Co-precipitation } & PEG & \multirow{2}{*}{ MRI } & {$[15,239-241]$} \\
\hline & & PEG/Poly(gallol) & & [242] \\
\hline & & PEG/Gallic acid/Dextran & MPI & [130] \\
\hline & & DSPE-mPEG 2000 & SPECT ( $\left.{ }^{111} \mathrm{In}\right)$ & [243] \\
\hline & & PEI-b-PCL-b-PEG & MRI & [244] \\
\hline & & Silica & $\begin{array}{l}\text { Contrast agents in biomedical } \\
\text { photoacoustic imaging }\end{array}$ & [245] \\
\hline & & Mesoporous Silica & MRI/CT/Fluorescence & [246] \\
\hline & \multirow{10}{*}{ Thermal decomposition } & \multirow{2}{*}{ PEG } & MRI & {$[247,248]$} \\
\hline & & & MPI & [249] \\
\hline & & PEG methyl ether & \multirow{4}{*}{ MRI } & [250] \\
\hline & & Amine-terminated PEG $\left(\mathrm{NH}_{2}-\mathrm{PEG}\right)$ & & [251] \\
\hline & & $\mathrm{HA} / \mathrm{mPEG}$-succinimidyl succinate & & [252] \\
\hline & & \multirow{3}{*}{ Silica } & & [253] \\
\hline & & & MRI/SPECT $\left({ }^{125} \mathrm{I}\right)$ & [254] \\
\hline & & & MRI/PET $\left({ }^{64} \mathrm{Cu}\right)$ & [255] \\
\hline & & Mesoporous Silica & MRI/Optical & [256] \\
\hline & & Silica/Hyaluronic acid (HA) & \multirow{3}{*}{ MRI } & [257] \\
\hline & Sol gel & Silica & & [258] \\
\hline & Polyol & PEG & & [259] \\
\hline \multirow{4}{*}{ USPIOs } & Co-precipitation & Silica/APTMS/AEAPTMS & MRI & [260] \\
\hline & Thermal decomposition & PEG & MRI/ SPECT $\left({ }^{99 \mathrm{~m}} \mathrm{Tc}\right)$ & [261] \\
\hline & Microwave & Phosphonate-PEG (PO-PEG-NH ${ }_{2}$ ) & MRI & [262] \\
\hline & Polyol & PEG & MRI/Optical (FITC) & [263] \\
\hline
\end{tabular}

\subsubsection{Silica Shells}

Silica and its derivatives offer high-quality, chemically stable, optically transparent, nontoxic and biocompatible shells to iron oxide cores. This tailored surface improves the nanoparticle dispersion in aqueous saline media, reduces aggregation and offers an excellent platform to attach various biological ligands like proteins, nucleic acids, etc. via silane linkers.

Magnetic iron oxide nanoparticles coated with silica or alkoxysilanes are currently being screened as contrast agents by numerous research groups, as presented in Table 5, demonstrating their efficacy and their dependence on composition, size and shape.

In 2004, Yan et al. [223] synthesized silica-embedded iron oxide nanoparticles via solgel hydrolysis as a new approach for MRI contrast agent design. The $220 \mathrm{~nm}$ nanoparticles were evaluated on a $7 \mathrm{~T}$ scanner. The in vitro results showed reduction in signal intensity in the $\mathrm{T}_{2}$-weighted images, demonstrating their potential as an effective MRI contrast agent carrier. Following this study-considered the first report to have used silica-coated iron oxide nanoparticles as a contrast agent in MRI—in 2007, Zhang et al. [260] studied the ability of silica- and alkoxysilane-coated USPIO particles to label immortalized progenitor cells for MRI. First, the authors synthesized USPIO particles by co-precipitation of ferric and ferrous salts, followed by three types of coatings: silica (using sodium metasilicate pentahydrate), APTMS, and AEAPTMS. Thereafter, starting from nearly $9.6 \mathrm{~nm}$ for USPIO particles, the authors obtained particles of 9.9 (silica), 10.5 (APTMS) and $10.9 \mathrm{~nm}$ (AEAPTMS) after the surface coating. MR measurements performed with cell pellets showed high $\mathrm{T}_{2}$ relaxivities for all particles and cell concentrations and were intensely internalized in immortalized progenitor cells, making them suitable for MRI cell labelling.

A more complex approach to developing a promising vehicle for MR imaging was reported in 2008 by Feng et al. [181]. The authors synthesized magnetite nanoparticles, 
coated with APTES using a silanization reaction and then linked with PEG diacid via covalent bonds. The well-dispersed surface-functionalized biocompatible-functionalized magnetic nanoparticles had an average size of $20 \mathrm{~nm}$ and exhibited superparamagnetism. They were used to perform MRI experiments on living rabbits with VX2 malignant tumours. The signal decreases in the tumours after intravenous administration of the magnetic vehicles indicated the accumulation in malignant tumour tissues, as presented in the $\mathrm{T}_{2}{ }^{*}$ weighted MR images, demonstrating the potential of the authors' nanoparticles to be used in MR imaging.

A multifunctional imaging probe for MRI was produced in 2010 [255] by combining SPIOs, a porous silica shell and $\mathrm{Cu}^{2+}$ for cell labelling. Highly crystalline and nonaggregated SPIOs, either single or clustered, were encapsulated within the silica matrix, providing stability, biocompatibility and a high surface area that could be easily functionalized with different ligands. It is important to mention that the authors developed a unique ligand based on EDTA-bis (3-triethoxysilyl-n-propyl amide) which exposed the dependence of the nanoparticles' endocytosis and uptake on the surface charge. Following the relaxivity measurements through the dispersion of the nanoparticles in $0.1 \%$ agarose gel, it was evident that the clustered nanoparticles provided a significantly enhanced $\mathrm{T}_{2}$ relaxivity in comparison to single SPIOs, comparable to commercially available Feridex. The presence of copper on the surface of the nanoparticles reduced the $r_{2}$ values but exhibited high cell uptake efficiency, which is useful for cell tracking for the detection of Wilson's disease.

Campbell et al. [264] evaluated quasi-cubic iron oxide/silica nanoparticles of sub-100 nm size as $T_{2}$ contrast agents for MRI of biological tissues. The authors noted that the silica coating improved the core-shell stability on long-term storage conditions, when compared with commercially available MRI contrast agents. In vitro cell studies and cytotoxicity assays on human prostate cancer cells ( $\mathrm{PC} 3$ cell line) demonstrated that their uptake was more efficient than a similar concentration of bare magnetite nanoparticles. The relaxivity measurements were performed in phantoms, after being uptaken by PC3 prostate cancer cells, on a $3 \mathrm{~T}$ clinical MRI scanner, which exposed their capability as $\mathrm{T}_{2} \mathrm{MR}$ contrast agents, as expected. This was mainly due to their relatively high relaxivity and saturation magnetization values. The preliminary in vivo MRI studies in a breast tumour mouse model also sustained the $\mathrm{T}_{2}$ signal enhancement at the tumour site post injection of the quasi-cubic magnetite/silica core-shell nanoparticles. As the authors mentioned in the conclusions section, future studies on this type of nanomaterial could be designed to accurately diagnose pathologies.

A dual-contrast $T_{1}$ - and $T_{2}$-weighted MRI agent of about $21 \mathrm{~nm}$ was designed by Yang et al. [183], comprising a superparamagnetic iron oxide core synthesized via a thermal decomposition approach, a silica shell aminated through silanization, gadolinium complex (Gd-DTPA) and an arginine-glycine-aspartic acid peptide as a targeting ligand, covalently conjugated onto the surface. Relaxivity measurements-along with the in vitro and in vivo MR imaging performed with a $3.0 \mathrm{~T}$ system — exhibited dual-contrast ability with a high degree of accuracy from the multifunctional Gd-labelled SPIONs for targeted imaging of a tumour model on a nude mouse.

A typical procedure for the synthesis of uniform mesoporous silica-coated iron oxide nanoparticles, e.g., thermal decomposition of Fe-oleate complex followed by silica coating via a surfactant-templated sol-gel method, was proposed by Ye et al. [204]. Different silica shell thicknesses were prepared in order to evaluate the effect of surface coating on MRI contrast efficiency. Results demonstrated a significant impact; thick layers enhanced the MRI contrast, results which were also demonstrated by NMR relaxometry studies. The biocompatible nanoparticles were examined on epithelial cells derived from the organ of Corti of transgenic mice, and displayed enhanced in vitro MRI efficiency in $T_{2}$ sequence, up to 21 times higher than commercial agents. These results supported the potential application of the material as a highly efficient MRI $\mathrm{T}_{2}$ contrast agent. 
The same concept, exploring the effects of silica shell thickness of iron oxide nanostructures on MRI contrast, was adopted by Joshi et al. [202] in the same year. In this paper, the authors prepared $9 \mathrm{~nm} \mathrm{Fe}_{3} \mathrm{O}_{4}$ in organic phase via a simple chemical decomposition method with 5,10 , and $13 \mathrm{~nm}$ silica shell thickness coatings by base-catalysed silica formation from tetraorthosilicate in a reverse micro-emulsion procedure. The multiple-echo-spin-echo sequence scans on a 3.0 T MR system showed that the increase in thickness of silica shells in core-shell nanostructures produced a decrease in $r_{2}$ relaxivity. This phenomenon was attributed to the long distance between the magnetic core and water molecules.

More complex architectures were developed over the years. A combined MRI/PET, easily-prepared agent that offered signal or contrast in both modalities was described by Burke et al. [225]. The new class of silica-coated iron oxide nanorods were coated with PEG and/or a tetraazamacrocyclic chelator (DO3A), and were developed by the same group in 2014 [224]. They were evaluated as in vivo $T_{2}$ MRI and PET contrast agents. The magnetic behaviour investigated in vitro at $3 \mathrm{~T}$ showed that all three types of nanorod constructs had fast relaxivity as $T_{2}$ contrast agents, but were relatively weak as $\mathrm{T}_{1}$. The in vivo imaging biodistribution and stability on PET-CT and MR imaging of gallium-68 radiolabelled nanorods displayed the expected high liver uptake with no significant release of the positron-emitting radioisotope metal. The results validated the novel method for chelator-free radiometal labelling of silica-coated iron oxide nanorods via surface interactions-that could be used for high-sensitivity liver imaging.

A classic route-co-precipitation and Stöber methods, followed by mebrofenin functionalization - was proposed by Yazdani et al. [184] in their work to produce a liver-targeting MRI contrast agent. Their in vitro studies (nanoparticles dispersed in water) on a 1.5 T MRI scanner showed the effects of iron concentration on relaxivity values $\left(\mathrm{r}_{2}\right)$; namely, that the $\mathrm{T}_{2}$-weighted signal decreased with increasing Fe concentration. More studies are needed to demonstrate the ability of the added liver targeting function to provide contrast to the envisioned organ, as we could not find any additional studies by the authors.

New silica-coated cubic SPIONs, synthesized using the thermal decomposition method, showed a synergistic $\mathrm{T}_{1}$ - and $\mathrm{T}_{2}$-contrast-enhancement for MRI on both in vitro (on phantom vials and L929 line cell) and in vivo studies (post injection on the tail vein of Sprague Dawley rats) [253]. The authors compared the relaxation performance of cubic SPIONs with their spherical counterparts of different sizes $(7,11$ and $14 \mathrm{~nm})$ on a $3 \mathrm{~T}$ MRI scanner, demonstrating that, when controlling the shape and size of the nanoparticles, the relaxivity values differed. Promising results were obtained for the $11 \mathrm{~nm}$ silica-coated cubic SPIONs, which were determined to be potential candidates for dual-mode contrast agents.

An alternative to the toxic Gd-based contrast agents used in MRI was proposed by the Mathieu team, who introduced the iron-iron oxide core-shell architectures, obtained as follows: synthesis of $10 \mathrm{~nm}$ large iron-iron oxide nanoparticles, silica coating with $11 \mathrm{~nm}$ thick layer by reverse emulsion method and functionalization with $5 \mathrm{kDa}$ PEG chains [238]. The nanoparticles produced were in the $100 \mathrm{~nm}$ range, displayed good stability in water, no cytotoxicity, high $r_{2}$ relaxivity values and low $r_{1}$, leading to enhanced $r_{2} / r_{1}$ ratios in comparison with commercially available Resovist, as observed on $\mathrm{T}_{2}$ MRI phantoms images acquired on $9.4 \mathrm{~T}$ scanner.

The ultrafine silica-coated superparamagnetic iron oxide fluorescent nanoparticles prepared in 2017 [265] were evaluated in 2019 [185] for their biocompatibility and biosafety profile when used to label human amniotic mesenchymal stromal/stem cells (hAMSCs) or when administered in vivo, along with in vitro magnetic responsiveness. Briefly, the synthesis involved the classic co-precipitation strategy, followed by one-pot synthetic procedure for thin silica shell coating and FITC covalent attachment. The obtained nanomaterials showed excellent cytocompatibility and were internalized with no interferences on the stem cells' characteristics on in vitro tests. The 7-week in vivo study in mice indicated the biocompatibility and biosafety profile over short and long term periods with a biodistribution dependent on time, demonstrating the potential for this material to be used as an excellent MRI tracking agent. 
Another prospective study with potential in imaging was found in 2020 by NavarroPalomares et al. [210]. Their paper showed the development of two-type multifunctional nanoparticles based on hydrophobic $\mathrm{Fe}_{3} \mathrm{O}_{4}$ (prepared by hydrothermal approach) and commercial $\mathrm{ZnO}$, both coated with $\mathrm{SiO}_{2}$ incorporating rhodamine $\mathrm{B}$ isothiocyanate, fluorescein or rhodamine $\mathrm{B}$, following either a reverse microemulsion route or a modified Stöber method, respectively. The in vitro studies on HeLa cell lines confirmed that the silica shell conferred stability and biocompatibility and could be degraded in different physiological media. These are relevant criteria for potential applications in biomedicine and related fields. No further studies related to imaging were found in the literature using the above-mentioned dye-doped biodegradable nanoparticle $\mathrm{SiO}_{2}$ coating in zinc- and iron oxide nanoparticles.

A dual MR/NIRF imaging agent, used to identify macrophage enrichment in atherosclerotic plaques, was successfully synthesized in several steps: iron oxide nanoparticles (produced by thermal decomposition approach), mesoporous silica deposition, PP1 peptide conjugation via the amide condensation reaction, and NIRF dye (IR820) loading [232]. The core/shell nanoparticles had a uniform size of $90 \mathrm{~nm}$, were internalized by active foamy macrophages and favoured atherosclerotic plaque imaging in MR/NIRF dual-modal (combined $\mathrm{T}_{2}$ and $\mathrm{T}_{2}{ }^{*}$ mapping on $3 \mathrm{~T}$ equipment) on atherosclerosis models of $\mathrm{ApoE}^{-/-}$mice.

\subsubsection{PEG}

PEG is a typical nontoxic, nonantigenic, coiled polymer composed of repeating ethylene ether units with dynamic conformations [266,267]. It is inexpensive, versatile and FDA approved for many applications. It exhibits many useful features, e.g., hydrophilicity, biocompatibility and the capacity to enhance nanoparticles' blood half-time. The PEG coating, named PEGylation, boosts stability in an aqueous medium, prevents particle surfaces from oxidizing, reduces toxicity, and lowers RES uptake, thus increasing circulation time.

In imaging, PEG moieties are added in the iron oxide nanoparticle reaction or in a subsequent step, as mentioned above for other polymers, in order to satisfy the contrast agent specifications: dispersibility in aqueous media, monodispersity, biocompatibility and so on.

Numerous studies were found in the literature that dealt with PEG coating, functionalization or attachment to the iron oxide core, starting from 1997. Below, we have highlighted a few of the achievements needed to reach preclinical and/or clinical use. More studies focused on PEGylated anchoring groups are presented in Table 5.

In 2008, Park et al. [268] carried out one-step synthesis of PEG surface-modified USPIONs in a polar organic solvent and quantified them with $1.5 \mathrm{~T}$ MRI in solution. The $\mathrm{T}_{1}$ and $\mathrm{T}_{2}$ map images showed a low $\mathrm{r}_{2} / \mathrm{r}_{1}$ relaxivity ratio with a clear dose-dependent effect, indicating that the as-prepared nanoparticles could be considered potential MRI contrast agents for both $\mathrm{T}_{1}$ and $\mathrm{T}_{2}$ sequences.

A PEG polymer containing a bisphosphonate anchor covered USPIOs surface using a simple method of $1 \mathrm{~h}$ at room temperature [261]. The resulting nanoparticles revealed a high $r_{1}$ of $9.5 \mathrm{mM}^{-1} \cdot \mathrm{s}^{-1}$ and low $\mathrm{r}_{2} / \mathrm{r}_{1}$ ratio of 2.97 , suitable for $\mathrm{T}_{1}$-weighted MRI contrast (results obtained in vitro at $3 \mathrm{~T}$ ). The PEGylated nanoparticles were injected into the tail veins of BALB/c mice and therein enhanced the signal from blood vessels and vascular systems with minor accumulation in the liver. This reinforced their potential use as a contrast agent for $\mathrm{T}_{1}$-MRI angiography. Furthermore, the authors tested them after radiolabelling with gamma-emitting isotopes $\left({ }^{99 \mathrm{~m}} \mathrm{Tc}\right)$ for biodistribution in vivo using SPECT imaging. The studies confirmed low RES uptake and long blood circulation times, validating their potential use as a dual-modality imaging agent.

Yang et al. [263] reported a simple one-pot reaction for highly water-stable iron oxide nanoparticles synthesis in 2014, using PEG as solvent, capping and reducing agent. The authors tried to develop multimodal-imaging agents. The USPIONs were aminefunctionalized using dicyclohexylcarbodiimide/ $N$-hydroxysuccinimide coupling, followed by fluorescein isothiocyanate labelling. The $\mathrm{T}_{2}{ }^{*}$ coronal $\mathrm{MR}$ and fluorescence imaging 
performed on BALB/c nude mice demonstrated that the simply-synthesized nanoparticles showed the potential to be used for in vivo multimodal imaging.

Functional magnetic nanoparticles, modified with PLA-PEG-D-glucosamine that showed good biocompatibility and stability both in vitro on RAW 264.7 macrophages and $4 \mathrm{~T} 1$ cell line and in vivo on tumour-bearing BABL/c mice, were successfully evaluated as MRI contrast agents for tumour imaging [182]. The authors synthesized superparamagnetic $\mathrm{Fe}_{3} \mathrm{O}_{4}$ nanoparticles capped with oleic acid via the co-precipitation method and PLA-PEGD-glucosamine complex, followed by their linkage through hydrophobic interactions. After demonstrating the ability of covalent-linked D-glucosamine on the nanoparticle surface to increase the specific uptake of tumour cells in vitro, the nanomaterials were injected via tail vein in a low dose, and their MRI performances were compared with Resovist. At $2 \mathrm{~h}$ post-injection, the multifunctional nanoparticles accumulated in tumour tissue, as observed on $\mathrm{T}_{2}{ }^{*}$ weighted images.

Multicore iron oxide nanoparticles (maghemite) coated with poly (4-vinylpyridine)PEG copolymer and having an average hydrodynamic diameter of approximately $20 \mathrm{~nm}$, crossed the glomerulus wall and were mostly excreted through the urine. Thus, they avoided the effects of RES, as confirmed by SPECT, gamma counting (after radiolabelling with ${ }^{111}$ In ions), $T_{2}$-MRI biodistribution studies on BALB/cJRj mice. The simple, new, reliable and direct radiolabelling method presented by the authors could be applied to prepare magnetic nanocarrier MRI/SPECT contrast agents for kidneys [222].

A promising $\mathrm{T}_{1}-\mathrm{T}_{2}$ dual-mode contrast agent for MRI was developed in a recent study, consisting of superparamagnetic manganese oxide-doped iron oxide $\left(\mathrm{Fe}_{3} \mathrm{O}_{4} / \mathrm{MnO}\right)$ nanoparticles of approximately $20 \mathrm{~nm}$ stabilized with hydroxyl- PEG-phosphonic acid [199]. The $\mathrm{T}_{1}-\mathrm{T}_{2}$ weighted images—obtained using a $0.5 \mathrm{~T}$ MRI scanner-validated the dual-mode contrast ability on phantoms. In vivo MR imaging on BALB/c mice using $7 \mathrm{~T}$ MRI equipment confirmed the positive signal enhancement and remarkable $\mathrm{T}_{1}-\mathrm{T}_{2}$ relaxivity of decorated superparamagnetic nanoparticles.

Tailor-made PEG-coated iron oxide nanoparticles were synthesized in a two-step reaction; first by solvothermal synthesis in organic medium, followed by surface modification with different molecular-weighted PEGs through amide bond formation. After a detailed physicochemical characterization, the $100 \mathrm{~nm}$ nanoparticles showed in vitro biocompatibility and in vivo safety, high cell uptake in tumoral cells and the highest $r_{2}$ relaxivity values when compared with commercial Ferumoxytol, promoting their applicability in MRI on mice bearing xenografted human breast cancer models [235].

Among various types of fabricated nanoparticles, the Karahaliloglu team [221] recently reported PEG-terminated, PS-linoleic copolymer-coated magnetic iron oxide nanoparticles as unique prospective candidates for diagnosis of hepatocellular carcinomas. Magnetic iron oxide nanoparticles were synthesized by the co-precipitation method and subsequently incorporated into the previously prepared PEG-terminated PS-linoleic copolymer core. The coated magnetic samples were scanned under a $3 \mathrm{~T}$ MRI scanner in an aqueous solution and showed good $\mathrm{T}_{2}$-weighted contrast at various concentrations, with signal intensity dependent on the iron oxide concentration.

\section{Imaging Pre-Clinical and Clinical Studies of Core-Shell Iron Oxide Agents}

The challenges for clinical translation start from the design of the preparation method and continue up until preclinical evaluation as one pillar and the ultimate goal, use in clinical practice, as the other pillar. As we can observe from the above sections, animal molecular imaging has become an efficient tool to understand and clarify the biological mechanisms for accurate diagnosis. Over the past 10 years, the two fields (preclinical and clinical) have begun to overlap more and more. The enormous progress made toward development of related imaging technologies has guided researchers down the road toward the already-available iron oxide nanoparticle-based contrast agents [269].

Table 6 points out just a few examples of nanomaterial tracers that have been assessed in numerous preclinical studies, ranging from breast and cardiac to brain monitoring. 
Notably, biocompatible iron oxide-based nanoparticles that have been approved by the FDA for clinical use as MRI contrast agents (as presented in Table 7) are still paving the road toward achievement of the critical requirements for use in practical applications [270]. Their chemical stability, dispersion in biological media, uniformity in size and diverse coatings continue to make them the subject of numerous articles and studies in ongoing efforts to develop new candidates.

Table 6. Examples of animal studies assessing the use of iron oxide-based nanoparticles in imaging.

\begin{tabular}{|c|c|c|c|}
\hline Core-Shell Iron Oxide Agent & Imaging Modality & In Vivo Model & Reference \\
\hline $\begin{array}{l}\text { SPIONs coated with silica, APTES and } \\
\text { (3-glycidoxypropyl) methyldiethoxysilane }\end{array}$ & $\begin{array}{l}\text { MRI: medium } \mathrm{T}_{2} \text { along with a } \\
\text { minor effect on } \mathrm{T}_{1}\end{array}$ & Zebrafish (Danio rerio) model & {$[271]$} \\
\hline $\begin{array}{l}\mathrm{Fe}_{3} \mathrm{O}_{4} \text { nanoparticles stabilized by PVP, } \\
\text { trisodium citrate, and maleic anhydride }\end{array}$ & \multirow{5}{*}{$\mathrm{MRI} \mathrm{T}_{2}$} & White rabbit & {$[272]$} \\
\hline IONPs coated with PEG & & $\begin{array}{l}\text { Tumour xenograft model on female } \\
\text { NOD-SCID IL2 mice with human } \\
\text { breast cell line (MDA-MB-231) }\end{array}$ & {$[235]$} \\
\hline $\begin{array}{c}\text { Luteinizing hormone-releasing } \\
\text { hormone-conjugated PEG-coated magnetite } \\
\text { nanoparticles }\end{array}$ & & $\begin{array}{l}\text { BALB/c nude mice (Triple negative } \\
\text { breast cancer model) }\end{array}$ & [273] \\
\hline $\begin{array}{l}\text { Magnetic fibrin nanoparticles conjugated with } \\
\text { folic acid }\end{array}$ & & $\begin{array}{l}\text { Albino Wistar rats with } \\
\text { antigen-induced arthritis }\end{array}$ & {$[274]$} \\
\hline HSA-coated iron oxide nanoparticles & & $\begin{array}{l}\text { BALB/c mice (breast cancer model } \\
\text { with MDA-MB-231 cells) }\end{array}$ & {$[142]$} \\
\hline PLA-PEG-D-glucosamine $\mathrm{Fe}_{3} \mathrm{O}_{4}$ nanoparticles & \multirow{3}{*}{$\mathrm{MRI}_{-} \mathrm{T}_{2}$} & $\begin{array}{l}\text { Tumour-bearing BABL/c mice } \\
\text { inoculated with } 4 \mathrm{~T}_{1} \text { cells }\end{array}$ & {$[182]$} \\
\hline PEG/PEI-SPIONs conjugated with transferrin & & Kunming mice brain & {$[275]$} \\
\hline $\begin{array}{l}\text { USPIOs coated with carboxymethyldextran } \\
\text { and coupled or not with a } \\
\text { low-molecular-weight aminated fucoidan }\end{array}$ & & Elastase-induced Wistar rat model & [141] \\
\hline $\begin{array}{c}\text { SPIONs coated with dextran and } \\
\text { functionalized with } \\
\text { anti-insulin-like-growth-factor binding protein } \\
7 \text { (anti-IGFBP7) }\end{array}$ & MRI-T 2 and $\mathrm{T}_{2}{ }^{*}$ & $\begin{array}{l}\text { Nude CD-1 mouse model of } \\
\text { glioblastoma multiforme }\end{array}$ & {$[276]$} \\
\hline
\end{tabular}

Table 7. Iron oxide-based nanoparticles currently under evaluation for human use in imaging (up to 10 March 2021) [277].

\begin{tabular}{|c|c|c|c|}
\hline Material & Disease & Imaging Technique & Status \\
\hline \multirow[b]{2}{*}{ IONPs } & Lymph node metastases & \multirow{9}{*}{ MRI } & Phase I, Withdrawn (NCT02689401) \\
\hline & $\begin{array}{l}\text { Healthy subjects-to determine MTD, } \\
\text { Pharmacokinetic, safety/tolerability }\end{array}$ & & Phase I, Completed (NCT02744248) \\
\hline \multirow{8}{*}{ SPIONs } & Lymph node metastases & & Phase IV, Completed (NCT00920023) \\
\hline & \multirow{4}{*}{ Sentinel lymph nodes } & & Completed (NCT03243435) \\
\hline & & & Phase IV, Unknown (NCT02612870) \\
\hline & & & Phase III, Recruiting (NCT04722692) \\
\hline & & & Unknown (NCT03449615) \\
\hline & Melanoma & & Not Applicable, Completed (NCT03898687) \\
\hline & Healthy volunteer-cell tracking & & Not Applicable, Unknown (NCT00972946) \\
\hline & Primary and metastatic hepatic malignancies & MRI/SPECT $\left({ }^{99 m} \mathrm{Tc}\right)$ & Recruiting (NCT04682847) \\
\hline \multirow{8}{*}{ USPIONs } & Lymph nodes & \multirow{8}{*}{ MRI } & Early Phase 1, Recruiting (NCT02857218) \\
\hline & \multirow{3}{*}{ Lymph node metastases } & & Phase III, Recruiting (NCT04261777) \\
\hline & & & Not Applicable, Completed (NCT01815333) \\
\hline & & & Not Applicable, Recruiting (NCT04311047) \\
\hline & Malignant pelvic lymph nodes & & Not Applicable, Terminated (NCT00147238) \\
\hline & Pelvic lymph nodes & & Early Phase 1, Recruiting (NCT03280277) \\
\hline & Pelvic nodal metastases & & Phase I and II, Completed (NCT00188695) \\
\hline & $\begin{array}{c}\text { Papillary carcinoma of thyroid gland/metastatic } \\
\text { medullary thyroid cancer/follicular thyroid cancer } \\
\text { lymph node metastasis }\end{array}$ & & Not Applicable, Completed (NCT01927887) \\
\hline
\end{tabular}


Table 7. Cont.

\begin{tabular}{|c|c|c|c|}
\hline Material & Disease & Imaging Technique & Status \\
\hline & Brain neoplasms & & Phase II, Terminated (NCT00659334) \\
\hline & Oesophageal neoplasms & & Not Applicable, Completed (NCT02253602) \\
\hline & Squamous cell carcinomas & & $\begin{array}{l}\text { Phase 1, Active } \\
\text { (NCT01895829) }\end{array}$ \\
\hline & Ischemic heart disease & & Phase I, Completed (NCT03651791) \\
\hline & Multiple sclerosis & & Phase I, Completed (NCT02511028) \\
\hline & Aortic dissection & & Recruiting (NCT03948555) \\
\hline & \multirow{2}{*}{ Myocardial infarction } & & Phase II, Unknown (NCT01995799) \\
\hline & & & Not Applicable, Completed (NCT01323296) \\
\hline & Myocardial cellular inflammation & & Phase II and III, Completed (NCT02319278) \\
\hline & Abdominal aortic aneurysm & & Terminated (NCT01749280) \\
\hline & Atherosclerosis & & Unknown (NCT01674257) \\
\hline & Coronary artery disease & MRI/PET & Recruiting (NCT03451448) \\
\hline
\end{tabular}

Although several nanoparticles with iron cores have been approved for human use, gaps in technical knowledge, capabilities and the lack of the safe-by-design mindset in many groups continue to prevent them from progressing from the bench to the bedside. This is the current situation, since the first nanoparticle-based iron oxide imaging agent, Feridex I.V. ${ }^{\circledR}$ (ferumoxides) was approved by the FDA in 1996 for the detection of liver lesions. According to Tassa et al. [278] in 2011, Combidex ${ }^{\circledR}$ (ferumoxtran-10) was the next approved agent, and was used for prostate cancer lymph-node metastases imaging. That was followed by Feraheme ${ }^{\circledR}$ (ferumoxytol), dedicated to treating iron deficiency anaemia in adult patients with chronic kidney disease and the detection of inflammation of the central nervous system, brain neoplasms and cerebral metastases from lung or breast cancer (still under clinical investigation).

According to FDA indications, there are critical facts about ferumoxytol, including fatal outcomes upon administration, serious allergic reactions, hypotension, and iron overload that could lead to death. Based on these side effects, the FDA gave strict warnings regarding potentially serious hypersensitivity/anaphylaxis reactions. Fatal events have occurred in patients receiving ferumoxytol; the initial symptoms were commonly hypotension, syncope, unresponsiveness, and cardiac/cardiorespiratory arrest [279].

In the same year, 2011, Wang [280] described SPIO-based MRI contrast agents, i.e., ferumoxides (Feridex in the USA, Endorem in Europe, also referred as AMI-25), ferucarbotran (Resovist, SH U 555A), ferumoxtran-10 (AMI-227, Combidex, Sinerem, Guerbet), Clariscan (PEG-fero; Feruglose; NC100150) and iron oxide-based agents for gastrointestinal contrast: AMI-121 (Ferumoxsil, Lumirem, Gastromark) and OMP (Abdoscan). The two clinicallyapproved SPIONs-defined as a conglomerate of numerous nano-sized iron oxide crystals coated with dextran or carboxydextran, e.g., ferumoxides and ferucarbotran-were specifically appropriate for MR imaging of the liver. Following intravenous administration, their pathway included clearing from the blood by phagocytosis by RES, intracellular uptake, metabolization and integration as ferritin/haemoglobin. Both SPIO particles produced strong $T_{2} / T_{2}{ }^{*}$ relaxation effects in the liver tissue with the capacity to differentiate lesions, while the smaller Resovist had an enhanced effect on $\mathrm{T}_{1}$-weighted images. The review paper concluded with the perspective that new applications of approved SPIO need to be determined and that new SPIOs with relevant properties need to be developed. 
However, ferumoxide and ferucarbotran agents (Endorem, Guerbet, Feridex, Resovist) were withdrawn from the market in 2009 due to multiple side effects. One example of these side effects was that the agents could not be administered as an intravenous bolus without risking the possible appearance of severe backache. Thus, it is imperative to evaluate biosafety before going to market [281]. Additionally, the clinically approved SPIONs were unable to differentiate between hepatocellular carcinoma and healthy liver tissue.

According to the information gathered from the ClinicalTrials.gov database (Table 7), there are currently numerous suitable MRI and MRI/SPECT-based contrast agents under evaluation for use in humans. They are undergoing extensive safety and toxicology studies, as the regulatory body demands, with the ultimate goal of improving patient quality of life [282]. Nonetheless, as numerous studies point out, the final judge of a contrast agent remains the patient that genuinely understands the significance of that experience.

\section{Authors Contributions}

The first step toward the use of iron oxide nanoparticles as a potential contrast agent was in 2019, when the group presented the design of a new multifunctional hybrid magnetic tracer that would be further radiolabelled and used as a dual-modality SPECT and MRI imaging probe at an international conference. Hybrid magnetic nanoparticles were synthesized using iron oxide core and multifunctional silica shell chains available for fluorescent marking and ${ }^{99} \mathrm{~m} \mathrm{Tc}$ radiolabelling. The magnetite nanoparticles were prepared by two wet methods, namely co-precipitation and partial oxidation, in order to compare their functionalization and assembly ability within the polymeric matrix under the influence of the magnetic field. The two types of iron oxide nanoparticles used were described in a published paper in 2015 [283], with minor modifications. The structure, external morphology, size distribution, colloidal and magnetic properties were characterized by FT-IR, TEM, XRD, DLS and VSM analyses. TEM and DLS results showed that the hybrid complex had nanostructures with broad distribution. The formation of crystalline magnetite nanoparticles was confirmed by XRD analysis. Magnetization measurements on the obtained samples showed a straightforward correlation between the saturation magnetization and morphology of the samples. These positive findings suggested that the multifunctional magnetic nanoparticles have the potential to be used in biomedical applications.

Therefore, in the same year, we presented a paper dealing with in vitro cytotoxicity based on MTT assay of magnetic amine-functionalized $\mathrm{Fe}_{3} \mathrm{O}_{4}$ nanoparticle (both types) solution containing BSA, in normal V79 cell line, revealing that the conjugates were noncytotoxic to normal cells.

Furthermore, the amine groups on the hybrid magnetic nanoparticles surfacesynthesized using iron oxide cores obtained by the co-precipitation method followed by multifunctional silica shell chain coverage-were radiolabelled with ${ }^{99 \mathrm{~m}} \mathrm{Tc}$, and tested as in vivo imaging agents. A paper was presented at the 32nd Annual Congress of the European Association of Nuclear Medicine and published as an extended abstract in the European Journal of Nuclear Medicine and Molecular Imaging Supplement [284]. Briefly, the magnetic amine-functionalized $\mathrm{Fe}_{3} \mathrm{O}_{4}$ nanoparticles were successfully labelled with ${ }^{99 \mathrm{~m}} \mathrm{Tc}$ using standard radiolabelling methods, as revealed by the radiolabelling yield $(\approx 90 \%)$ assessed using instant thin layer chromatography. Both the ex vivo biodistribution at $6 \mathrm{~h}$ post injection and in vivo SPECT imaging on healthy animals showed a similar pharmacokinetic biodistribution profile for ${ }^{99} \mathrm{~m}$ Tc-amine $\mathrm{Fe}_{3} \mathrm{O}_{4}$ nanoparticles-but differed from the control batch $\left({ }^{99 \mathrm{~m}} \mathrm{Tc}\right)$. The hepatic and splenic accumulations of the radiolabelled nanoparticles demonstrated the high uptake in the mononuclear phagocyte system, which was in agreement with the behaviour and clearance of nano-targeted nanoparticles in vivo. In summary, we developed new molecular imaging probes based on hybrid magnetic nanoparticles radiolabelled with the diagnostic radionuclide ${ }^{99 \mathrm{~m}}$ Tc for SPECT imaging and evaluated their biodistribution profiles in healthy animals.

However, our group objective was to develop a multifunctional radiolabelled hybrid magnetic nanoparticle agent for dual-modality (SPECT and MRI) medical imaging. There- 
fore, in 2020, we prepared and evaluated the toxicity and MRI biodistribution of the same magnetic hybrid nanoparticles. As mentioned above, the hybrid magnetic nanoparticles synthesis (about $21 \mathrm{~nm}$ as depicted by TEM images) included the iron oxide core obtained by co-precipitation method and silica shell chain coverage. The in-situ stability of the magnetic hybrid nano-systems was explored over time by size quantification and revealed relative stable nanoparticles in simulated physiological media. The in vivo toxicity studies of the synthesized nanoparticles in healthy animal models over short and long-term periods were assessed by evaluating changes in blood chemistries, variations of blood cell parameters, profiles in liver and kidney or change in gross or histologic features of organs as well as monitoring of clinical and weight changes after intravenous administration. The results exhibited slight variations in Wistar rats during the experimental period, mainly due to an enhanced immune response and inflammatory reactions. Significant MRI signal change was observed over time on liver, aorta, cava vein and hepatic vein on $T_{2}$ sequence biodistribution of the obtained hybrid magnetic nanoparticle probe on healthy experimental animals using $1 \mathrm{~T}$ PET/MRI scanner. Furthermore, the quantification of liver iron concentration by signal intensity ratio on MRI demonstrated the ability of the synthesized nanoparticles to act as a new contrast agent. The obtained results present opportunities: to extend this new nanotracer for therapeutic use due to its versatile functionality, or to link different molecules to the same core. Overall, our results suggest that the multifunctional hybrid magnetic nanoparticles could be employed as potential imaging vehicles for targeting tumour tissues.

\section{Conclusions and Perspectives}

Since the first MRI contrast agent based on ferric chloride in 1980, many tracers have been developed and evaluated in vitro, in vivo and also in clinical practice-though some of them were later withdrawn as a result of safety concerns. It is well known that iron oxidebased nanomaterials can enhance diagnostic imaging techniques, and their fusion with molecular imaging agents permit accurate diagnostics at the molecular level. This review points out that a single magnetic nanoparticle can be tagged with various moieties, ligands, imaging agents and/or radionuclides to construct a personalized diagnostic agent characterized by biocompatibility, biodegradability, biosafety, selectivity, stability and controlled biodistribution. However, even after many years of investigation, there are still multiple challenges-from chemical, biological and even economic perspectives-that must be taken into account in translating nanoparticle imaging agents to a clinical setting. Understanding these considerations will define the future of nanoparticle imaging agents that will one day have the capability and functionalization required for personalized diagnostics.

Author Contributions: All authors contributed equally to this manuscript. G.D. and B.E.-B.C. were responsible for the review concept and design. G.D., B.E.-B.C., A.S., I.G. and V.B. were responsible for draft preparation. G.D. and B.E.-B.C. were responsible for the review and editing of the manuscript. G.D. and V.B. were responsible for visualization and funding acquisition. G.D., A.S., I.L.S., I.G. and V.B. were responsible for the revision of the manuscript. All authors have read and agreed to the published version of the manuscript.

Funding: This work was supported by a grant of the Ministry of Research and Innovation, CNCSUEFISCDI, project number PN-III-P1-1.1-PD-2016-1642, within PNCDI III and by a grant of the Ministry of Research, Innovation and Digitization, CNCS/CCCDI-UEFISCDI, project number PN-IIIP1-1.1-TE-2019-1671, within PNCDI III.

Conflicts of Interest: The authors declare no conflict of interest. 


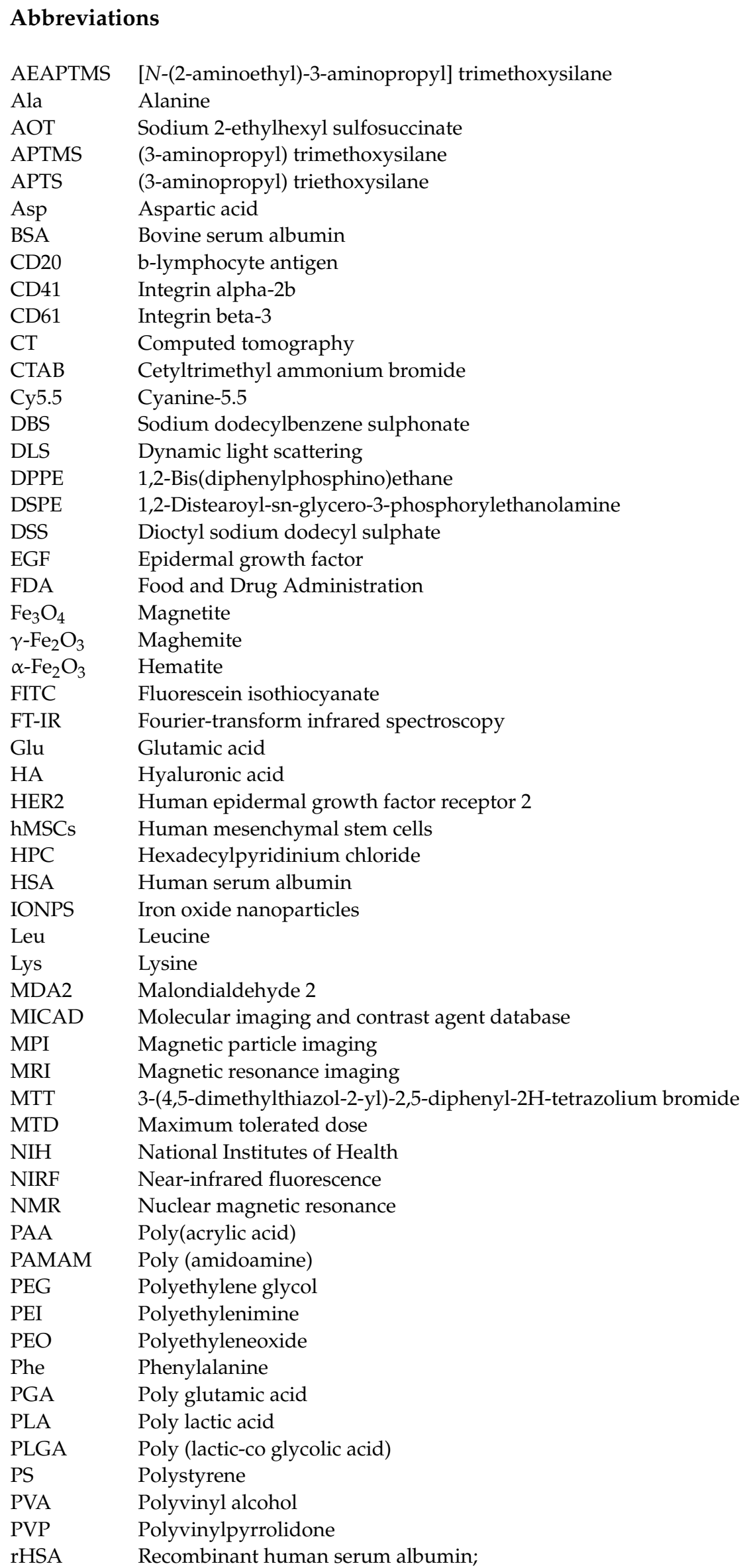




$\begin{array}{ll}\text { RITC } & \text { Rhodamine B isothiocyanate } \\ \text { SDS } & \text { Sodium dodecylsulfonate } \\ \text { SPECT } & \text { Single-photon emission computed tomography } \\ \text { SPIO } & \text { Superparamagnetic iron oxide } \\ \text { SPIONs } & \text { Superparamagnetic iron oxide nanoparticles } \\ \mathrm{t}_{1 / 2} & \text { Half-life } \\ \text { TEM } & \text { Transmission electron microscopy } \\ \mathrm{T} & \text { Tesla } \\ \text { Tyr } & \text { Tyrosine } \\ \text { US } & \text { Ultrasound } \\ \text { USPIO } & \text { Ultrasmall superparamagnetic iron oxide } \\ \text { USPIONs } & \text { Ultrasmall superparamagnetic iron oxide nanoparticles } \\ \text { Val } & \text { Valine } \\ \text { VCAM-1 } & \text { Vascular cell adhesion molecule-1 } \\ \text { VSM } & \text { Vibrating sample magnetometer } \\ \text { VT680 } & \text { Vivotag } 680 \\ \text { XRD } & \text { X-ray diffraction analysis }\end{array}$

\section{References}

1. Hong, H.; Zhang, Y.; Sun, J.; Cai, W. Molecular Imaging and Therapy of Cancer with Radiolabeled Nanoparticles. Nano Today 2009, 4, 399-413. [CrossRef] [PubMed]

2. Fass, L. Imaging and Cancer: A Review. Mol. Oncol. 2008, 2, 115-152. [CrossRef] [PubMed]

3. Barreto, J.A.; O’Malley, W.; Kubeil, M.; Graham, B.; Stephan, H.; Spiccia, L. Nanomaterials: Applications in Cancer Imaging and Therapy. Adv. Mater. 2011, 23, H18-H40. [CrossRef]

4. Janib, S.M.; Moses, A.S.; MacKay, J.A. Imaging and Drug Delivery Using Theranostic Nanoparticles. Adv. Drug Deliv. Rev. 2010, 62, 1052-1063. [CrossRef]

5. Ellis, C.M.; Pellico, J.; Davis, J.J. Magnetic Nanoparticles Supporting Bio-Responsive T1/T2 Magnetic Resonance Imaging Materials 2019, 12, 4096. [CrossRef]

6. National Institute of Biomedical Imaging and Bioengineering (NIBIB). Available online: https://www.nibib.nih.gov/ScienceEducation/Science-Topics/Nuclear-Medicine (accessed on 11 April 2021).

7. Assadi, M.; Afrasiabi, K.; Nabipour, I.; Seyedabadi, M. Nanotechnology and Nuclear Medicine; Research and Preclinical Applications. Hell. J. Nucl. Med. 2011, 14, 149-159. [PubMed]

8. Morales-Avila, E.; Ferro-Flores, G.; Ocampo-García, B.E.; de María Ramírez, F. Radiolabeled Nanoparticles for Molecular Imaging. In Molecular Imaging; Schaller, B., Ed.; IntechOpen: London, UK, 2012; ISBN 978-953-51-0359-2.

9. Sun, G.; Xu, J.; Hagooly, A.; Rossin, R.; Li, Z.; Moore, D.A.; Hawker, C.J.; Welch, M.J.; Wooley, K.L. Strategies for Optimized Radiolabeling of Nanoparticles for in Vivo PET Imaging. Adv. Mater. 2007, 19, 3157-3162. [CrossRef]

10. Gomes, C.M.; Abrunhosa, A.J.; Ramos, P.; Pauwels, E.K.J. Molecular Imaging with SPECT as a Tool for Drug Development. Adv. Drug Deliv. Rev. 2011, 63, 547-554. [CrossRef] [PubMed]

11. Brigger, I.; Dubernet, C.; Couvreur, P. Nanoparticles in Cancer Therapy and Diagnosis. Adv. Drug Deliv. Rev. 2002, 54, 631-651. [CrossRef]

12. Phillips, M.A.; Gran, M.L.; Peppas, N.A. Targeted Nanodelivery of Drugs and Diagnostics. Nano Today 2010, 5, 143-159. [CrossRef] [PubMed]

13. Jeong, H.-J.; Lee, B.C.; Ahn, B.-C.; Kang, K.W. Development of Drugs and Technology for Radiation Theragnosis. Nucl. Eng. Technol. 2016, 48, 597-607. [CrossRef]

14. Huang, H.-C.; Barua, S.; Sharma, G.; Dey, S.K.; Rege, K. Inorganic Nanoparticles for Cancer Imaging and Therapy. J. Control. Release 2011, 155, 344-357. [CrossRef]

15. Molecular Imaging and Contrast Agent Database (MICAD); National Center for Biotechnology Information (US): Bethesda, MD, USA, 2004-2013. Available online: https:/ / www.ncbi.nlm.nih.gov/books/NBK5330/ (accessed on 18 March 2021).

16. Ali, A.; Zafar, H.; Zia, M.; ul Haq, I.; Phull, A.R.; Ali, J.S.; Hussain, A. Synthesis, Characterization, Applications, and Challenges of Iron Oxide Nanoparticles. Nanotechnol. Sci. Appl. 2016, 9, 49-67. [CrossRef]

17. Laurent, S.; Forge, D.; Port, M.; Roch, A.; Robic, C.; Vander Elst, L.; Muller, R.N. Magnetic Iron Oxide Nanoparticles: Synthesis, Stabilization, Vectorization, Physicochemical Characterizations, and Biological Applications. Chem. Rev. 2008, 108, 2064-2110. [CrossRef] [PubMed]

18. Laurent, S.; Bridot, J.-L.; Elst, L.V.; Muller, R.N. Magnetic Iron Oxide Nanoparticles for Biomedical Applications. Future Med. Chem. 2010, 2, 427-449. [CrossRef] [PubMed]

19. Ramimoghadam, D.; Bagheri, S.; Hamid, S.B.A. Progress in Electrochemical Synthesis of Magnetic Iron Oxide Nanoparticles. J. Magn. Magn. Mater. 2014, 368, 207-229. [CrossRef]

20. Avasthi, A.; Caro, C.; Pozo-Torres, E.; Leal, M.P.; García-Martín, M.L. Magnetic Nanoparticles as MRI Contrast Agents. Top. Curr. Chem. 2020, 378, 40. [CrossRef] [PubMed] 
21. Caspani, S.; Magalhães, R.; Araújo, J.P.; Sousa, C.T. Magnetic Nanomaterials as Contrast Agents for MRI. Materials 2020, 13 , 2586. [CrossRef] [PubMed]

22. Chouhan, R.S.; Horvat, M.; Ahmed, J.; Alhokbany, N.; Alshehri, S.M.; Gandhi, S. Magnetic Nanoparticles-A Multifunctional Potential Agent for Diagnosis and Therapy. Cancers 2021, 13, 2213. [CrossRef]

23. Niculescu, A.-G.; Chircov, C.; Grumezescu, A.M. Magnetite Nanoparticles: Synthesis Methods-A Comparative Review. Methods 2021, in press. [CrossRef]

24. Fatima, H.; Kim, K.-S. Iron-Based Magnetic Nanoparticles for Magnetic Resonance Imaging. Adv. Powder Technol. 2018, 29, 2678-2685. [CrossRef]

25. Khalafalla, S.; Reimers, G. Preparation of Dilution-Stable Aqueous Magnetic Fluids. IEEE Trans. Magn. 1980, 16, 178-183. [CrossRef]

26. Massart, R. Preparation of Aqueous Magnetic Liquids in Alkaline and Acidic Media. IEEE Trans. Magn. 1981, 17, 1247-1248. [CrossRef]

27. Dadfar, S.M.; Roemhild, K.; Drude, N.I.; von Stillfried, S.; Knüchel, R.; Kiessling, F.; Lammers, T. Iron Oxide Nanoparticles: Diagnostic, Therapeutic and Theranostic Applications. Adv. Drug Deliv. Rev. 2019, 138, 302-325. [CrossRef]

28. Adewunmi, A.A.; Kamal, M.S.; Solling, T.I. Application of Magnetic Nanoparticles in Demulsification: A Review on Synthesis, Performance, Recyclability, and Challenges. J. Pet. Sci. Eng. 2021, 196, 107680. [CrossRef]

29. Xia, T.; Wang, J.; Wu, C.; Meng, F.; Shi, Z.; Lian, J.; Feng, J.; Meng, J. Novel Complex-Co-precipitation Route to Form High Quality Triethanolamine-Coated Fe3O4 Nanocrystals: Their High Saturation Magnetizations and Excellent Water Treatment Properties. CrystEngComm 2012, 14, 5741-5744. [CrossRef]

30. Majidi, S.; Zeinali Sehrig, F.; Farkhani, S.M.; Soleymani Goloujeh, M.; Akbarzadeh, A. Current Methods for Synthesis of Magnetic Nanoparticles. Artif. Cells Nanomed. Biotechnol. 2016, 44, 722-734. [CrossRef]

31. Lu, A.-H.; Salabas, E.L.; Schüth, F. Magnetic Nanoparticles: Synthesis, Protection, Functionalization, and Application. Angew. Chem. Int. Ed. 2007, 46, 1222-1244. [CrossRef]

32. Wu, W.; He, Q.; Jiang, C. Magnetic Iron Oxide Nanoparticles: Synthesis and Surface Functionalization Strategies. Nanoscale Res. Lett. 2008, 3, 397-415. [CrossRef]

33. Xu, C.; Lee, J.; Teja, A.S. Continuous Hydrothermal Synthesis of Lithium Iron Phosphate Particles in Subcritical and Supercritical Water. J. Supercrit. Fluids 2008, 44, 92-97. [CrossRef]

34. Al-Rawi, N.N.; Anwer, B.A.; Al-Rawi, N.H.; Uthman, A.T.; Ahmed, I.S. Magnetism in Drug Delivery: The Marvels of Iron Oxides and Substituted Ferrites Nanoparticles. Saudi Pharm. J. 2020, 28, 876-887. [CrossRef] [PubMed]

35. Soenen, S.J.H.; De Cuyper, M. Assessing Cytotoxicity of (Iron Oxide-Based) Nanoparticles: An Overview of Different Methods Exemplified with Cationic Magnetoliposomes. Contrast Media Mol. Imaging 2009, 4, 207-219. [CrossRef] [PubMed]

36. Caruntu, D.; Caruntu, G.; Chen, Y.; O'Connor, C.J.; Goloverda, G.; Kolesnichenko, V.L. Synthesis of Variable-Sized Nanocrystals of Fe3O4 with High Surface Reactivity. Chem. Mater. 2004, 16, 5527-5534. [CrossRef]

37. Iacovita, C.; Fizeșan, I.; Pop, A.; Scorus, L.; Dudric, R.; Stiufiuc, G.; Vedeanu, N.; Tetean, R.; Loghin, F.; Stiufiuc, R.; et al. In Vitro Intracellular Hyperthermia of Iron Oxide Magnetic Nanoparticles, Synthesized at High Temperature by a Polyol Process. Pharmaceutics 2020, 12, 424. [CrossRef] [PubMed]

38. Cheng, C.; Xu, F.; Gu, H. Facile Synthesis and Morphology Evolution of Magnetic Iron Oxide Nanoparticles in Different Polyol Processes. New J. Chem. 2011, 35, 1072. [CrossRef]

39. Hachani, R.; Lowdell, M.; Birchall, M.; Hervault, A.; Mertz, D.; Begin-Colin, S.; Thanh, N.T.K. Polyol Synthesis, Functionalisation, and Biocompatibility Studies of Superparamagnetic Iron Oxide Nanoparticles as Potential MRI Contrast Agents. Nanoscale 2016, 8, 3278-3287. [CrossRef]

40. Alphandéry, E. Applications of Magnetosomes Synthesized by Magnetotactic Bacteria in Medicine. Front. Bioeng. Biotechnol. 2014, 2, 5. [CrossRef] [PubMed]

41. Vargas, G.; Cypriano, J.; Correa, T.; Leão, P.; Bazylinski, D.A.; Abreu, F. Applications of Magnetotactic Bacteria, Magnetosomes and Magnetosome Crystals in Biotechnology and Nanotechnology: Mini-Review. Molecules 2018, 23, 2438. [CrossRef] [PubMed]

42. Zhao, D. Bacteriogenic Magnetic Nanoparticles as Magnetic Resonance Imaging Contrast Agents. Transl. Cancer Res. 2017, 6, S512-S514. [CrossRef]

43. González-Carreño, T.; Morales, M.P.; Gracia, M.; Serna, C.J. Preparation of Uniform $\gamma$-Fe ${ }_{2} \mathrm{O} 3$ Particles with Nanometer Size by Spray Pyrolysis. Mater. Lett. 1993, 18, 151-155. [CrossRef]

44. Teoh, W.Y.; Amal, R.; Mädler, L. Flame Spray Pyrolysis: An Enabling Technology for Nanoparticles Design and Fabrication. Nanoscale 2010, 2, 1324-1347. [CrossRef]

45. Sequeira, C.A.C. Electrochemical Synthesis of Iron Oxide Nanoparticles for Biomedical Application. Org. Med. Chem. Int. J. 2018, 5. [CrossRef]

46. Fu, X.; Cai, J.; Zhang, X.; Li, W.-D.; Ge, H.; Hu, Y. Top-down Fabrication of Shape-Controlled, Monodisperse Nanoparticles for Biomedical Applications. Adv. Drug Deliv. Rev. 2018, 132, 169-187. [CrossRef] [PubMed]

47. Valencia, P.M.; Farokhzad, O.C.; Karnik, R.; Langer, R. Microfluidic Technologies for Accelerating the Clinical Translation of Nanoparticles. Nat. Nanotechnol. 2012, 7, 623-629. [CrossRef]

48. Shrimal, P.; Jadeja, G.; Patel, S. A Review on Novel Methodologies for Drug Nanoparticle Preparation: Microfluidic Approach. Chem. Eng. Res. Des. 2020, 153, 728-756. [CrossRef] 
49. Suryawanshi, P.L.; Sonawane, S.H.; Bhanvase, B.A.; Ashokkumar, M.; Pimplapure, M.S.; Gogate, P.R. Synthesis of Iron Oxide Nanoparticles in a Continuous Flow Spiral Microreactor and Corning ${ }^{\circledR}$ Advanced Flow ${ }^{\mathrm{TM}}$ Reactor. Green Process. Synth. 2018, 7 , 1-11. [CrossRef]

50. Dodi, G.; Hritcu, D.; Lisa, G.; Popa, M.I. Core-Shell Magnetic Chitosan Particles Functionalized by Grafting: Synthesis and Characterization. Chem. Eng. J. 2012, 203, 130-141. [CrossRef]

51. Jain, T.K.; Reddy, M.K.; Morales, M.A.; Leslie-Pelecky, D.L.; Labhasetwar, V. Biodistribution, Clearance, and Biocompatibility of Iron Oxide Magnetic Nanoparticles in Rats. Mol. Pharm. 2008, 5, 316-327. [CrossRef] [PubMed]

52. Cojocaru, F.D.; Balan, V.; Popa, I.M.; Munteanu, A.; Anghelache, A.; Verestiuc, L. Magnetic Composite Scaffolds for Potential Applications in Radiochemotherapy of Malignant Bone Tumors. Medicina 2019, 55, 153. [CrossRef] [PubMed]

53. Muthiah, M.; Park, I.-K.; Cho, C.-S. Surface Modification of Iron Oxide Nanoparticles by Biocompatible Polymers for Tissue Imaging and Targeting. Biotechnol. Adv. 2013, 31, 1224-1236. [CrossRef] [PubMed]

54. Zhu, N.; Ji, H.; Yu, P.; Niu, J.; Farooq, M.U.; Akram, M.W.; Udego, I.O.; Li, H.; Niu, X. Surface Modification of Magnetic Iron Oxide Nanoparticles. Nanomaterials 2018, 8, 810. [CrossRef]

55. Ansari, S.; Ficiarà, E.; Ruffinatti, F.; Stura, I.; Argenziano, M.; Abollino, O.; Cavalli, R.; Guiot, C.; D'Agata, F. Magnetic Iron Oxide Nanoparticles: Synthesis, Characterization and Functionalization for Biomedical Applications in the Central Nervous System. Materials 2019, 12, 465. [CrossRef] [PubMed]

56. Palanisamy, S.; Wang, Y.-M. Superparamagnetic Iron Oxide Nanoparticulate System: Synthesis, Targeting, Drug Delivery and Therapy in Cancer. Dalton Trans. 2019, 48, 9490-9515. [CrossRef]

57. Narayanaswamy, R.; Kanagesan, S.; Pandurangan, A.; Padmanabhan, P. Basics to different imaging techniques, different nanobiomaterials for image enhancement. In Nanobiomaterials in Medical Imaging; Elsevier: Amsterdam, The Netherlands, 2016; pp. 101-129. ISBN 978-0-323-41736-5.

58. Nelson, N.; Port, J.; Pandey, M. Use of Superparamagnetic Iron Oxide Nanoparticles (SPIONs) via Multiple Imaging Modalities and Modifications to Reduce Cytotoxicity: An Educational Review. J. Nanotheranostics 2020, 1, 105-135. [CrossRef]

59. Gholipour, N.; Akhlaghi, M.; Mokhtari Kheirabadi, A.; Geramifar, P.; Beiki, D. Development of Ga-68 Labeled, Biotinylated Thiosemicarbazone Dextran-Coated Iron Oxide Nanoparticles as Multimodal PET/MRI Probe. Int. J. Biol. Macromol. 2020, 148, 932-941. [CrossRef] [PubMed]

60. Unterweger, H.; Dézsi, L.; Matuszak, J.; Janko, C.; Poettler, M.; Jordan, J.; Bäuerle, T.; Szebeni, J.; Fey, T.; Boccaccini, A.; et al. Dextran-Coated Superparamagnetic Iron Oxide Nanoparticles for Magnetic Resonance Imaging: Evaluation of Size-Dependent Imaging Properties, Storage Stability and Safety. Int. J. Nanomed. 2018, 13, 1899-1915. [CrossRef] [PubMed]

61. Balan, V.; Dodi, G.; Tudorachi, N.; Ponta, O.; Simon, V.; Butnaru, M.; Verestiuc, L. Doxorubicin-Loaded Magnetic Nanocapsules Based on N-Palmitoyl Chitosan and Magnetite: Synthesis and Characterization. Chem. Eng. J. 2015, 279, 188-197. [CrossRef]

62. Zheng, S.; Han, J.; Jin, Z.; Kim, C.-S.; Park, S.; Kim, K.-P.; Park, J.-O.; Choi, E. Dual Tumor-Targeted Multifunctional Magnetic Hyaluronic Acid Micelles for Enhanced MR Imaging and Combined Photothermal-Chemotherapy. Colloids Surf. B Biointerfaces 2018, 164, 424-435. [CrossRef] [PubMed]

63. Tudorachi, N.; Chiriac, A.P.; Nita, L.E.; Mustata, F.; Diaconu, A.; Balan, V.; Rusu, A.; Lisa, G. Studies on the Nanocomposites Based on Carboxymethyl Starch-g-Lactic Acid-Co-Glycolic Acid Copolymer and Magnetite. J. Therm. Anal. Calorim. 2018, 131, 1867-1880. [CrossRef]

64. Vismara, E.; Bongio, C.; Coletti, A.; Edelman, R.; Serafini, A.; Mauri, M.; Simonutti, R.; Bertini, S.; Urso, E.; Assaraf, Y.G.; et al. Albumin and Hyaluronic Acid-Coated Superparamagnetic Iron Oxide Nanoparticles Loaded with Paclitaxel for Biomedical Applications. Molecules 2017, 22, 1030. [CrossRef]

65. Castelló, J.; Gallardo, M.; Busquets, M.A.; Estelrich, J. Chitosan (or Alginate)-Coated Iron Oxide Nanoparticles: A Comparative Study. Colloids Surf. A Physicochem. Eng. Asp. 2015, 468, 151-158. [CrossRef]

66. Tomitaka, A.; Jo, J.; Aoki, I.; Tabata, Y. Preparation of Biodegradable Iron Oxide Nanoparticles with Gelatin for Magnetic Resonance Imaging. Inflamm. Regen. 2014, 34, 45-55. [CrossRef]

67. Farokhi, M.; Mottaghitalab, F.; Saeb, M.R.; Thomas, S. Functionalized Theranostic Nanocarriers with Bio-Inspired Polydopamine for Tumor Imaging and Chemo-Photothermal Therapy. J. Control. Release 2019, 309, 203-219. [CrossRef] [PubMed]

68. Wu, M.; Zhang, D.; Zeng, Y.; Wu, L.; Liu, X.; Liu, J. Nanocluster of Superparamagnetic Iron Oxide Nanoparticles Coated with Poly (Dopamine) for Magnetic Field-Targeting, Highly Sensitive MRI and Photothermal Cancer Therapy. Nanotechnology 2015, 26, 115102. [CrossRef] [PubMed]

69. Ge, Y.; Zhang, Y.; He, S.; Nie, F.; Teng, G.; Gu, N. Fluorescence Modified Chitosan-Coated Magnetic Nanoparticles for HighEfficient Cellular Imaging. Nanoscale Res. Lett. 2009, 4, 287-295. [CrossRef] [PubMed]

70. Unsoy, G.; Yalcin, S.; Khodadust, R.; Gunduz, G.; Gunduz, U. Synthesis Optimization and Characterization of Chitosan-Coated Iron Oxide Nanoparticles Produced for Biomedical Applications. J. Nanopart. Res. 2012, 14, 964. [CrossRef]

71. Rhee, I.; Hong, S.; Chang, Y. Chitosan-Coated Ferrite (Fe3O4) Nanoparticles as a T2 Contrast Agent for Magnetic Resonance Imaging. J. Korean Phys. Soc. 2010, 56, 868-873. [CrossRef]

72. Khmara, I.; Strbak, O.; Zavisova, V.; Koneracka, M.; Kubovcikova, M.; Antal, I.; Kavecansky, V.; Lucanska, D.; Dobrota, D.; Kopcansky, P. Chitosan-Stabilized Iron Oxide Nanoparticles for Magnetic Resonance Imaging. J. Magn. Magn. Mater. 2019, 474, 319-325. [CrossRef] 
73. Hajiramezanali, M.; Atyabi, F.; Mosayebnia, M.; Akhlaghi, M.; Geramifar, P.; Jalilian, A.R.; Mazidi, S.M.; Yousefnia, H.; Shahhosseini, S.; Beiki, D. ${ }^{68}$ Ga-Radiolabeled Bombesin-Conjugated to Trimethyl Chitosan-Coated Superparamagnetic Nanoparticles for Molecular Imaging: Preparation, Characterization and Biological Evaluation. Int. J. Nanomed. 2019, 14, 2591-2605. [CrossRef]

74. Su, H.; Han, X.; He, L.; Deng, L.; Yu, K.; Jiang, H.; Wu, C.; Jia, Q.; Shan, S. Synthesis and Characterization of Magnetic Dextran Nanogel Doped with Iron Oxide Nanoparticles as Magnetic Resonance Imaging Probe. Int. J. Biol. Macromol. 2019, 128, 768-774. [CrossRef]

75. Hsieh, W.-J.; Liang, C.-J.; Chieh, J.-J.; Wang, S.-H.; Lai, I.-R.; Chen, J.-H.; Chang, F.-H.; Tseng, W.-K.; Yang, S.-Y.; Wu, C.-C.; et al. In Vivo Tumor Targeting and Imaging with Anti-Vascular Endothelial Growth Factor Antibody-Conjugated Dextran-Coated Iron Oxide Nanoparticles. Int. J. Nanomed. 2012, 7, 2833-2842. [CrossRef]

76. Mishra, S.K.; Kumar, B.S.H.; Khushu, S.; Tripathi, R.P.; Gangenahalli, G. Increased Transverse Relaxivity in Ultrasmall Superparamagnetic Iron Oxide Nanoparticles Used as MRI Contrast Agent for Biomedical Imaging. Contrast Media Mol. Imaging 2016, 11, 350-361. [CrossRef]

77. Jafari, A.; Salouti, M.; Shayesteh, S.F.; Heidari, Z.; Rajabi, A.B.; Boustani, K.; Nahardani, A. Synthesis and Characterization of Bombesin-Superparamagnetic Iron Oxide Nanoparticles as a Targeted Contrast Agent for Imaging of Breast Cancer Using MRI. Nanotechnology 2015, 26, 075101. [CrossRef]

78. Torres Martin de Rosales, R.; Tavaré, R.; Glaria, A.; Varma, G.; Protti, A.; Blower, P.J. 99m Tc-Bisphosphonate-Iron Oxide Nanoparticle Conjugates for Dual-Modality Biomedical Imaging. Bioconjug. Chem. 2011, 22, 455-465. [CrossRef] [PubMed]

79. Liu, G.; Hong, R.Y.; Guo, L.; Li, Y.G.; Li, H.Z. Preparation, Characterization and MRI Application of Carboxymethyl Dextran Coated Magnetic Nanoparticles. Appl. Surf. Sci. 2011, 257, 6711-6717. [CrossRef]

80. Tao, C.; Zheng, Q.; An, L.; He, M.; Lin, J.; Tian, Q.; Yang, S. T1-Weight Magnetic Resonance Imaging Performances of Iron Oxide Nanoparticles Modified with a Natural Protein Macromolecule and an Artificial Macromolecule. Nanomaterials 2019, 9, 170. [CrossRef] [PubMed]

81. Li, H.; Yan, K.; Shang, Y.; Shrestha, L.; Liao, R.; Liu, F.; Li, P.; Xu, H.; Xu, Z.; Chu, P.K. Folate-Bovine Serum Albumin Functionalized Polymeric Micelles Loaded with Superparamagnetic Iron Oxide Nanoparticles for Tumor Targeting and Magnetic Resonance Imaging. Acta Biomater. 2015, 15, 117-126. [CrossRef] [PubMed]

82. Ma, H.; Qi, X.; Maitani, Y.; Nagai, T. Preparation and Characterization of Superparamagnetic Iron Oxide Nanoparticles Stabilized by Alginate. Int. J. Pharm. 2007, 333, 177-186. [CrossRef] [PubMed]

83. Ma, H.L.; Xu, Y.F.; Qi, X.R.; Maitani, Y.; Nagai, T. Superparamagnetic Iron Oxide Nanoparticles Stabilized by Alginate: Pharmacokinetics, Tissue Distribution, and Applications in Detecting Liver Cancers. Int. J. Pharm. 2008, 354, 217-226. [CrossRef] [PubMed]

84. Torres Martin de Rosales, R.; Tavaré, R.; Paul, R.L.; Jauregui-Osoro, M.; Protti, A.; Glaria, A.; Varma, G.; Szanda, I.; Blower, P.J. Synthesis of $64 \mathrm{Cu}$ (II)-Bis(Dithiocarbamatebisphosphonate) and Its Conjugation with Superparamagnetic Iron Oxide Nanoparticles: In Vivo Evaluation as Dual-Modality PET-MRI Agent. Angew. Chem. Int. Ed. 2011, 50, 5509-5513. [CrossRef] [PubMed]

85. Zhang, B.; Li, Q.; Yin, P.; Rui, Y.; Qiu, Y.; Wang, Y.; Shi, D. Ultrasound-Triggered BSA/SPION Hybrid Nanoclusters for LiverSpecific Magnetic Resonance Imaging. ACS Appl. Mater. Interfaces 2012, 4, 6479-6486. [CrossRef]

86. Sun, W.; Yang, J.; Zhu, J.; Zhou, Y.; Li, J.; Zhu, X.; Shen, M.; Zhang, G.; Shi, X. Immobilization of Iron Oxide Nanoparticles within Alginate Nanogels for Enhanced MR Imaging Applications. Biomater. Sci. 2016, 4, 1422-1430. [CrossRef] [PubMed]

87. Widder, D.J.; Greif, W.L.; Widder, K.J.; Edelman, R.R.; Brady, T.J. Magnetite Albumin Microspheres: A New MR Contrast Material. AJR Am. J. Roentgenol. 1987, 148, 399-404. [CrossRef] [PubMed]

88. Ye, M.; Zhou, J.; Zhong, Y.; Xu, J.; Hou, J.; Wang, X.; Wang, Z.; Guo, D. SR-A-Targeted Phase-Transition Nanoparticles for the Detection and Treatment of Atherosclerotic Vulnerable Plaques. ACS Appl. Mater. Interfaces 2019, 11, 9702-9715. [CrossRef] [PubMed]

89. Choi, H.; Choi, S.R.; Zhou, R.; Kung, H.F.; Chen, I.-W. Iron Oxide Nanoparticles as Magnetic Resonance Contrast Agent for Tumor Imaging via Folate Receptor-Targeted Delivery1. Acad. Radiol. 2004, 11, 996-1004. [CrossRef]

90. Xu, S.; Wang, J.; Wei, Y.; Zhao, H.; Tao, T.; Wang, H.; Wang, Z.; Du, J.; Wang, H.; Qian, J.; et al. In Situ One-Pot Synthesis of Fe2O3@BSA Core-Shell Nanoparticles as Enhanced T1-Weighted Magnetic Resonance Imagine Contrast Agents. ACS Appl. Mater. Interfaces 2020, 12, 56701-56711. [CrossRef]

91. Wang, X.; Tu, M.; Tian, B.; Yi, Y.; Wei, Z.; Wei, F. Synthesis of Tumor-Targeted Folate Conjugated Fluorescent Magnetic Albumin Nanoparticles for Enhanced Intracellular Dual-Modal Imaging into Human Brain Tumor Cells. Anal. Biochem. 2016, 512, 8-17. [CrossRef]

92. Rosenberger, I.; Schmithals, C.; Vandooren, J.; Bianchessi, S.; Milani, P.; Locatelli, E.; Israel, L.L.; Hübner, F.; Matteoli, M.; Lellouche, J.-P.; et al. Physico-Chemical and Toxicological Characterization of Iron-Containing Albumin Nanoparticles as Platforms for Medical Imaging. J. Control. Release 2014, 194, 130-137. [CrossRef]

93. Skaat, H.; Margel, S. Synthesis of Fluorescent-Maghemite Nanoparticles as Multimodal Imaging Agents for Amyloid-Beta Fibrils Detection and Removal by a Magnetic Field. Biochem. Biophys. Res. Commun. 2009, 386, 645-649. [CrossRef]

94. Shen, F.; Poncet-Legrand, C.; Somers, S.; Slade, A.; Yip, C.; Duft, A.M.; Winnik, F.M.; Chang, P.L. Properties of a Novel Magnetized Alginate for Magnetic Resonance Imaging. Biotechnol. Bioeng. 2003, 83, 282-292. [CrossRef] 
95. Yuk, S.H.; Oh, K.S.; Cho, S.H.; Lee, B.S.; Kim, S.Y.; Kwak, B.-K.; Kim, K.; Kwon, I.C. Glycol Chitosan/Heparin Immobilized Iron Oxide Nanoparticles with a Tumor-Targeting Characteristic for Magnetic Resonance Imaging. Biomacromolecules 2011, 12, 2335-2343. [CrossRef]

96. Moore, A.; Marecos, E.; Bogdanov, A.; Weissleder, R. Tumoral Distribution of Long-Circulating Dextran-Coated Iron Oxide Nanoparticles in a Rodent Model. Radiology 2000, 214, 568-574. [CrossRef] [PubMed]

97. Mandeville, J.B.; Moore, J.; Chesler, D.A.; Garrido, L.; Weissleder, R.; Weisskoff, R.M. Dynamic Liver Imaging with Iron Oxide Agents: Effects of Size and Biodistribution on Contrast. Magn. Reson. Med. 1997, 37, 885-890. [CrossRef]

98. Borny, R.; Lechleitner, T.; Schmiedinger, T.; Hermann, M.; Tessadri, R.; Redhammer, G.; Neumüller, J.; Kerjaschki, D.; Berzaczy, G.; Erman, G.; et al. Nucleophilic Cross-Linked, Dextran Coated Iron Oxide Nanoparticles as Basis for Molecular Imaging: Synthesis, Characterization, Visualization and Comparison with Previous Product. Contrast Media Mol. Imaging 2015, 10, 18-27. [CrossRef] [PubMed]

99. Shin, T.-H.; Kim, P.K.; Kang, S.; Cheong, J.; Kim, S.; Lim, Y.; Shin, W.; Jung, J.-Y.; Lah, J.D.; Choi, B.W.; et al. High-Resolution T1 MRI via Renally Clearable Dextran Nanoparticles with an Iron Oxide Shell. Nat. Biomed. Eng. 2021, 5, 252-263. [CrossRef]

100. Thorek, D.L.J.; Ulmert, D.; Diop, N.-F.M.; Lupu, M.E.; Doran, M.G.; Huang, R.; Abou, D.S.; Larson, S.M.; Grimm, J. Non-Invasive Mapping of Deep-Tissue Lymph Nodes in Live Animals Using a Multimodal PET/MRI Nanoparticle. Nat. Commun. 2014, 5, 3097. [CrossRef] [PubMed]

101. Naha, P.C.; Zaki, A.A.; Hecht, E.; Chorny, M.; Chhour, P.; Blankemeyer, E.; Yates, D.M.; Witschey, W.R.T.; Litt, H.I.; Tsourkas, A.; et al. Dextran Coated Bismuth-Iron Oxide Nanohybrid Contrast Agents for Computed Tomography and Magnetic Resonance Imaging. J. Mater. Chem. B 2014, 2, 8239-8248. [CrossRef]

102. Fu, C.; Zhou, H.; Wang, Y.; Liu, D.; Li, J.; Deng, H.; Qi, X.; Chen, T.; Zhang, L.-M.; Li, G. One-Pot Synthesis of Dextran-Coated Iron Oxide Nanoclusters for Real-Time Regional Lymph Node Mapping. Int. J. Nanomed. 2017, 12, 3365-3374. [CrossRef]

103. Jarrett, B.R.; Frendo, M.; Vogan, J.; Louie, A.Y. Size-Controlled Synthesis of Dextran Sulfate Coated Iron Oxide Nanoparticles for Magnetic Resonance Imaging. Nanotechnology 2007, 18, 035603. [CrossRef] [PubMed]

104. Tu, C.; Ng, T.S.C.; Sohi, H.K.; Palko, H.A.; House, A.; Jacobs, R.E.; Louie, A.Y. Receptor-Targeted Iron Oxide Nanoparticles for Molecular MR Imaging of Inflamed Atherosclerotic Plaques. Biomaterials 2011, 32, 7209-7216. [CrossRef]

105. Jarrett, B.R.; Gustafsson, B.; Kukis, D.L.; Louie, A.Y. Synthesis of 64Cu-Labeled Magnetic Nanoparticles for Multimodal Imaging. Bioconjug. Chem. 2008, 19, 1496-1504. [CrossRef]

106. Liu, S.; Jia, B.; Qiao, R.; Yang, Z.; Yu, Z.; Liu, Z.; Liu, K.; Shi, J.; Ouyang, H.; Wang, F.; et al. A Novel Type of Dual-Modality Molecular Probe for MR and Nuclear Imaging of Tumor: Preparation, Characterization and in Vivo Application. Mol. Pharm. 2009, 6, 1074-1082. [CrossRef]

107. Lee, C.-M.; Jang, D.; Kim, J.; Cheong, S.-J.; Kim, E.-M.; Jeong, M.-H.; Kim, S.-H.; Kim, D.W.; Lim, S.T.; Sohn, M.-H.; et al. Oleyl-Chitosan Nanoparticles Based on a Dual Probe for Optical/MR Imaging in Vivo. Bioconjug. Chem. 2011, 22, 186-192. [CrossRef] [PubMed]

108. Xie, M.; Wang, Z.; Lu, Q.; Nie, S.; Butch, C.J.; Wang, Y.; Dai, B. Ultracompact Iron Oxide Nanoparticles with a Monolayer Coating of Succinylated Heparin: A New Class of Renal-Clearable and Nontoxic T1 Agents for High-Field MRI. ACS Appl. Mater. Interfaces 2020, 12, 53994-54004. [CrossRef]

109. Sherwood, J.; Rich, M.; Lovas, K.; Warram, J.; Bolding, M.S.; Bao, Y. T 1 -Enhanced MRI-Visible Nanoclusters for Imaging-Guided Drug Delivery. Nanoscale 2017, 9, 11785-11792. [CrossRef]

110. Gervits, N.E.; Gippius, A.A.; Tkachev, A.V.; Demikhov, E.I.; Starchikov, S.S.; Lyubutin, I.S.; Vasiliev, A.L.; Chekhonin, V.P.; Abakumov, M.A.; Semkina, A.S.; et al. Magnetic Properties of Biofunctionalized Iron Oxide Nanoparticles as Magnetic Resonance Imaging Contrast Agents. Beilstein J. Nanotechnol. 2019, 10, 1964-1972. [CrossRef]

111. Ostroverkhov, P.; Semkina, A.; Naumenko, V.; Plotnikova, E.; Yakubovskaya, R.; Vodopyanov, S.; Abakumov, A.; Majouga, A.; Grin, M.; Chekhonin, V.; et al. HSA-Coated Magnetic Nanoparticles for MRI-Guided Photodynamic Cancer Therapy. Pharmaceutics 2018, 10, 284. [CrossRef]

112. Murata, Y.; Jo, J.; Tabata, Y. Preparation of Gelatin Nanospheres Incorporating Quantum Dots and Iron Oxide Nanoparticles for Multimodal Cell Imaging. J. Biomater. Sci. Polym. Ed. 2017, 28, 555-568. [CrossRef] [PubMed]

113. Pellico, J.; Ruiz-Cabello, J.; Saiz-Alía, M.; del Rosario, G.; Caja, S.; Montoya, M.; Fernández de Manuel, L.; Morales, M.P.; Gutiérrez, L.; Galiana, B.; et al. Fast Synthesis and Bioconjugation of ${ }^{68} \mathrm{Ga}$ Core-Doped Extremely Small Iron Oxide Nanoparticles for PET/MR Imaging. Contrast Media Mol. Imaging 2016, 11, 203-210. [CrossRef]

114. Groult, H.; Poupard, N.; Herranz, F.; Conforto, E.; Bridiau, N.; Sannier, F.; Bordenave, S.; Piot, J.-M.; Ruiz-Cabello, J.; FruitierArnaudin, I.; et al. Family of Bioactive Heparin-Coated Iron Oxide Nanoparticles with Positive Contrast in Magnetic Resonance Imaging for Specific Biomedical Applications. Biomacromolecules 2017, 18, 3156-3167. [CrossRef] [PubMed]

115. Osborne, E.A.; Atkins, T.M.; Gilbert, D.A.; Kauzlarich, S.M.; Liu, K.; Louie, A.Y. Rapid Microwave-Assisted Synthesis of Dextran-Coated Iron Oxide Nanoparticles for Magnetic Resonance Imaging. Nanotechnology 2012, 23, 215602. [CrossRef]

116. Wong, R.M.; Gilbert, D.A.; Liu, K.; Louie, A.Y. Rapid Size-Controlled Synthesis of Dextran-Coated, 64Cu-Doped Iron Oxide Nanoparticles. ACS Nano 2012, 6, 3461-3467. [CrossRef] [PubMed]

117. Tzameret, A.; Ketter-Katz, H.; Edelshtain, V.; Sher, I.; Corem-Salkmon, E.; Levy, I.; Last, D.; Guez, D.; Mardor, Y.; Margel, S.; et al. In Vivo MRI Assessment of Bioactive Magnetic Iron Oxide/Human Serum Albumin Nanoparticle Delivery into the Posterior Segment of the Eye in a Rat Model of Retinal Degeneration. J. Nanobiotechnol. 2019, 17, 3. [CrossRef] 
118. Levy, I.; Sher, I.; Corem-Salkmon, E.; Ziv-Polat, O.; Meir, A.; Treves, A.J.; Nagler, A.; Kalter-Leibovici, O.; Margel, S.; Rotenstreich, Y. Bioactive Magnetic near Infra-Red Fluorescent Core-Shell Iron Oxide/Human Serum Albumin Nanoparticles for Controlled Release of Growth Factors for Augmentation of Human Mesenchymal Stem Cell Growth and Differentiation. J. Nanobiotechnol. 2015, 13, 34. [CrossRef] [PubMed]

119. Tsai, Z.-T.; Wang, J.-F.; Kuo, H.-Y.; Shen, C.-R.; Wang, J.-J.; Yen, T.-C. In Situ Preparation of High Relaxivity Iron Oxide Nanoparticles by Coating with Chitosan: A Potential MRI Contrast Agent Useful for Cell Tracking. J. Magn. Magn. Mater. 2010, 322, 208-213. [CrossRef]

120. Kania, G.; Sternak, M.; Jasztal, A.; Chlopicki, S.; Błażejczyk, A.; Nasulewicz-Goldeman, A.; Wietrzyk, J.; Jasiński, K.; Skórka, T.; Zapotoczny, S.; et al. Uptake and Bioreactivity of Charged Chitosan-Coated Superparamagnetic Nanoparticles as Promising Contrast Agents for Magnetic Resonance Imaging. Nanomedicine 2018, 14, 131-140. [CrossRef]

121. Xiao, Y.; Lin, Z.T.; Chen, Y.; Wang, H.; Deng, Y.L.; Le, D.E.; Bin, J.; Li, M.; Liao, Y.; Liu, Y.; et al. High Molecular Weight Chitosan Derivative Polymeric Micelles Encapsulating Superparamagnetic Iron Oxide for Tumor-Targeted Magnetic Resonance Imaging. Int. J. Nanomed. 2015, 10, 1155-1172. [CrossRef]

122. Lee, D.Y. Highly Effective T2 MR Contrast Agent Based on Heparinized Superparamagnetic Iron Oxide Nanoparticles. Macromol. Res. 2011, 19, 843-847. [CrossRef]

123. Lee, J.; Jung, M.J.; Hwang, Y.H.; Lee, Y.J.; Lee, S.; Lee, D.Y.; Shin, H. Heparin-Coated Superparamagnetic Iron Oxide for in Vivo MR Imaging of Human MSCs. Biomaterials 2012, 33, 4861-4871. [CrossRef]

124. Saraswathy, A.; Nazeer, S.S.; Nimi, N.; Arumugam, S.; Shenoy, S.J.; Jayasree, R.S. Synthesis and Characterization of Dextran Stabilized Superparamagnetic Iron Oxide Nanoparticles for In Vivo MR Imaging of Liver Fibrosis. Carbohydr. Polym. 2014, 101, 760-768. [CrossRef]

125. Dai, F.; Du, M.; Liu, Y.; Liu, G.; Liu, Q.; Zhang, X. Folic Acid-Conjugated Glucose and Dextran Coated Iron Oxide Nanoparticles as MRI Contrast Agents for Diagnosis and Treatment Response of Rheumatoid Arthritis. J. Mater. Chem. B 2014, 2, $2240-2247$. [CrossRef]

126. Barrow, M.; Taylor, A.; Nieves, D.J.; Bogart, L.K.; Mandal, P.; Collins, C.M.; Moore, L.R.; Chalmers, J.J.; Lévy, R.; Williams, S.R.; et al. Tailoring the Surface Charge of Dextran-Based Polymer Coated SPIONs for Modulated Stem Cell Uptake and MRI Contrast. Biomater. Sci. 2015, 3, 608-616. [CrossRef] [PubMed]

127. Chauhan, R.P.; Mathur, R.; Singh, G.; Kaul, A.; Bag, N.; Singh, S.; Kumar, H.; Patra, M.; Mishra, A.K. Evaluation of Folate Conjugated Superparamagnetic Iron Oxide Nanoparticles for Scintigraphic/Magnetic Resonance Imaging. J. Biomed. Nanotechnol. 2013, 9, 323-334. [CrossRef]

128. Chen, T.-J.; Cheng, T.-H.; Chen, C.-Y.; Hsu, S.C.N.; Cheng, T.-L.; Liu, G.-C.; Wang, Y.-M. Targeted Herceptin-Dextran Iron Oxide Nanoparticles for Noninvasive Imaging of HER2/Neu Receptors Using MRI. J. Biol. Inorg. Chem. 2009, 14, 253-260. [CrossRef] [PubMed]

129. Unterweger, H.; Janko, C.; Schwarz, M.; Dézsi, L.; Urbanics, R.; Matuszak, J.; Ôrfi, E.; Fülöp, T.; Bäuerle, T.; Szebeni, J.; et al. Non-Immunogenic Dextran-Coated Superparamagnetic Iron Oxide Nanoparticles: A Biocompatible, Size-Tunable Contrast Agent for Magnetic Resonance Imaging. Int. J. Nanomed. 2017, 12, 5223-5238. [CrossRef]

130. Ziemian, S.; Löwa, N.; Kosch, O.; Bajj, D.; Wiekhorst, F.; Schütz, G. Optimization of Iron Oxide Tracer Synthesis for Magnetic Particle Imaging. Nanomaterials 2018, 8, 180. [CrossRef]

131. Lindemann, A.; Lüdtke-Buzug, K.; Fräderich, B.M.; Gräfe, K.; Pries, R.; Wollenberg, B. Biological Impact of Superparamagnetic Iron Oxide Nanoparticles for Magnetic Particle Imaging of Head and Neck Cancer Cells. Int. J. Nanomed. 2014, 9, 5025-5040. [CrossRef]

132. You, D.G.; Saravanakumar, G.; Son, S.; Han, H.S.; Heo, R.; Kim, K.; Kwon, I.C.; Lee, J.Y.; Park, J.H. Dextran Sulfate-Coated Superparamagnetic Iron Oxide Nanoparticles as a Contrast Agent for Atherosclerosis Imaging. Carbohydr. Polym. 2014, 101, 1225-1233. [CrossRef] [PubMed]

133. Lind, K.; Kresse, M.; Debus, N.P.; Müller, R.H. A Novel Formulation for Superparamagnetic Iron Oxide (SPIO) Particles Enhancing MR Lymphography: Comparison of Physicochemical Properties and the In Vivo Behaviour. J. Drug Target. 2002, 10, 221-230. [CrossRef]

134. Abdollah, M.R.A.; Carter, T.J.; Jones, C.; Kalber, T.L.; Rajkumar, V.; Tolner, B.; Gruettner, C.; Zaw-Thin, M.; Baguña Torres, J.; Ellis, M.; et al. Fucoidan Prolongs the Circulation Time of Dextran-Coated Iron Oxide Nanoparticles. ACS Nano 2018, 12, 1156-1169. [CrossRef]

135. Wan, X.; Song, Y.; Song, N.; Li, J.; Yang, L.; Li, Y.; Tan, H. The Preliminary Study of Immune Superparamagnetic Iron Oxide Nanoparticles for the Detection of Lung Cancer in Magnetic Resonance Imaging. Carbohydr. Res. 2016, 419, 33-40. [CrossRef] [PubMed]

136. Zheng, S.; Huang, M.; Hong, R.; Deng, S.; Cheng, L.; Gao, B.; Badami, D. RGD-Conjugated Iron Oxide Magnetic Nanoparticles for Magnetic Resonance Imaging Contrast Enhancement and Hyperthermia. J. Biomater. Appl. 2014, 28, 1051-1059. [CrossRef]

137. Misri, R.; Meier, D.; Yung, A.C.; Kozlowski, P.; Häfeli, U.O. Development and Evaluation of a Dual-Modality (MRI/SPECT) Molecular Imaging Bioprobe. Nanomed. Nanotechnol. Biol. Med. 2012, 8, 1007-1016. [CrossRef] [PubMed]

138. Boros, E.; Bowen, A.M.; Josephson, L.; Vasdev, N.; Holland, J.P. Chelate-Free Metal Ion Binding and Heat-Induced Radiolabeling of Iron Oxide Nanoparticles. Chem. Sci. 2015, 6, 225-236. [CrossRef] 
139. Jang, E.S.; Lee, S.Y.; Cha, E.-J.; Sun, I.-C.; Kwon, I.C.; Kim, D.; Kim, Y.I.; Kim, K.; Ahn, C.-H. Fluorescent Dye Labeled Iron Oxide/Silica Core/Shell Nanoparticle as a Multimodal Imaging Probe. Pharm. Res. 2014, 31, 3371-3378. [CrossRef]

140. Yuan, H.; Wilks, M.Q.; Normandin, M.D.; El Fakhri, G.; Kaittanis, C.; Josephson, L. Heat-Induced Radiolabeling and Fluorescence Labeling of Feraheme Nanoparticles for PET/SPECT Imaging and Flow Cytometry. Nat. Protoc. 2018, 13, 392-412. [CrossRef]

141. Suzuki, M.; Bachelet-Violette, L.; Rouzet, F.; Beilvert, A.; Autret, G.; Maire, M.; Menager, C.; Louedec, L.; Choqueux, C.; Saboural, P.; et al. Ultrasmall Superparamagnetic Iron Oxide Nanoparticles Coated with Fucoidan for Molecular MRI of Intraluminal Thrombus. Nanomedicine 2015, 10, 73-87. [CrossRef] [PubMed]

142. Erdal, E.; Demirbilek, M.; Yeh, Y.; Akbal, Ö.; Ruff, L.; Bozkurt, D.; Cabuk, A.; Senel, Y.; Gumuskaya, B.; Algin, O.; et al. A Comparative Study of Receptor-Targeted Magnetosome and HSA-Coated Iron Oxide Nanoparticles as MRI Contrast-Enhancing Agent in Animal Cancer Model. Appl. Biochem. Biotechnol. 2018, 185, 91-113. [CrossRef]

143. Bar-Shir, A.; Avram, L.; Yariv-Shoushan, S.; Anaby, D.; Cohen, S.; Segev-Amzaleg, N.; Frenkel, D.; Sadan, O.; Offen, D.; Cohen, Y. Alginate-Coated Magnetic Nanoparticles for Noninvasive MRI of Extracellular Calcium. NMR Biomed. 2014, $27,774-783$. [CrossRef]

144. Hobson, N.J.; Weng, X.; Siow, B.; Veiga, C.; Ashford, M.; Thanh, N.T.; Schätzlein, A.G.; Uchegbu, I.F. Clustering Superparamagnetic Iron Oxide Nanoparticles Produces Organ-Targeted High-Contrast Magnetic Resonance Images. Nanomedicine 2019, 14, 1135-1152. [CrossRef]

145. Xie, M.; Liu, S.; Butch, C.J.; Liu, S.; Wang, Z.; Wang, J.; Zhang, X.; Nie, S.; Lu, Q.; Wang, Y. Succinylated Heparin Monolayer Coating Vastly Increases Superparamagnetic Iron Oxide Nanoparticle $T_{2}$ Proton Relaxivity. Nanoscale 2019, 11, 12905-12914. [CrossRef]

146. Su, H.; Liu, Y.; Wang, D.; Wu, C.; Xia, C.; Gong, Q.; Song, B.; Ai, H. Amphiphilic Starlike Dextran Wrapped Superparamagnetic Iron Oxide Nanoparticle Clusters as Effective Magnetic Resonance Imaging Probes. Biomaterials 2013, 34, 1193-1203. [CrossRef]

147. Lee, P.-W.; Hsu, S.-H.; Wang, J.-J.; Tsai, J.-S.; Lin, K.-J.; Wey, S.-P.; Chen, F.-R.; Lai, C.-H.; Yen, T.-C.; Sung, H.-W. The Characteristics, Biodistribution, Magnetic Resonance Imaging and Biodegradability of Superparamagnetic Core-Shell Nanoparticles. Biomaterials 2010, 31, 1316-1324. [CrossRef] [PubMed]

148. Lachowicz, D.; Szpak, A.; Malek-Zietek, K.E.; Kepczynski, M.; Muller, R.N.; Laurent, S.; Nowakowska, M.; Zapotoczny, S. Biocompatible and Fluorescent Superparamagnetic Iron Oxide Nanoparticles with Superior Magnetic Properties Coated with Charged Polysaccharide Derivatives. Colloids Surf. B Biointerfaces 2017, 150, 402-407. [CrossRef]

149. Yan, L.; Luo, L.; Amirshaghaghi, A.; Miller, J.; Meng, C.; You, T.; Busch, T.M.; Tsourkas, A.; Cheng, Z. Dextran-Benzoporphyrin Derivative (BPD) Coated Superparamagnetic Iron Oxide Nanoparticle (SPION) Micelles for T2-Weighted Magnetic Resonance Imaging and Photodynamic Therapy. Bioconjug. Chem. 2019, 30, 2974-2981. [CrossRef] [PubMed]

150. Kumar, K.; Nightingale, A.M.; Krishnadasan, S.H.; Kamaly, N.; Wylenzinska-Arridge, M.; Zeissler, K.; Branford, W.R.; Ware, E.; deMello, A.J.; deMello, J.C. Direct Synthesis of Dextran-Coated Superparamagnetic Iron Oxide Nanoparticles in a Capillary-Based Droplet Reactor. J. Mater. Chem. 2012, 22, 4704. [CrossRef]

151. Li, H.; Yin, Y.; Xiang, Y.; Liu, H.; Guo, R. A Novel 3D Printing PCL/GelMA Scaffold Containing USPIO for MRI-Guided Bile Duct Repair. Biomed. Mater. 2020, 15, 045004. [CrossRef] [PubMed]

152. Dash, M.; Chiellini, F.; Ottenbrite, R.M.; Chiellini, E. Chitosan-A Versatile Semi-Synthetic Polymer in Biomedical Applications. Prog. Polym. Sci. 2011, 36, 981-1014. [CrossRef]

153. Rostami, E. Progresses in Targeted Drug Delivery Systems Using Chitosan Nanoparticles in Cancer Therapy: A Mini-Review. J. Drug Deliv. Sci. Technol. 2020, 58, 101813. [CrossRef]

154. Agrawal, P.; Strijkers, G.J.; Nicolay, K. Chitosan-Based Systems for Molecular Imaging. Adv. Drug Deliv. Rev. 2010, 62, 42-58. [CrossRef]

155. Anitha, A.; Sowmya, S.; Kumar, P.T.S.; Deepthi, S.; Chennazhi, K.P.; Ehrlich, H.; Tsurkan, M.; Jayakumar, R. Chitin and Chitosan in Selected Biomedical Applications. Prog. Polym. Sci. 2014, 39, 1644-1667. [CrossRef]

156. Balan, V.; Malihin, S.; Verestiuc, L. Chitosan-Based Systems for Theranostic Applications. In Functional Chitosan; Jana, S., Jana, S., Eds.; Springer: Singapore, 2019; pp. 343-384. ISBN 978-981-150-262-0.

157. Mohammed, L.; Gomaa, H.G.; Ragab, D.; Zhu, J. Magnetic Nanoparticles for Environmental and Biomedical Applications: A Review. Particuology 2017, 30, 1-14. [CrossRef]

158. Hemalatha, T.; Prabu, P.; Gunadharini, D.N.; Gowthaman, M.K. Fabrication and Characterization of Dual Acting Oleyl Chitosan Functionalised Iron Oxide/Gold Hybrid Nanoparticles for MRI and CT Imaging. Int. J. Biol. Macromol. 2018, 112, $250-257$. [CrossRef]

159. Estelrich, J.; Sánchez-Martín, M.J.; Busquets, M.A. Nanoparticles in Magnetic Resonance Imaging: From Simple to Dual Contrast Agents. Int. J. Nanomed. 2015, 10, 1727-1741. [CrossRef]

160. Sun, J.-Z.; Sun, Y.-C.; Sun, L. Synthesis of Surface Modified $\mathrm{Fe}_{3} \mathrm{O}_{4}$ Super Paramagnetic Nanoparticles for Ultrasound Examination and Magnetic Resonance Imaging for Cancer Treatment. J. Photochem. Photobiol. B Biol. 2019, 197, 111547. [CrossRef]

161. Chung, I.J.; Jeon, S.I.; Cha, E.-J.; Byun, Y.; Kwon, I.C.; Kim, Y.I.; Kim, K.; Ahn, C.-H. Activatable NIRF/MRI Dual Imaging Probe Using Bio-Inspired Coating of Glycol Chitosan on Superparamagnetic Iron Oxide Nanoparticles. J. Ind. Eng. Chem. 2019, 76, 403-409. [CrossRef]

162. Molday, R.S.; MacKenzie, D. Immunospecific Ferromagnetic Iron-Dextran Reagents for the Labeling and Magnetic Separation of Cells. J. Immunol. Methods 1982, 52, 353-367. [CrossRef] 
163. Magin, R.L.; Bacic, G.; Niesman, M.R.; Alameda, J.C.; Wright, S.M.; Swartz, H.M. Dextran Magnetite as a Liver Contrast Agent. Magn. Reson. Med. 1991, 20,1-16. [CrossRef]

164. Wabler, M.; Zhu, W.; Hedayati, M.; Attaluri, A.; Zhou, H.; Mihalic, J.; Geyh, A.; DeWeese, T.L.; Ivkov, R.; Artemov, D. Magnetic Resonance Imaging Contrast of Iron Oxide Nanoparticles Developed for Hyperthermia Is Dominated by Iron Content. Int. J. Hyperth. 2014, 30, 192-200. [CrossRef] [PubMed]

165. Gleich, B.; Weizenecker, J. Tomographic Imaging Using the Nonlinear Response of Magnetic Particles. Nature 2005, 435, 1214-1217. [CrossRef] [PubMed]

166. Kim, S.J.; Lewis, B.; Steiner, M.-S.; Bissa, U.V.; Dose, C.; Frank, J.A. Superparamagnetic Iron Oxide Nanoparticles for Direct Labeling of Stem Cells and In Vivo MRI Tracking. Contrast Media Mol. Imaging 2016, 11, 55-64. [CrossRef] [PubMed]

167. Sonoda, A.; Nitta, N.; Tsuchiya, K.; Nitta-Seko, A.; Ohta, S.; Otani, H.; Murata, K. A Novel Blood-Pooling MR Contrast Agent: Carboxymethyl-Diethylaminoethyl Dextran Magnetite. Mol. Med. Rep. 2016, 14, 5195-5198. [CrossRef] [PubMed]

168. Sharkey, J.; Starkey Lewis, P.J.; Barrow, M.; Alwahsh, S.M.; Noble, J.; Livingstone, E.; Lennen, R.J.; Jansen, M.A.; Carrion, J.G.; Liptrott, N.; et al. Functionalized Superparamagnetic Iron Oxide Nanoparticles Provide Highly Efficient Iron-Labeling in Macrophages for Magnetic Resonance-Based Detection In Vivo. Cytotherapy 2017, 19, 555-569. [CrossRef]

169. Das Merces, A.A.D.; Ferreira, R.d.S.; Silva, K.J.S.; Salu, B.R.; Maciel, J.d.C.; Aguiar, J.A.O.; Tashima, A.K.; Oliva, M.L.V.; de Carvalho, L.B., Jr. Identification of Blood Plasma Proteins Using Heparin-Coated Magnetic Chitosan Particles. Carbohydr. Polym. 2020, 247, 116671. [CrossRef] [PubMed]

170. Shin, T.-H.; Choi, Y.; Kim, S.; Cheon, J. Recent Advances in Magnetic Nanoparticle-Based Multi-Modal Imaging. Chem. Soc. Rev. 2015, 44, 4501-4516. [CrossRef]

171. Severino, P.; da Silva, C.F.; Andrade, L.N.; de Lima Oliveira, D.; Campos, J.; Souto, E.B. Alginate Nanoparticles for Drug Delivery and Targeting. Curr. Pharm. Des. 2019, 25, 1312-1334. [CrossRef]

172. Joglekar, M.; Trewyn, B.G. Polymer-Based Stimuli-Responsive Nanosystems for Biomedical Applications. Biotechnol. J. 2013, 8, 931-945. [CrossRef]

173. Mojica Pisciotti, M.L.; Lima, E.; Vasquez Mansilla, M.; Tognoli, V.E.; Troiani, H.E.; Pasa, A.A.; Creczynski-Pasa, T.B.; Silva, A.H.; Gurman, P.; Colombo, L.; et al. In Vitro and in Vivo Experiments with Iron Oxide Nanoparticles Functionalized with DEXTRAN or Polyethylene Glycol for Medical Applications: Magnetic Targeting. J. Biomed. Mater. Res. B Appl. Biomater. 2014, 102, 860-868. [CrossRef]

174. Gao, Z.; Hou, Y.; Zeng, J.; Chen, L.; Liu, C.; Yang, W.; Gao, M. Tumor Microenvironment-Triggered Aggregation of Antiphagocytosis ${ }^{99 \mathrm{~m}} \mathrm{Tc}-$ Labeled $\mathrm{Fe}_{3} \mathrm{O}_{4}$ Nanoprobes for Enhanced Tumor Imaging In Vivo. Adv. Mater. 2017, 29, 1701095. [CrossRef]

175. Wang, Q.; Xiao, A.; Liu, Y.; Zou, Q.; Zhou, Q.; Wang, H.; Yang, X.; Zheng, C.; Yang, Y.; Zhu, Y. One-Step Preparation of Nano-in-Micro Poly(Vinyl Alcohol) Embolic Microspheres and Used for Dual-Modal T1/T2-Weighted Magnetic Resonance Imaging. Nanomedicine 2018, 14, 2551-2561. [CrossRef]

176. Llop, J.; Jiang, P.; Marradi, M.; Gómez-Vallejo, V.; Echeverría, M.; Yu, S.; Puigivila, M.; Baz, Z.; Szczupak, B.; Pérez-Campaña, C.; et al. Visualisation of Dual Radiolabelled Poly(Lactide-Co-Glycolide) Nanoparticle Degradation In Vivo Using EnergyDiscriminant SPECT. J. Mater. Chem. B 2015, 3, 6293-6300. [CrossRef]

177. Thong-On, B.; Rutnakornpituk, M. Controlled Magnetite Nanoclustering in the Presence of Glycidyl-Functionalized ThermoResponsive Poly(N-Isopropylacrylamide). Eur. Polym. J. 2016, 85, 519-531. [CrossRef]

178. Thapa, B.; Diaz-Diestra, D.; Beltran-Huarac, J.; Weiner, B.R.; Morell, G. Enhanced MRI T 2 Relaxivity in Contrast-Probed Anchor-Free PEGylated Iron Oxide Nanoparticles. Nanoscale Res. Lett. 2017, 12, 312. [CrossRef]

179. Liu, D.; Wu, W.; Ling, J.; Wen, S.; Gu, N.; Zhang, X. Effective PEGylation of Iron Oxide Nanoparticles for High Performance In Vivo Cancer Imaging. Adv. Funct. Mater. 2011, 21, 1498-1504. [CrossRef]

180. Zeng, J.; Jia, B.; Qiao, R.; Wang, C.; Jing, L.; Wang, F.; Gao, M. In Situ ${ }^{111}$ In-Doping for Achieving Biocompatible and Non-Leachable 111In-Labeled Fe3O4 Nanoparticles. Chem. Commun. 2014, 50, 2170-2172. [CrossRef]

181. Feng, B.; Hong, R.Y.; Wang, L.S.; Guo, L.; Li, H.Z.; Ding, J.; Zheng, Y.; Wei, D.G. Synthesis of Fe3O4/APTES/PEG Diacid Functionalized Magnetic Nanoparticles for MR Imaging. Colloids Surf. A Physicochem. Eng. Asp. 2008, 328, 52-59. [CrossRef]

182. Xiong, F.; Hu, K.; Yu, H.; Zhou, L.; Song, L.; Zhang, Y.; Shan, X.; Liu, J.; Gu, N. A Functional Iron Oxide Nanoparticles Modified with PLA-PEG-DG as Tumor-Targeted MRI Contrast Agent. Pharm. Res. 2017, 34, 1683-1692. [CrossRef] [PubMed]

183. Yang, H.; Zhuang, Y.; Sun, Y.; Dai, A.; Shi, X.; Wu, D.; Li, F.; Hu, H.; Yang, S. Targeted Dual-Contrast T1- and T2-Weighted Magnetic Resonance Imaging of Tumors Using Multifunctional Gadolinium-Labeled Superparamagnetic Iron Oxide Nanoparticles. Biomaterials 2011, 32, 4584-4593. [CrossRef] [PubMed]

184. Yazdani, F.; Fattahi, B.; Azizi, N. Synthesis of Functionalized Magnetite Nanoparticles to Use as Liver Targeting MRI Contrast Agent. J. Magn. Magn. Mater. 2016, 406, 207-211. [CrossRef]

185. Ledda, M.; Fioretti, D.; Lolli, M.G.; Papi, M.; Di Gioia, C.; Carletti, R.; Ciasca, G.; Foglia, S.; Palmieri, V.; Marchese, R.; et al Biocompatibility Assessment of Sub-5 Nm Silica-Coated Superparamagnetic Iron Oxide Nanoparticles in Human Stem Cells and in Mice for Potential Application in Nanomedicine. Nanoscale 2020, 12, 1759-1778. [CrossRef] [PubMed]

186. Sharma, R.; Xu, Y.; Kim, S.W.; Schueller, M.J.; Alexoff, D.; Smith, S.D.; Wang, W.; Schlyer, D. Carbon-11 Radiolabeling of Iron-Oxide Nanoparticles for Dual-Modality PET/MR Imaging. Nanoscale 2013, 5, 7476. [CrossRef]

187. Hurley, K.R.; Lin, Y.-S.; Zhang, J.; Egger, S.M.; Haynes, C.L. Effects of Mesoporous Silica Coating and Post-Synthetic Treatment on the Transverse Relaxivity of Iron Oxide Nanoparticles. Chem. Mater. 2013, 25, 1968-1978. [CrossRef] 
188. Tsiapa, I.; Efthimiadou, E.K.; Fragogeorgi, E.; Loudos, G.; Varvarigou, A.D.; Bouziotis, P.; Kordas, G.C.; Mihailidis, D.; Nikiforidis, G.C.; Xanthopoulos, S.; et al. (99m)Tc-Labeled Aminosilane-Coated Iron Oxide Nanoparticles for Molecular Imaging of Av $\beta 3$ Mediated Tumor Expression and Feasibility for Hyperthermia Treatment. J. Colloid Interface Sci. 2014, 433, 163-175. [CrossRef]

189. King, A.M.; Bray, C.; Hall, S.C.L.; Bear, J.C.; Bogart, L.K.; Perrier, S.; Davies, G.-L. Exploring Precision Polymers to Fine-Tune Magnetic Resonance Imaging Properties of Iron Oxide Nanoparticles. J. Colloid Interface Sci. 2020, 579, 401-411. [CrossRef] [PubMed]

190. Lee, J.E.; Lee, N.; Kim, H.; Kim, J.; Choi, S.H.; Kim, J.H.; Kim, T.; Song, I.C.; Park, S.P.; Moon, W.K.; et al. Uniform Mesoporous DyeDoped Silica Nanoparticles Decorated with Multiple Magnetite Nanocrystals for Simultaneous Enhanced Magnetic Resonance Imaging, Fluorescence Imaging, and Drug Delivery. J. Am. Chem. Soc. 2010, 132, 552-557. [CrossRef]

191. Lee, D.Y.; Kang, S.; Lee, Y.; Kim, J.Y.; Yoo, D.; Jung, W.; Lee, S.; Jeong, Y.Y.; Lee, K.; Jon, S. PEGylated Bilirubin-Coated Iron Oxide Nanoparticles as a Biosensor for Magnetic Relaxation Switching-Based ROS Detection in Whole Blood. Theranostics 2020, 10, 1997-2007. [CrossRef]

192. Yue-Jian, C.; Juan, T.; Fei, X.; Jia-Bi, Z.; Ning, G.; Yi-Hua, Z.; Ye, D.; Liang, G. Synthesis, Self-Assembly, and Characterization of PEG-Coated Iron Oxide Nanoparticles as Potential MRI Contrast Agent. Drug Dev. Ind. Pharm. 2010, 36, 1235-1244. [CrossRef]

193. Cheng, D.; Li, X.; Zhang, C.; Tan, H.; Wang, C.; Pang, L.; Shi, H. Detection of Vulnerable Atherosclerosis Plaques with a DualModal Single-Photon-Emission Computed Tomography/Magnetic Resonance Imaging Probe Targeting Apoptotic Macrophages. ACS Appl. Mater. Interfaces 2015, 7, 2847-2855. [CrossRef]

194. Park, J.C.; Yu, M.K.; An, G.I.; Park, S.-I.; Oh, J.; Kim, H.J.; Kim, J.-H.; Wang, E.K.; Hong, I.-H.; Ha, Y.S.; et al. Facile Preparation of a Hybrid Nanoprobe for Triple-Modality Optical/PET/MR Imaging. Small 2010, 6, 2863-2868. [CrossRef]

195. Madru, R.; Tran, T.A.; Axelsson, J.; Ingvar, C.; Bibic, A.; Ståhlberg, F.; Knutsson, L.; Strand, S.-E. (68)Ga-Labeled Superparamagnetic Iron Oxide Nanoparticles (SPIONs) for Multi-Modality PET/MR/Cherenkov Luminescence Imaging of Sentinel Lymph Nodes. Am. J. Nucl. Med. Mol. Imaging 2013, 4, 60-69.

196. Yang, X.; Hong, H.; Grailer, J.J.; Rowland, I.J.; Javadi, A.; Hurley, S.A.; Xiao, Y.; Yang, Y.; Zhang, Y.; Nickles, R.J.; et al. CRGDFunctionalized, DOX-Conjugated, and 64Cu-Labeled Superparamagnetic Iron Oxide Nanoparticles for Targeted Anticancer Drug Delivery and PET/MR Imaging. Biomaterials 2011, 32, 4151-4160. [CrossRef]

197. Chen, F.; Ellison, P.A.; Lewis, C.M.; Hong, H.; Zhang, Y.; Shi, S.; Hernandez, R.; Meyerand, M.E.; Barnhart, T.E.; Cai, W. Chelator-Free Synthesis of a Dual-Modality PET/MRI Agent. Angew. Chem. Int. Ed. 2013, 52, 13319-13323. [CrossRef] [PubMed]

198. Tromsdorf, U.I.; Bruns, O.T.; Salmen, S.C.; Beisiegel, U.; Weller, H. A Highly Effective, Nontoxic T1 MR Contrast Agent Based on Ultrasmall PEGylated Iron Oxide Nanoparticles. Nano Lett. 2009, 9, 4434-4440. [CrossRef]

199. Lu, C.; Dong, P.; Pi, L.; Wang, Z.; Yuan, H.; Liang, H.; Ma, D.; Chai, K.Y. Hydroxyl-PEG-Phosphonic Acid-Stabilized Superparamagnetic Manganese Oxide-Doped Iron Oxide Nanoparticles with Synergistic Effects for Dual-Mode MR Imaging. Langmuir 2019, 35, 9474-9482. [CrossRef]

200. Kim, S.; Chae, M.K.; Yim, M.S.; Jeong, I.H.; Cho, J.; Lee, C.; Ryu, E.K. Hybrid PET/MR Imaging of Tumors Using an Oleanolic Acid-Conjugated Nanoparticle. Biomaterials 2013, 34, 8114-8121. [CrossRef]

201. Iqbal, M.Z.; Ma, X.; Chen, T.; Zhang, L.; Ren, W.; Xiang, L.; Wu, A. Silica-Coated Super-Paramagnetic Iron Oxide Nanoparticles (SPIONPs): A New Type Contrast Agent of $\mathrm{T}_{1}$ Magnetic Resonance Imaging (MRI). J. Mater. Chem. B 2015, 3, 5172-5181. [CrossRef]

202. Joshi, H.M.; De, M.; Richter, F.; He, J.; Prasad, P.V.; Dravid, V.P. Effect of Silica Shell Thickness of Fe3O4-SiOx Core-Shell Nanostructures on MRI Contrast. J. Nanopart. Res. 2013, 15, 1448. [CrossRef]

203. Huang, Y.-K.; Su, C.-H.; Chen, J.-J.; Chang, C.-T.; Tsai, Y.-H.; Syu, S.-F.; Tseng, T.-T.; Yeh, C.-S. Fabrication of Silica-Coated Hollow Carbon Nanospheres Encapsulating Fe3O4 Cluster for Magnetical and MR Imaging Guided NIR Light Triggering Hyperthermia and Ultrasound Imaging. ACS Appl. Mater. Interfaces 2016, 8, 14470-14480. [CrossRef] [PubMed]

204. Ye, F.; Laurent, S.; Fornara, A.; Astolfi, L.; Qin, J.; Roch, A.; Martini, A.; Toprak, M.S.; Muller, R.N.; Muhammed, M. Uniform Mesoporous Silica Coated Iron Oxide Nanoparticles as a Highly Efficient, Nontoxic MRI T(2) Contrast Agent with Tunable Proton Relaxivities. Contrast Media Mol. Imaging 2012, 7, 460-468. [CrossRef]

205. Peng, Y.-K.; Lui, C.N.P.; Lin, T.-H.; Chang, C.; Chou, P.-T.; Yung, K.K.L.; Tsang, S.C.E. Multifunctional Silica-Coated Iron Oxide Nanoparticles: A Facile Four-in-One System for In Situ Study of Neural Stem Cell Harvesting. Faraday Discuss. 2014, 175, 13-26. [CrossRef]

206. Thomas, G.; Boudon, J.; Maurizi, L.; Moreau, M.; Walker, P.; Severin, I.; Oudot, A.; Goze, C.; Poty, S.; Vrigneaud, J.-M.; et al. Innovative Magnetic Nanoparticles for PET/MRI Bimodal Imaging. ACS Omega 2019, 4, 2637-2648. [CrossRef]

207. Ruiz-de-Angulo, A.; Zabaleta, A.; Gómez-Vallejo, V.; Llop, J.; Mareque-Rivas, J.C. Microdosed Lipid-Coated (67)Ga-Magnetite Enhances Antigen-Specific Immunity by Image Tracked Delivery of Antigen and CpG to Lymph Nodes. ACS Nano 2016, 10, 1602-1618. [CrossRef]

208. Li, J.; Zheng, L.; Cai, H.; Sun, W.; Shen, M.; Zhang, G.; Shi, X. Polyethyleneimine-Mediated Synthesis of Folic Acid-Targeted Iron Oxide Nanoparticles for In Vivo Tumor MR Imaging. Biomaterials 2013, 34, 8382-8392. [CrossRef] [PubMed]

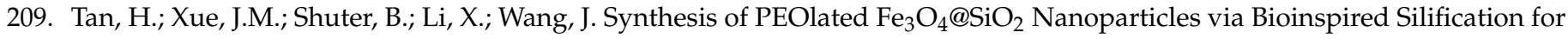
Magnetic Resonance Imaging. Adv. Funct. Mater. 2010, 20, 722-731. [CrossRef] 
210. Navarro-Palomares, E.; González-Saiz, P.; Renero-Lecuna, C.; Martín-Rodríguez, R.; Aguado, F.; González-Alonso, D.; Fernández Barquín, L.; González, J.; Bañobre-López, M.; Fanarraga, M.L.; et al. Dye-Doped Biodegradable Nanoparticle SiO2 Coating on Zinc- and Iron-Oxide Nanoparticles to Improve Biocompatibility and for in Vivo Imaging Studies. Nanoscale 2020, 12, 6164-6175. [CrossRef] [PubMed]

211. Das, R.K.; Pramanik, A.; Majhi, M.; Mohapatra, S. Magnetic Mesoporous Silica Gated with Doped Carbon Dot for Site-Specific Drug Delivery, Fluorescence, and MR Imaging. Langmuir 2018, 34, 5253-5262. [CrossRef]

212. Beg, M.S.; Mohapatra, J.; Pradhan, L.; Patkar, D.; Bahadur, D. Porous Fe3O4-SiO2 Core-Shell Nanorods as High-Performance MRI Contrast Agent and Drug Delivery Vehicle. J. Magn. Magn. Mater. 2017, 428, 340-347. [CrossRef]

213. Yallapu, M.M.; Foy, S.P.; Jain, T.K.; Labhasetwar, V. PEG-Functionalized Magnetic Nanoparticles for Drug Delivery and Magnetic Resonance Imaging Applications. Pharm. Res. 2010, 27, 2283-2295. [CrossRef]

214. Li, J.; Hu, Y.; Yang, J.; Sun, W.; Cai, H.; Wei, P.; Sun, Y.; Zhang, G.; Shi, X.; Shen, M. Facile Synthesis of Folic Acid-Functionalized Iron Oxide Nanoparticles with Ultrahigh Relaxivity for Targeted Tumor MR Imaging. J. Mater. Chem. B 2015, 3, 5720-5730. [CrossRef] [PubMed]

215. Hu, F.; MacRenaris, K.W.; Waters, E.A.; Liang, T.; Schultz-Sikma, E.A.; Eckermann, A.L.; Meade, T.J. Ultrasmall, Water-Soluble Magnetite Nanoparticles with High Relaxivity for Magnetic Resonance Imaging. J. Phys. Chem. C Nanomater. Interfaces 2009, 113, 20855-20860. [CrossRef]

216. Xiao, N.; Gu, W.; Wang, H.; Deng, Y.; Shi, X.; Ye, L. T1-T2 Dual-Modal MRI of Brain Gliomas Using PEGylated Gd-Doped Iron Oxide Nanoparticles. J. Colloid Interface Sci. 2014, 417, 159-165. [CrossRef] [PubMed]

217. Malinge, J.; Géraudie, B.; Savel, P.; Nataf, V.; Prignon, A.; Provost, C.; Zhang, Y.; Ou, P.; Kerrou, K.; Talbot, J.-N.; et al. Liposomes for PET and MR Imaging and for Dual Targeting (Magnetic Field/Glucose Moiety): Synthesis, Properties, and In Vivo Studies. Mol. Pharm. 2017, 14, 406-414. [CrossRef] [PubMed]

218. Pinho, S.L.C.; Pereira, G.A.; Voisin, P.; Kassem, J.; Bouchaud, V.; Etienne, L.; Peters, J.A.; Carlos, L.; Mornet, S.; Geraldes, C.F.G.C.; et al. Fine Tuning of the Relaxometry of $\gamma-\mathrm{Fe}_{2} \mathrm{O}_{3} @ \mathrm{SiO}_{2}$ Nanoparticles by Tweaking the Silica Coating Thickness. ACS Nano 2010, 4, 5339-5349. [CrossRef]

219. Ji, X.; Shao, R.; Elliott, A.M.; Stafford, R.J.; Esparza-Coss, E.; Bankson, J.A.; Liang, G.; Luo, Z.-P.; Park, K.; Markert, J.T.; et al. Bifunctional Gold Nanoshells with a Superparamagnetic Iron Oxide-Silica Core Suitable for Both MR Imaging and Photothermal Therapy. J. Phys. Chem. C Nanomater. Interfaces 2007, 111, 6245-6251. [CrossRef]

220. Lee, H.-Y.; Li, Z.; Chen, K.; Hsu, A.R.; Xu, C.; Xie, J.; Sun, S.; Chen, X. PET/MRI Dual-Modality Tumor Imaging Using ArginineGlycine-Aspartic (RGD)-Conjugated Radiolabeled Iron Oxide Nanoparticles. J. Nucl. Med. 2008, 49, 1371-1379. [CrossRef]

221. Karahaliloglu, Z.; Kilicay, E.; Hazer, B. PLinaS-g-PEG Coated Magnetic Nanoparticles as a Contrast Agent for Hepatocellular Carcinoma Diagnosis. J. Biomater. Sci. Polym. Ed. 2020, 31, 1580-1603. [CrossRef]

222. Gómez-Vallejo, V.; Puigivila, M.; Plaza-García, S.; Szczupak, B.; Piñol, R.; Murillo, J.L.; Sorribas, V.; Lou, G.; Veintemillas, S.; Ramos-Cabrer, P.; et al. PEG-Copolymer-Coated Iron Oxide Nanoparticles That Avoid the Reticuloendothelial System and Act as Kidney MRI Contrast Agents. Nanoscale 2018, 10, 14153-14164. [CrossRef]

223. Yan, F.; Xu, H.; Anker, J.; Kopelman, R.; Ross, B.; Rehemtulla, A.; Reddy, R. Synthesis and Characterization of Silica-Embedded Iron Oxide Nanoparticles for Magnetic Resonance Imaging. J. Nanosci. Nanotechnol. 2004, 4, 72-76. [CrossRef] [PubMed]

224. Burke, B.P.; Baghdadi, N.; Clemente, G.S.; Camus, N.; Guillou, A.; Kownacka, A.E.; Domarkas, J.; Halime, Z.; Tripier, R.; Archibald S.J. Final Step Gallium-68 Radiolabelling of Silica-Coated Iron Oxide Nanorods as Potential PET/MR Multimodal Imaging Agents. Faraday Discuss. 2014, 175, 59-71. [CrossRef]

225. Burke, B.P.; Baghdadi, N.; Kownacka, A.E.; Nigam, S.; Clemente, G.S.; Al-Yassiry, M.M.; Domarkas, J.; Lorch, M.; Pickles, M.; Gibbs, P.; et al. Chelator Free Gallium-68 Radiolabelling of Silica Coated Iron Oxide Nanorods via Surface Interactions. Nanoscale 2015, 7, 14889-14896. [CrossRef]

226. Abushrida, A.; Elhuni, I.; Taresco, V.; Marciani, L.; Stolnik, S.; Garnett, M.C. A Simple and Efficient Method for Polymer Coating of Iron Oxide Nanoparticles. J. Drug Deliv. Sci. Technol. 2020, 55, 101460. [CrossRef]

227. Lu, Y.; Xu, Y.-J.; Zhang, G.-B.; Ling, D.; Wang, M.-Q.; Zhou, Y.; Wu, Y.-D.; Wu, T.; Hackett, M.J.; Hyo Kim, B.; et al. Iron Oxide Nanoclusters for T1 Magnetic Resonance Imaging of Non-Human Primates. Nat. Biomed. Eng. 2017, 1, 637-643. [CrossRef]

228. Xiao, S.; Yu, X.; Zhang, L.; Zhang, Y.; Fan, W.; Sun, T.; Zhou, C.; Liu, Y.; Liu, Y.; Gong, M.; et al. Synthesis Of PEG-Coated, Ultrasmall, Manganese-Doped Iron Oxide Nanoparticles with High Relaxivity For $\mathrm{T}_{1} / \mathrm{T}_{2}$ Dual-Contrast Magnetic Resonance Imaging. Int. J. Nanomed. 2019, 14, 8499-8507. [CrossRef]

229. Liu, T.; Shi, S.; Liang, C.; Shen, S.; Cheng, L.; Wang, C.; Song, X.; Goel, S.; Barnhart, T.E.; Cai, W.; et al. Iron Oxide Decorated MoS2 Nanosheets with Double PEGylation for Chelator-Free Radiolabeling and Multimodal Imaging Guided Photothermal Therapy. ACS Nano 2015, 9, 950-960. [CrossRef]

230. Calcagno, V.; Vecchione, R.; Quagliariello, V.; Marzola, P.; Busato, A.; Giustetto, P.; Profeta, M.; Gargiulo, S.; Cicco, C.D.; Yu, H.; et al. Oil Core-PEG Shell Nanocarriers for In Vivo MRI Imaging. Adv. Healthc. Mater. 2019, 8, 1801313. [CrossRef]

231. Arami, H.; Krishnan, K.M. Highly Stable Amine Functionalized Iron Oxide Nanoparticles Designed for Magnetic Particle Imaging (MPI). IEEE Trans. Magn. 2013, 49, 3500-3503. [CrossRef]

232. Wu, M.; Li, X.; Guo, Q.; Li, J.; Xu, G.; Li, G.; Wang, J.; Zhang, X. Magnetic Mesoporous Silica Nanoparticles-Aided Dual MR/NIRF Imaging to Identify Macrophage Enrichment in Atherosclerotic Plaques. Nanomedicine 2020, 32, 102330. [CrossRef] [PubMed] 
233. Lee, H.-Y.; Lee, S.-H.; Xu, C.; Xie, J.; Lee, J.-H.; Wu, B.; Koh, A.L.; Wang, X.; Sinclair, R.; Wang, S.X.; et al. Synthesis and Characterization of PVP-Coated Large Core Iron Oxide Nanoparticles as an MRI Contrast Agent. Nanotechnology 2008, $19,165101$. [CrossRef] [PubMed]

234. Hurley, K.R.; Ring, H.L.; Etheridge, M.; Zhang, J.; Gao, Z.; Shao, Q.; Klein, N.D.; Szlag, V.M.; Chung, C.; Reineke, T.M.; et al. Predictable Heating and Positive MRI Contrast from a Mesoporous Silica-Coated Iron Oxide Nanoparticle. Mol. Pharm. 2016, 13, 2172-2183. [CrossRef]

235. Lazaro-Carrillo, A.; Filice, M.; Guillén, M.J.; Amaro, R.; Viñambres, M.; Tabero, A.; Paredes, K.O.; Villanueva, A.; Calvo, P.; del Puerto Morales, M.; et al. Tailor-Made PEG Coated Iron Oxide Nanoparticles as Contrast Agents for Long Lasting Magnetic Resonance Molecular Imaging of Solid Cancers. Mater. Sci. Eng. C 2020, 107, 110262. [CrossRef] [PubMed]

236. Mykhaylyk, O.; Sobisch, T.; Almstätter, I.; Sanchez-Antequera, Y.; Brandt, S.; Anton, M.; Döblinger, M.; Eberbeck, D.; Settles, M.; Braren, R.; et al. Silica-Iron Oxide Magnetic Nanoparticles Modified for Gene Delivery: A Search for Optimum and Quantitative Criteria. Pharm. Res. 2012, 29, 1344-1365. [CrossRef] [PubMed]

237. Kunzmann, A.; Andersson, B.; Vogt, C.; Feliu, N.; Ye, F.; Gabrielsson, S.; Toprak, M.S.; Buerki-Thurnherr, T.; Laurent, S.; Vahter, M.; et al. Efficient Internalization of Silica-Coated Iron Oxide Nanoparticles of Different Sizes by Primary Human Macrophages and Dendritic Cells. Toxicol. Appl. Pharmacol. 2011, 253, 81-93. [CrossRef] [PubMed]

238. Mathieu, P.; Coppel, Y.; Respaud, M.; Nguyen, Q.T.; Boutry, S.; Laurent, S.; Stanicki, D.; Henoumont, C.; Novio, F.; Lorenzo, J.; et al. Silica Coated Iron/Iron Oxide Nanoparticles as a Nano-Platform for T2 Weighted Magnetic Resonance Imaging. Molecules 2019, 24, 4629. [CrossRef] [PubMed]

239. Yoo, M.-K.; Park, I.-K.; Lim, H.-T.; Lee, S.-J.; Jiang, H.-L.; Kim, Y.-K.; Choi, Y.-J.; Cho, M.-H.; Cho, C.-S. Folate-PEGSuperparamagnetic Iron Oxide Nanoparticles for Lung Cancer Imaging. Acta Biomater. 2012, 8, 3005-3013. [CrossRef] [PubMed]

240. Naseroleslami, M.; Parivar, K.; Khoei, S.; Aboutaleb, N. Magnetic Resonance Imaging of Human-Derived Amniotic Membrane Stem Cells Using PEGylated Superparamagnetic Iron Oxide Nanoparticles. Cell J. 2016, 18, 332-339. [CrossRef]

241. Liu, D.-F.; Qian, C.; An, Y.-L.; Chang, D.; Ju, S.-H.; Teng, G.-J. Magnetic Resonance Imaging of Post-Ischemic Blood-Brain Barrier Damage with PEGylated Iron Oxide Nanoparticles. Nanoscale 2014, 6, 15161-15167. [CrossRef]

242. Yoo, E.; Cheng, H.A.; Nardacci, L.E.; Beaman, D.J.; Drinnan, C.T.; Lee, C.; Fishbein, K.W.; Spencer, R.G.; Fisher, O.Z.; Doiron, A.L. Activatable Interpolymer Complex-Superparamagnetic Iron Oxide Nanoparticles as Magnetic Resonance Contrast Agents Sensitive to Oxidative Stress. Colloids Surf. B Biointerfaces 2017, 158, 578-588. [CrossRef] [PubMed]

243. Wang, H.; Kumar, R.; Nagesha, D.; Duclos, R.I.; Sridhar, S.; Gatley, S.J. Integrity of 111In-Radiolabeled Superparamagnetic Iron Oxide Nanoparticles in the Mouse. Nucl. Med. Biol. 2015, 42, 65-70. [CrossRef]

244. Pöselt, E.; Kloust, H.; Tromsdorf, U.; Janschel, M.; Hahn, C.; Maßlo, C.; Weller, H. Relaxivity Optimization of a PEGylated IronOxide-Based Negative Magnetic Resonance Contrast Agent for $\mathrm{T}_{2}$-Weighted Spin-Echo Imaging. ACS Nano 2012, 6, 1619-1624. [CrossRef]

245. Alwi, R.; Telenkov, S.; Mandelis, A.; Leshuk, T.; Gu, F.; Oladepo, S.; Michaelian, K. Silica-Coated Super Paramagnetic Iron Oxide Nanoparticles (SPION) as Biocompatible Contrast Agent in Biomedical Photoacoustics. Biomed. Opt. Express 2012, 3, $2500-2509$. [CrossRef]

246. Xue, S.; Wang, Y.; Wang, M.; Zhang, L.; Du, X.; Gu, H.; Zhang, C. Iodinated Oil-Loaded, Fluorescent Mesoporous Silica-Coated Iron Oxide Nanoparticles for Magnetic Resonance Imaging/Computed Tomography/Fluorescence Trimodal Imaging. Int. J. Nanomed. 2014, 9, 2527-2538. [CrossRef]

247. Tong, S.; Hou, S.; Zheng, Z.; Zhou, J.; Bao, G. Coating Optimization of Superparamagnetic Iron Oxide Nanoparticles for High $\mathrm{T}_{2}$ Relaxivity. Nano Lett. 2010, 10, 4607-4613. [CrossRef]

248. Hsu, F.-T.; Wei, Z.-H.; Hsuan, Y.C.-Y.; Lin, W.; Su, Y.-C.; Liao, C.-H.; Hsieh, C.-L. MRI Tracking of Polyethylene Glycol-Coated Superparamagnetic Iron Oxide-Labelled Placenta-Derived Mesenchymal Stem Cells toward Glioblastoma Stem-like Cells in a Mouse Model. Artif. Cells Nanomed. Biotechnol. 2018, 46, S448-S459. [CrossRef] [PubMed]

249. Khandhar, A.P.; Keselman, P.; Kemp, S.J.; Ferguson, R.M.; Goodwill, P.W.; Conolly, S.M.; Krishnan, K.M. Evaluation of PEGCoated Iron Oxide Nanoparticles as Blood Pool Tracers for Preclinical Magnetic Particle Imaging. Nanoscale 2017, 9, 1299-1306. [CrossRef] [PubMed]

250. Deng, L.-H.; Jiang, H.; Lu, F.-L.; Wang, H.-W.; Pu, Y.; Wu, C.-Q.; Tang, H.-J.; Xu, Y.; Chen, T.-W.; Zhu, J.; et al. Size and PEG Length-Controlled PEGylated Monocrystalline Superparamagnetic Iron Oxide Nanocomposite for MRI Contrast Agent. Int. J. Nanomed. 2021, 16, 201-211. [CrossRef]

251. Park, Y.C.; Smith, J.B.; Pham, T.; Whitaker, R.D.; Sucato, C.A.; Hamilton, J.A.; Bartolak-Suki, E.; Wong, J.Y. Effect of PEG Molecular Weight on Stability, $\mathrm{T}_{2}$ Contrast, Cytotoxicity, and Cellular Uptake of Superparamagnetic Iron Oxide Nanoparticles (SPIONs). Colloids Surf. B Biointerfaces 2014, 119, 106-114. [CrossRef]

252. Thomas, R.G.; Moon, M.J.; Lee, H.; Sasikala, A.R.K.; Kim, C.S.; Park, I.-K.; Jeong, Y.Y. Hyaluronic Acid Conjugated Superparamagnetic Iron Oxide Nanoparticle for Cancer Diagnosis and Hyperthermia Therapy. Carbohydr. Polym. 2015, 131, 439-446. [CrossRef]

253. Alipour, A.; Soran-Erdem, Z.; Utkur, M.; Sharma, V.K.; Algin, O.; Saritas, E.U.; Demir, H.V. A New Class of Cubic SPIONs as a Dual-Mode T1 and T2 Contrast Agent for MRI. Magn. Reson. Imaging 2018, 49, 16-24. [CrossRef] 
254. Tang, Y.; Zhang, C.; Wang, J.; Lin, X.; Zhang, L.; Yang, Y.; Wang, Y.; Zhang, Z.; Bulte, J.W.M.; Yang, G.-Y. MRI/SPECT/Fluorescent Tri-Modal Probe for Evaluating the Homing and Therapeutic Efficacy of Transplanted Mesenchymal Stem Cells in a Rat Ischemic Stroke Model. Adv. Funct. Mater. 2015, 25, 1024-1034. [CrossRef] [PubMed]

255. Patel, D.; Kell, A.; Simard, B.; Deng, J.; Xiang, B.; Lin, H.-Y.; Gruwel, M.; Tian, G. Cu2+-Labeled, SPION Loaded Porous Silica Nanoparticles for Cell Labeling and Multifunctional Imaging Probes. Biomaterials 2010, 31, 2866-2873. [CrossRef] [PubMed]

256. Liong, M.; Lu, J.; Kovochich, M.; Xia, T.; Ruehm, S.G.; Nel, A.E.; Tamanoi, F.; Zink, J.I. Multifunctional Inorganic Nanoparticles for Imaging, Targeting, and Drug Delivery. ACS Nano 2008, 2, 889-896. [CrossRef]

257. Huang, L.; Ao, L.; Wang, W.; Hu, D.; Sheng, Z.; Su, W. Multifunctional Magnetic Silica Nanotubes for MR Imaging and Targeted Drug Delivery. Chem. Commun. 2015, 51, 3923-3926. [CrossRef]

258. Raschzok, N.; Langer, C.M.; Schmidt, C.; Lerche, K.H.; Billecke, N.; Nehls, K.; Schlüter, N.B.; Leder, A.; Rohn, S.; Mogl, M.T.; et al. Functionalizable Silica-Based Micron-Sized Iron Oxide Particles for Cellular Magnetic Resonance Imaging. Cell Transplant. 2013, 22, 1959-1970. [CrossRef]

259. Dai, L.; Liu, Y.; Wang, Z.; Guo, F.; Shi, D.; Zhang, B. One-Pot Facile Synthesis of PEGylated Superparamagnetic Iron Oxide Nanoparticles for MRI Contrast Enhancement. Mater. Sci. Eng. C Mater. Biol. Appl. 2014, 41, 161-167. [CrossRef] [PubMed]

260. Zhang, C.; Wängler, B.; Morgenstern, B.; Zentgraf, H.; Eisenhut, M.; Untenecker, H.; Krüger, R.; Huss, R.; Seliger, C.; Semmler, W.; et al. Silica- and Alkoxysilane-Coated Ultrasmall Superparamagnetic Iron Oxide Particles: A Promising Tool to Label Cells for Magnetic Resonance Imaging. Langmuir 2007, 23, 1427-1434. [CrossRef]

261. Sandiford, L.; Phinikaridou, A.; Protti, A.; Meszaros, L.K.; Cui, X.; Yan, Y.; Frodsham, G.; Williamson, P.A.; Gaddum, N.; Botnar, R.M.; et al. Bisphosphonate-Anchored PEGylation and Radiolabeling of Superparamagnetic Iron Oxide: Long-Circulating Nanoparticles for In Vivo Multimodal (T1 MRI-SPECT) Imaging. ACS Nano 2013, 7, 500-512. [CrossRef] [PubMed]

262. Belkahla, H.; Antunes, J.C.; Lalatonne, Y.; Sainte Catherine, O.; Illoul, C.; Journé, C.; Jandrot-Perrus, M.; Coradin, T.; Gigoux, V.; Guenin, E.; et al. USPIO-PEG Nanoparticles Functionalized with a Highly Specific Collagen-Binding Peptide: A Step towards MRI Diagnosis of Fibrosis. J. Mater. Chem. B 2020, 8, 5515-5528. [CrossRef] [PubMed]

263. Yang, K.M.; Cho, H.-I.; Choi, H.J.; Piao, Y. Synthesis of Water Well-Dispersed PEGylated Iron Oxide Nanoparticles for MR/Optical Lymph Node Imaging. J. Mater. Chem. B 2014, 2, 3355-3364. [CrossRef]

264. Campbell, J.L.; Arora, J.; Cowell, S.F.; Garg, A.; Eu, P.; Bhargava, S.K.; Bansal, V. Quasi-Cubic Magnetite/Silica Core-Shell Nanoparticles as Enhanced MRI Contrast Agents for Cancer Imaging. PLoS ONE 2011, 6, e21857. [CrossRef]

265. Foglia, S.; Ledda, M.; Fioretti, D.; Iucci, G.; Papi, M.; Capellini, G.; Lolli, M.G.; Grimaldi, S.; Rinaldi, M.; Lisi, A. In Vitro Biocompatibility Study of Sub-5 Nm Silica-Coated Magnetic Iron Oxide Fluorescent Nanoparticles for Potential Biomedical Application. Sci. Rep. 2017, 7, 46513. [CrossRef]

266. Jokerst, J.V.; Lobovkina, T.; Zare, R.N.; Gambhir, S.S. Nanoparticle PEGylation for Imaging and Therapy. Nanomedicine 2011, 6, 715-728. [CrossRef]

267. Kozma, G.T.; Shimizu, T.; Ishida, T.; Szebeni, J. Anti-PEG Antibodies: Properties, Formation, Testing and Role in Adverse Immune Reactions to PEGylated Nano-Biopharmaceuticals. Adv. Drug Deliv. Rev. 2020, 154-155, 163-175. [CrossRef]

268. Park, J.Y.; Daksha, P.; Lee, G.H.; Woo, S.; Chang, Y. Highly Water-Dispersible PEG Surface Modified Ultra Small Superparamagnetic Iron Oxide Nanoparticles Useful for Target-Specific Biomedical Applications. Nanotechnology 2008, 19, 365603. [CrossRef]

269. Loudos, G.; Kagadis, G.C.; Psimadas, D. Current Status and Future Perspectives of in Vivo Small Animal Imaging Using Radiolabeled Nanoparticles. Eur. J. Radiol. 2011, 78, 287-295. [CrossRef] [PubMed]

270. Fernández-Barahona, I.; Muñoz-Hernando, M.; Ruiz-Cabello, J.; Herranz, F.; Pellico, J. Iron Oxide Nanoparticles: An Alternative for Positive Contrast in Magnetic Resonance Imaging. Inorganics 2020, 8, 28. [CrossRef]

271. Carvalho, A.; Domingues, I.; Gonçalves, M.C. Core-Shell Superparamagnetic Nanoparticles with Interesting Properties as Contrast Agents for MRI. Mater. Chem. Phys. 2015, 168, 42-49. [CrossRef]

272. Song, Y.; Wang, R.; Rong, R.; Ding, J.; Liu, J.; Li, R.; Liu, Z.; Li, H.; Wang, X.; Zhang, J.; et al. Synthesis of Well-Dispersed Aqueous-Phase Magnetite Nanoparticles and Their Metabolism as an MRI Contrast Agent for the Reticuloendothelial System. Eur. J. Inorg. Chem. 2011, 2011, 3303-3313. [CrossRef]

273. Hu, J.; Obayemi, J.; Malatesta, K.; Yurkow, E.; Adler, D.; Soboyejo, W. Luteinizing Hormone-Releasing Hormone (LHRH) Conjugated Magnetite Nanoparticles as MRI Contrast Agents for Breast Cancer Imaging. Appl. Sci. 2020, 10, 5175. [CrossRef]

274. Periyathambi, P.; Sastry, T.P.; Anandasadagopan, S.K.; Manickavasagam, K. Macrophages Mediated Diagnosis of Rheumatoid Arthritis Using Fibrin Based Magnetic Nanoparticles as MRI Contrast Agents. Biochim. Biophys. Acta Gen. Subj. 2017, 1861, 2992-3001. [CrossRef]

275. Wang, J.; Zhang, B.; Yang, G.; Su, L.; Wang, L.; Gao, F. Transferrin-Conjugated Superparamagnetic Iron Oxide Nanoparticles as In Vivo Magnetic Resonance Imaging Contrast Agents. J. Nanosci. Nanotechnol. 2020, 20, 2018-2024. [CrossRef]

276. Tomanek, B.; Iqbal, U.; Blasiak, B.; Abulrob, A.; Albaghdadi, H.; Matyas, J.R.; Ponjevic, D.; Sutherland, G.R. Evaluation of Brain Tumor Vessels Specific Contrast Agents for Glioblastoma Imaging. Neuro-Oncol. 2012, 14, 53-63. [CrossRef] [PubMed]

277. National Institutes of Health (NIH); US National Library of Medicine (NLM). Available online: https:/ / www.clinicaltrials.gov (accessed on 10 March 2021).

278. Tassa, C.; Shaw, S.Y.; Weissleder, R. Dextran-Coated Iron Oxide Nanoparticles: A Versatile Platform for Targeted Molecular Imaging, Molecular Diagnostics, and Therapy. Acc. Chem. Res. 2011, 44, 842-852. [CrossRef] [PubMed] 
279. Medscape. Dosing \& Uses. Available online: https:/ / reference.medscape.com/drug/feraheme-ferumoxytol-999457 (accessed on 20 May 2021).

280. Wang, Y.-X.J. Superparamagnetic Iron Oxide Based MRI Contrast Agents: Current Status of Clinical Application. Quant. Imaging Med. Surg. 2011, 1, 35-40. [CrossRef] [PubMed]

281. Liu, T.; Bai, R.; Zhou, H.; Wang, R.; Liu, J.; Zhao, Y.; Chen, C. The Effect of Size and Surface Ligands of Iron Oxide Nanoparticles on Blood Compatibility. RSC Adv. 2020, 10, 7559-7569. [CrossRef]

282. Gardikiotis, I.; Manole, A.; Azoicăi, D. Quality of life with mastectomy for breast cancer, in terms of patients' responses of sf-36 questionnaire. Med. Surg. J. 2015, 119, 529-535.

283. Dodi, G.; Hritcu, D.; Draganescu, D.; Popa, M.I. Iron Oxide Nanoparticles for Magnetically Assisted Patterned Coatings. J. Magn. Magn. Mater. 2015, 388, 49-58. [CrossRef]

284. Dodi, G.; Uritu, C.M.; Gardikiotis, I.; Mihai, C.T.; Agrigoroaie, L.; Furcea, M.; Tamba, B.I.; Stefanescu, C. Radiolabelled Multifunctional Hybrid Magnetic Nanoparticle Probe for Dual-Modality (SPECT and MRI) Medical In Vivo Imaging. Annual Congress of the European Association of Nuclear Medicine October 12-16, 2019, Barcelona, Spain-Abstracts. Eur. J. Nucl. Med. Mol. Imaging 2019, 46 (Suppl. 1), S1-S952. [CrossRef] 